\title{
Title: Dexi disruption depletes gut microbial metabolites and accelerates autoimmune diabetes
}

LJ Davison, MD Wallace, C Preece, K Hughes, JA Todd, B Davies, CA O’Callaghan 
Abstract: Non-coding genetic variants in the CLEC16A gene on human chromosome 16p13.13 are associated with risk of autoimmune diseases, including type 1 diabetes and multiple sclerosis. In this region, we previously identified $D E X I$, a candidate causal gene of unknown function, which alters the risk of type 1 diabetes, where the T1D predisposing allele is associated with lower DEXI expression. Here, we demonstrate by CRISPR mutagenesis in vivo and deep phenotyping that disrupted Dexi expression accelerates diabetes in the non-obese diabetic (NOD) mouse, a spontaneous model of autoimmune pancreatic beta-cell destruction. Mutant mice have increased serum IgM and IgA concentrations compared to wild-type NOD mice, as well as changes in both the gut microbiome and molecular metabolites associated with microbial metabolism. These findings suggest that the mechanism by which $D E X I$ alters diabetes risk involves the composition and function of the microbiome and its impact on host metabolites. Such metabolites, including short chain fatty acids such as butyrate, have been shown to alter the activity of the immune cells involved in beta-cell destruction and susceptibility of the beta cells to autoimmune attack.

One Sentence Summary: Disruption of the Dexi gene leads to accelerated diabetes in the nonobese diabetic (NOD) mouse, accompanied by changes in serum immunoglobulins, gut microbiome and microbial metabolites. 


\section{Main Text:}

\section{Introduction}

Common autoimmune diseases, such as type 1 diabetes (T1D), are caused by a complex, heterogeneous blend of numerous, mostly common, predisposing DNA variants across the genome, alongside a range of environmental factors. Genome-wide association studies (GWAS) have so far mapped over 57 chromosome regions (immunobase.org) affecting T1D risk and, in addition to yielding insights into the inherited mechanisms of disease, also provide clues to identify more elusive environmental factors. Nevertheless for many of these risk regions the actual causal genes and variants are not known. Considerable uncertainty remains around the identity of the environmental factors that, together with a susceptible genetic background, lead to the destructive autoimmune response against the insulin-producing beta cells of the pancreatic islets. Twin, birth cohort and other population studies, along with investigations of animal models, particularly the non-obese diabetic (NOD) mouse, demonstrate the importance of environmental influences in the development of autoimmune disease (1), such as exposure to viruses (2) and alterations in the gut microbiome (3). Some T1D-associated regions identified by GWAS contain genes with known functions in the immune system, several of which are convincing candidate causal genes. Some T1D regions also contain genes with known effects in the target beta cells. In addition to underpinning further understanding of the disease by mapping candidate genes of known functions, GWAS and its follow up studies can identify candidates with no known function at all. Investigation of these genes is challenging, but has the potential to provide entirely novel insights into disease pathogenesis and reveal new therapeutic or preventative strategies. 
The T1D-associated 16p13.13 region of the human genome contains multiple genes (Figure S1). Single nucleotide polymorphisms (SNPs) in intron 19 of CLEC16A in the region have been associated with risk of many autoimmune diseases including T1D $(4,5)$, primary biliary sclerosis (6), multiple sclerosis (7), primary adrenal insufficiency (8), systemic lupus erythematosus (9), alopecia areata (10) and juvenile arthritis (11). Associations with autoimmune disease in number of different SNPs in high linkage disequilibrium have been reported, with the same direction of effect in multiple diseases. A summary of previous association study data is provided in Supplementary Table S1. Non-coding T1D-associated variants are in high to moderate linkage disequilibrium with the variants in intron 19 of CLEC16A that have been associated with bone density, (12), myocardial infarction (13), ischemic stroke in metabolic syndrome (14) primary IgA deficiency (15), combined variable immunodeficiency (16), and microbial diversity in the human gut (17).

Within the complex 16p13.13 region, most studies have focussed upon the function of CLEC16A itself because the most associated SNPs are located in intron 19 of the gene (18-24). However, we have identified DEXI as a causal candidate gene in the $16 \mathrm{p} 13.13$ region our previous work, using expression quantitative trait locus (eQTL) mapping and chromosome confirmation capture (3C) in human monocytes. The DEXI protein is predicted to be $10 \mathrm{kDa}$ in size, with a potential transmembrane domain but no other clearly defined features. The DEXI gene is highly conserved among species, including the mouse, and has no paralogue in the human genome.

The DEXI promoter is $150 \mathrm{~kb}$ away from the T1D-associated SNPs (25). We have proposed that the disease-associated SNPs affect disease risk by altering transcription factor binding to the DEXI 
promoter, which we have shown to be physically linked to intron 19 of CLEC16A by a chromatin loop. We have also demonstrated that increased T1D risk mediated through 16p13.13 is associated with decreased $D E X I$ expression, implying that wild-type or normal $D E X I$ function has a protective function in autoimmune disease (25). Our eQTL result has since been replicated by other groups $(24,26)$, but in the absence of a Dexi knockout mouse model, definitive studies to extend evidence in support of DEXI's preventive role in T1D have not been possible. Furthermore, there are so far no known rare variants of $D E X I$ in humans with informative phenotypes.

The NOD mouse develops spontaneous T1D from around 12 weeks of age, with approximately $75 \%$ of females affected by 30 weeks of age (27). The disease is characterized by lymphocytic pancreatic islet infiltration (insulitis) and progressive autoimmune destruction of the pancreatic beta cells, which is evident from 6-8 weeks of age (27). Here, in agreement with our prediction that $D E X I$ has a protective role in T1D, we report that disruption of Dexi in the NOD mouse leads to accelerated spontaneous autoimmune diabetes when compared to the wild-type NOD. Furthermore, we show that Dexi disruption alters the host metabolome, gut microbiome, and serum IgA and IgM levels in a manner consistent with a role for DEXI in influencing the interaction between the immune system and microbiota. Our results support the role of $D E X I$ as a causal factor in human T1D risk, related to a direct or indirect effect on the production of microbial metabolites.

\section{Dexi disruption in NOD mice does not alter breeding fitness or histological phenotype}


We used CRISPR-Cas9 genome-editing technology in NOD zygotes to introduce disruptive mutations in the coding sequence of Dexi in NOD offspring. Two mutations contained entirely within the Dexi protein-coding sequence were selected for study. These mutations were a one basepair insertion $(I N S 1 B P)$ and a twelve base-pair deletion (DEL12BP) (Figure 1A and 1B; Supplementary Figures S2A and S2B; Supplementary Table S2), occurring early in the protein coding sequence. The INSIBP mutation has the potential to cause a more severe phenotype than the DEL12BP mutation since it causes a frame shift and nonsense transcript, whereas the 12-bp deletion removes 4 amino acids but leaves the rest of the protein in frame.

Homozygous mice were viable and the mutations had no apparent impact on breeding fitness. Littermate wild-type NOD and homozygous NOD mice carrying the INSIBP or DEL12BP mutations were evaluated by histopathology of multiple tissues including pancreas, salivary gland, liver, spleen, kidney, bone marrow, thymus, lung, heart, gastro-intestinal tract and brain. Neither Dexi mutation was associated with histologically identifiable changes (representative images are shown in Supplementary Figure S8).

In order to establish the effect of the introduced mutation on Dexi protein expression, we first sought to identify the endogenous Dexi protein in wild-type NOD mice using a range of commercially available anti-DEXI antibodies for western blotting of mouse tissue lysates. However, the available commercial antibodies did not allow a conclusive investigation of Dexi protein levels in the mutant NOD mice Supplementary Figures S2C, S2D and S2E. Quantitative PCR of thymus and spleen demonstrated that transcripts of the disrupted Dexi gene were still detectable in both lines of Dexi-disrupted mice, despite the presence of CRISPR-induced mutations (Supplementary Figure 2F). 


\section{Dexi disruption in NOD mice accelerates diabetes onset in females}

A female bias in diabetes incidence in NOD mice has been reported (27), in association with hormonally-driven variations in the microbiome $(28,29)$. In agreement with other studies, in our wild-type NOD colony, $75 \%$ of females are diabetic (glycosuric) by 30 weeks of age, compared to $50 \%$ of males.

In a 300-day diabetes cumulative frequency study, homozygous female mice in both the INSIBP and DEL12BP lines had accelerated and increased cumulative diabetes incidence compared to wild-type NOD mice without Dexi mutations (Figure 1C and 1D; Supplementary Table S3), confirming the protective effect of a functional Dexi gene in autoimmune diabetes. There was a trend towards more exaggerated phenotypic changes in the INSIBP line, with the potentially more disruptive mutation, compared to the $D E L 12 B P$ line. However, the experiments were not designed to investigate this issue, so numbers were not high enough to demonstrate statistically significant differences between the two Dexi-disrupted lines.

In contrast to our findings in females, no acceleration or increase in cumulative diabetes incidence was seen in male mice in the INS1BP and DEL12BP lines (Supplementary Figures S3A and S3B). This result in males could reflect reduced power due to the lower incidence of diabetes in male wild-type NOD mice compared to females, however no trend towards a difference was observed to suggest this is the case. 
bioRxiv preprint doi: https://doi.org/10.1101/393421; this version posted August 16,2018 . The copyright holder for this preprint (which was not certified by peer review) is the author/funder. All rights reserved. No reuse allowed without permission.

\title{
Figure 1A
}

\section{CRISPR-induced DNA mutations in the Dexi coding sequence}

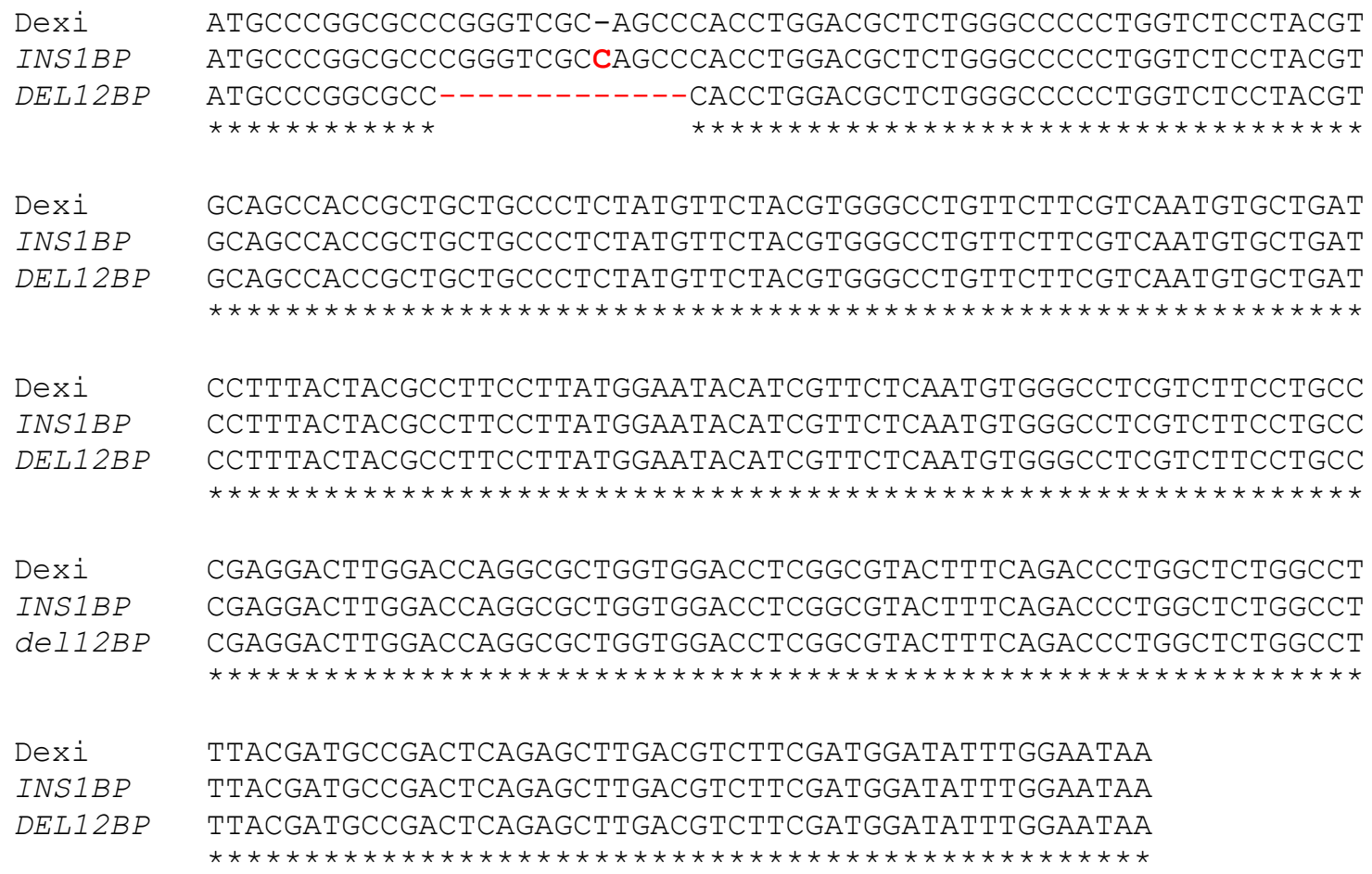

\section{Figure 1B}

\section{Predicted effect of Dexi DNA mutations on the Dexi protein sequence}

\author{
Dexi MPGARVAAHLDALGPLVSYVQPPLLPSMFYVGLFFVNVLILYYAFLMEYIVLNVGLVFLP \\ INSIBP MPGARVASPPGRSGPPGLLRAATAALYVLRGPVLRQCADPLLRLPYGIHRSQCGPRLPA \\ DEL12BP MPGA----HLDALGPLVSYVQPPLLPSMFYVGLFFVNVLILYYAFLMEYIVLNVGLVFLP \\ Dexi EDLDQALVDLGVLSDPGSGLYDADSELDVFDGYLE* \\ INSIBP RGLGPGAGGPRRTFRPWLWPLRCRLRA* \\ DEL12BP EDLDQALVDLGVLSDPGSGLYDADSELDVFDGYLE*
}


Figure 1C The INSIBP mutation reduces diabetes-free survival in female NOD mice
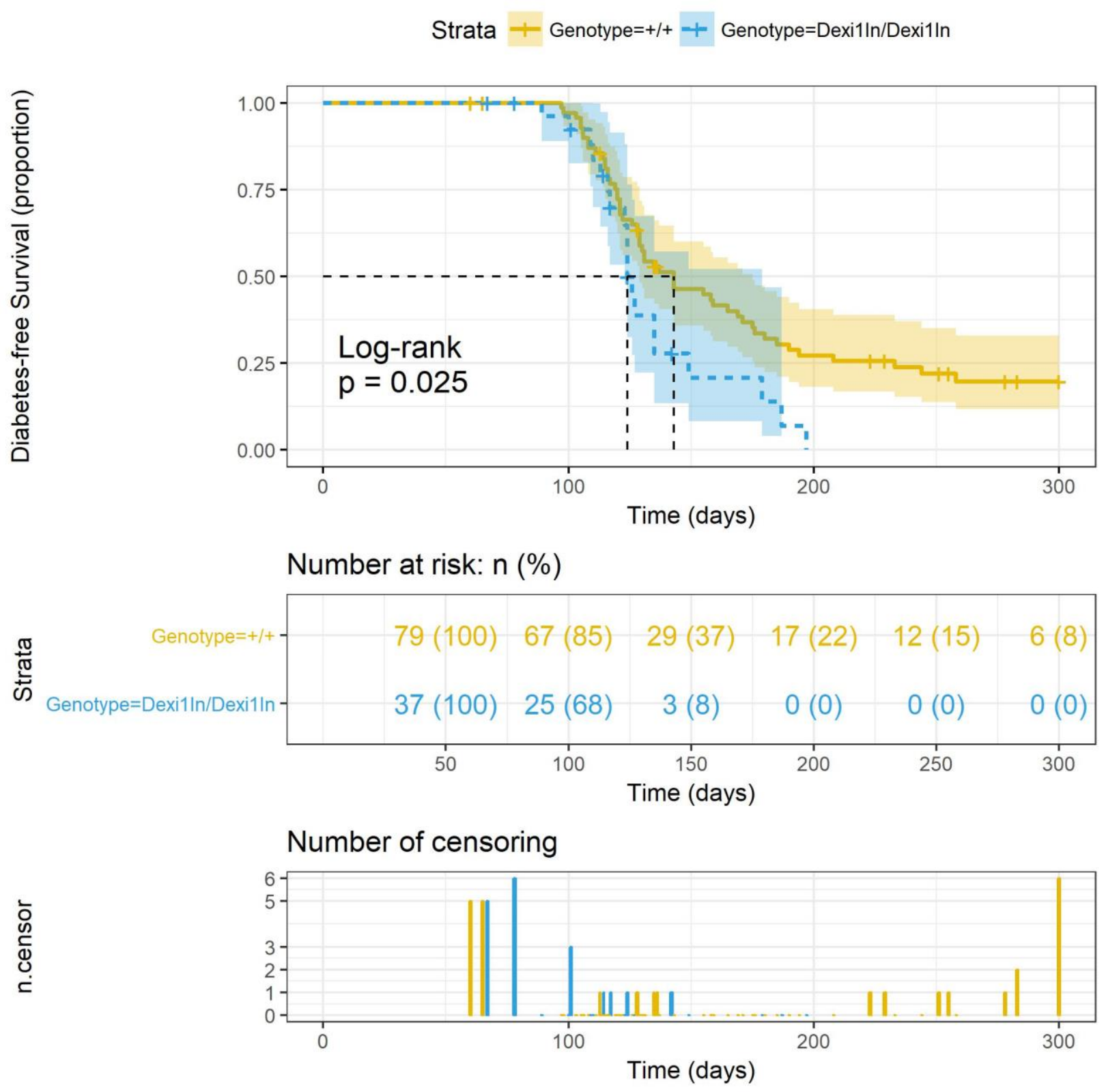
Figure 1D The $D E D 12 B P$ mutation reduces diabetes-free survival in female NOD mice

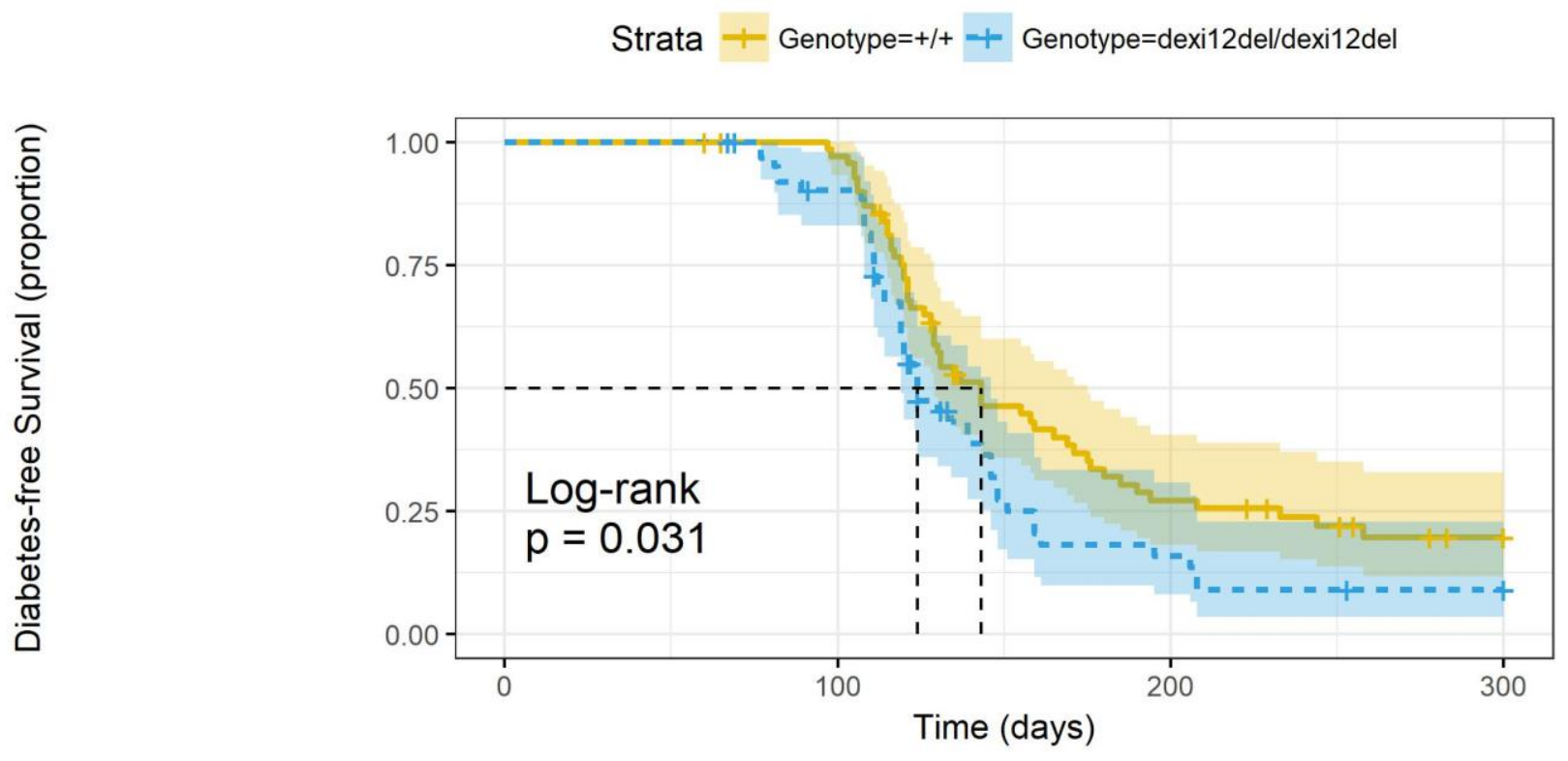

Number at risk: $\mathrm{n}(\%)$

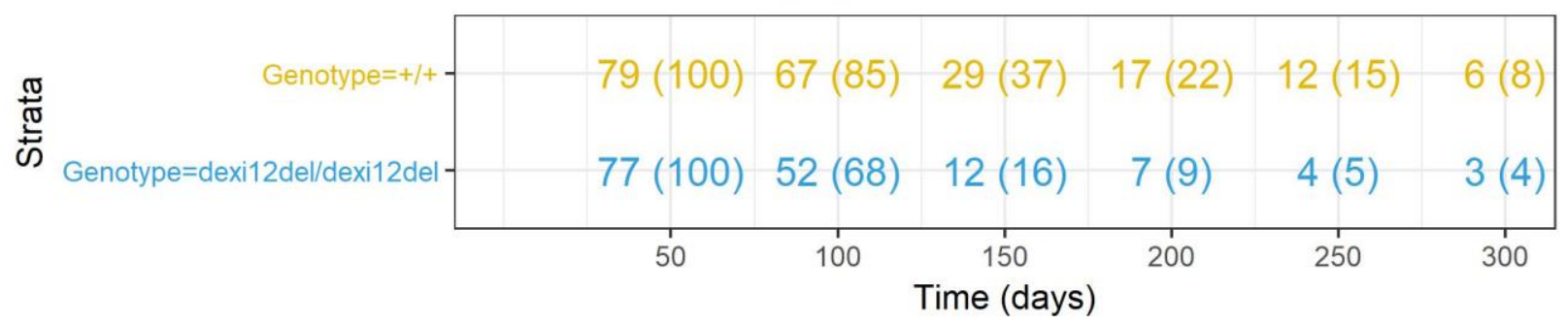

Number of censoring

ธั

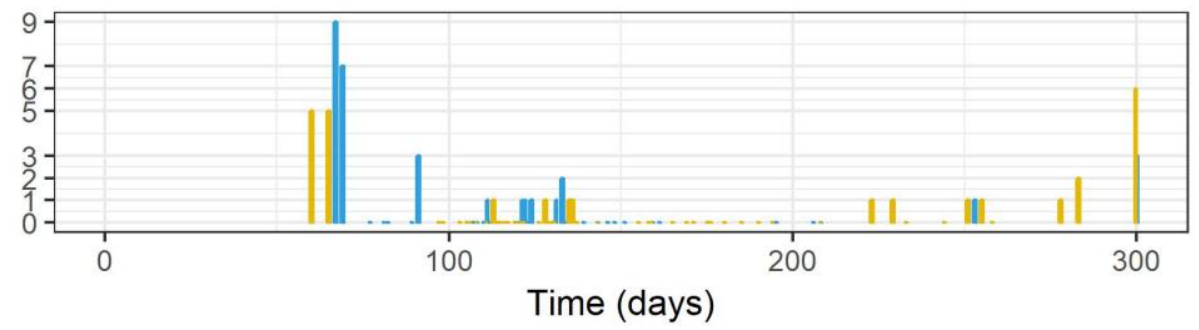


Figure 1 CRISPR induced mutations in Dexi gene and predicted effect on protein sequence

A: The INS1BP and DEL12BP CRISPR-induced mutations in the Dexi DNA coding sequence. Mutations are shown in red.

B: The predicted impact of the INS1BP and DEX12BP mutations on the Dexi protein. Changes in the amino acid sequence are shown in red.

C and D: The presence of a homozygous INS1BP (C) or DEL12BP (D) Dexi mutation reduces diabetes-free survival in female NOD mice.

Top panel for each line: Kaplan-Meier diabetes-free survival curve with log-rank p-value for wild-type NOD mice $(n=79)$ represented as yellow-orange $(+/+)$. Dexi-disrupted mice survival curves are represented in blue, for homozygous INS1BP mice ( $\mathrm{n}=37$; labelled as Dexi1in/Dexi1in) and DEL12BP mice ( $\mathrm{n}=77)$; labelled as dexi12del/dexi12del).

95\% Confidence Intervals are shown for each genotype as translucent shaded regions surrounding the genotype line.

Mid panel: Numbers of animals at risk over time.

Bottom panel: Bar plot of censorship data for each line. 


\section{Dexi disruption in the NOD mouse does not influence the presence of insulitis}

To investigate whether the acceleration and increase in diabetes incidence in Dexi-disrupted female mice was associated with increased lymphocytic infiltrate in the islets, blinded histopathology of the pancreas was undertaken in 6-week old mice (Supplementary Table S4; Supplementary Figure S4). Multiple tissue sections and islets were cut and examined from each mouse and no significant difference in insulitis could be identified between wild-type NOD and Dexi-disrupted mice. This suggests that if Dexi disruption affects infiltrating lymphocytes, it alters their function or kinetics of the infiltration rather than their steady state presence or absence in the islets.

Insulin autoantibodies (IAA) were measured as a marker of autoimmunity in serum from in agematched female Dexi-disrupted NOD and wild-type NOD mice (Supplementary Table S6). Two of 12 wild-type NOD mice were positive compared to 4 of 12 in each of the Dexi-disrupted lines (Supplementary Figure S7). Whilst not statistically significant, this trend is consistent with the finding of accelerated diabetes in NOD mice following disruption of the Dexi gene.

\section{Dexi disruption in NOD mice affects serum IgA and IgM but not cellular immune-phenotype}

Since T1D is an immune-mediated condition, to assess the impact of Dexi disruption on the cellular immune system, flow cytometric analysis of thymus, spleen and bone marrow in wild-type and Dexi-disrupted mice was undertaken using a panel of B-cell, T-cell and myeloid lineage markers (Supplementary Table S5). After accounting for multiple tests and hypotheses, no consistent significant differences were detected in cellular immune-phenotype between Dexi-disrupted and wild-type NOD mice (Supplementary Figures S5A to S5F). To assess the impact of Dexi 
disruption on the humoral immune system, serum IgG, IgM and IgA were evaluated in agematched female Dexi-disrupted NOD and wild-type NOD mice (Supplementary Table S6), prior to the onset of the diabetic phenotype. A significant increase in serum $\operatorname{IgA}(\mathrm{p}=0.0102)$ and $\operatorname{IgM}$ ( $\mathrm{p}=0.0393$ ) was evident in Dexi-disrupted compared to wild-type NOD mice (Figure 2). 
Figure 2
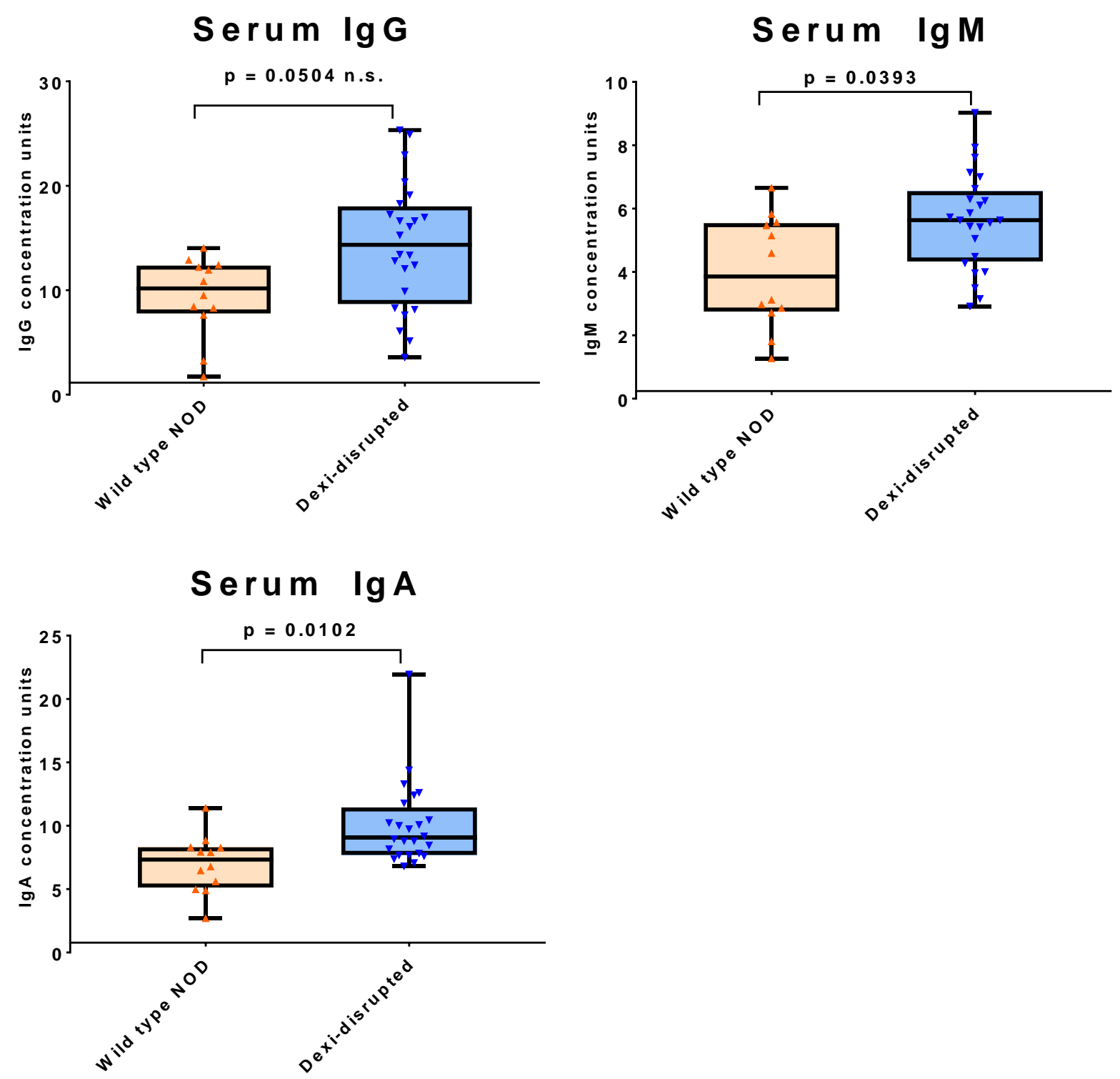

Figure 2: Dexi-disrupted NOD mice demonstrate increased serum IgA and IgM compared to wild-type NOD mice. Serum $\operatorname{IgG}, \operatorname{IgM}$ and $\operatorname{IgA}$ were measured by ELISA in age-matched nondiabetic female Dexi-disrupted (blue; $n=24$ ) and wild-type (orange; $n=12$ ) NOD mice by ELISA and quantified against a standard curve. Groups were compared using the Mann-Whitney test and $\mathrm{p}$ values are shown after Bonferroni correction for multiple testing. 
The most striking finding was the elevation in serum $\operatorname{Ig}$ A identified in Dexi-disrupted mice. Immunoglobulin A is secreted in the gut, and has multiple functions in mucosal immunity (30). Both circulating IgA deficiency and human combined immunodeficiency are associated with variants in the $16 \mathrm{p} 13.13$ region of the genome $(15,16,31)$, so DEXI may play a role in IgA biology. Due to the high degree of linkage disequilibrium in the $16 \mathrm{p} 13.13$ region, multiple non-coding variants have been associated with both T1D and IgA deficiency. As the direction of risk for T1D and IgA deficiency is the same at 16p13.13 (15), the raised serum IgA in association with diabetes risk in this study is surprising.

The regulation of $\operatorname{Ig} \mathrm{A}$ production is complex and multifactorial, and as well as endogenous host factors, IgA production relates to the presence of microbiota in the intestine and other mucosal surfaces (32-34). The relationship between IgA and the microbiome is likely to be bi-directional, since microbiota influence $\operatorname{IgA}$ production, but the presence and repertoire of mucosal $\operatorname{IgA}$ can influence which organisms are able to thrive in the gastrointestinal tract (35). Dexi dosage may also be important here, since the Dexi disruption afforded by CRISPR in our model is much more severe than the effect typically seen with a common human allele.

\section{The fecal microbiome of NOD mice is affected by Dexi-disruption}

Gut microbiota influence the immune system and development of diabetes in the NOD mouse (28, 29, 36-39), as well as susceptibility to T1D in young children (40-43). For example, in the NOD model, mice lacking Toll-like Receptor (TLR) signaling, due to absence of the MyD88 adapter protein, are protected from diabetes in the presence of gut microbiota, but protection is not observed in germ-free mice (44). Reconstitution of the gut flora of these germ-free mice with 
specific bacterial lineages restores the diabetes protection afforded by MyD88 deficiency (45). Furthermore, female NOD mice can be protected from the development of diabetes by gavage transfer of male NOD mouse fecal microbiota (29). Our finding of diabetes acceleration in Dexidisrupted female but not male NOD mice would be consistent with a sex-influenced microbiomedependent protective effect of the Dexi gene $(28,29,46)$.

It has previously been shown that the NOD genetic background is associated with distinct fecal microbiota compared to B6 mice (47). Recent evidence also suggests that a small proportion of microbial diversity in the human gut is driven by the host genome (48). Since the $16 \mathrm{p} 13.13$ region has previously been associated with microbial diversity in the human gut (17), and diabetesassociated alleles in other genomic regions have been shown to influence the microbiota in the human gut (47), we investigated whether Dexi-disruption was associated with changes in the gut microbiome in the NOD mouse.

We examined the fecal microbiome in age-matched ( 4 weeks, 6 weeks and 10 weeks) female mice across multiple litters and cages (Supplementary Table S7), prior to the onset of diabetes. Normoglycemic mice were used for this experiment to avoid any potential consequential impact of the accelerated diabetes phenotype in the Dexi-disrupted NOD mouse on the fecal microbiome. DNA was extracted from fecal samples from 44 mice and applied to a microarray designed to detect all known microorganisms in a sample, with species- and strain-level identification (Supplementary Tables S8, S9, S10). Eight microbial species showed significantly altered representation in homozygous Dexi-disrupted mice compared to wild-type NOD mice (Figure 3 and Supplementary Figures S7A and S7B). 
Several of the microbial species that were present in a significantly different proportion of Dexidisrupted NOD mice compared to wild-type NOD mice have been implicated in human T1D risk. For example, we found significantly higher representation of the Bacteriodetes phylum in Dexidisrupted NOD mice, including Bacteroides, Parabacteroides distasonis, and Parabacteroides goldsteinii. Notably, children with T1D have been shown to have a significant increase in the number of Bacteroidetes as well as Bacteroides (49). We also found inverse representation between two strains of Lactobacillus reuteri, with Dexi-disrupted mice being low in strain LTH2584 (31\% vs WT 89\%) and high in strain LTH5448 (62\% vs WT 6\%). L. reuteri is an established and widely used probiotic species in research and clinical trials (50). It is also notable that Akkermansia muciniphilia, a mucus-degrading bacteria detected predominantly Dexidisrupted mice, is one of the microbial species consistently targeted by mucosal IgA in the gut (33). 


\section{Figure 3}

Differential detection of bacterial species in feces of wild type NOD compared to Dexi-disrupted NOD mice $(\mathbf{p}<0.05)$

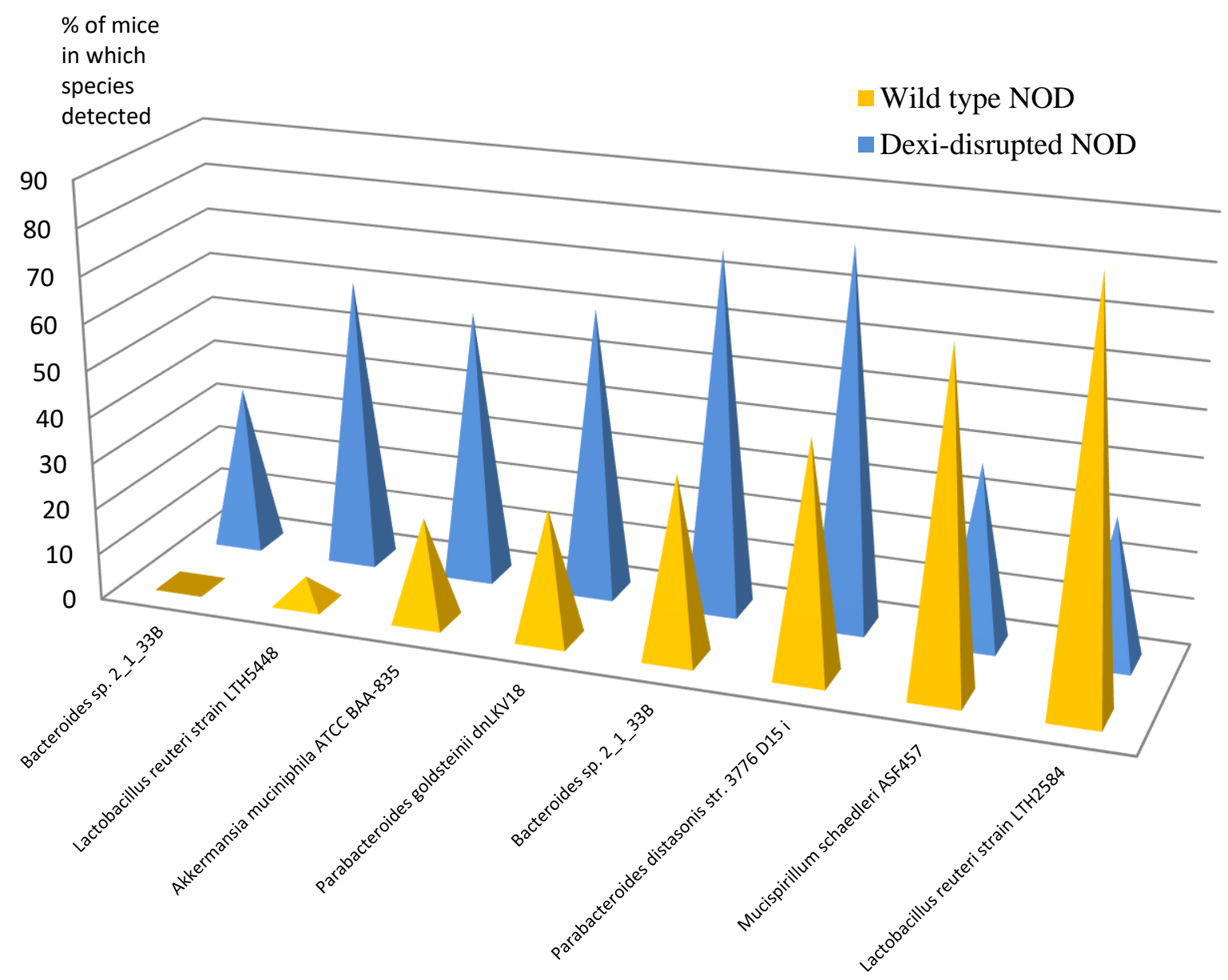

Figure 3: The fecal microbiome of Dexi-disrupted NOD mice is different to that of wild-type

NOD mice. Bar plot showing robustly detected microbial species on a microbiome array with a significantly different prevalence in DNA extracted from the feces of Dexi-disrupted mice compared to wild-type NOD mice. Blue peaks correspond to Dexi-disrupted mice (n=26), orange peaks correspond to wild-type NOD mice $(n=18)$. 
The mechanism(s) by which microbiota impact on diabetes risk are unclear, but may relate to the production of bacterial metabolites which influence the function of immune cells, such as regulatory $\mathrm{T}$ cells $(51)$.

\section{Dexi disruption in NOD mice leads to metabolic changes in liver, spleen and blood}

To investigate whether the metabolomic profiles of Dexi-disrupted and wild-type NOD mice differ, particularly with respect to microbial metabolites, we undertook extensive metabolomic and lipidomic analyses of 6-week-old female mice. Mice of this age were chosen to ensure that any changes were related to Dexi disruption rather than an early diabetic phenotype. In addition to whole blood, we examined spleen because of its central role in the immune system and liver because it receives a blood supply directly from the gut, via the hepatic portal vein. The levels of multiple non-lipid low molecular weight metabolites differed between Dexi-deficient and wildtype NOD mice (Figure 4A). Liver showed the highest number of significant changes, but a proportion of these changes were also seen in spleen and blood. These differences were not associated with changes in the histological appearance of the liver in any mice (Supplementary Figure S8). There was no significant difference in lipid profile among the groups of mice in blood, spleen or liver.

The metabolomic analysis demonstrated that the two pathways most significantly and consistently impacted by Dexi disruption were those of nucleotide synthesis and amino acid metabolism (Figure 4B). Several compounds associated with pyrimidine and purine metabolism were consistently depleted in 6-week-old INS1BP and DEL12BP mice, including allantoin, 
methyluridine, dihydrouridine, beta-alanine and 7-methylguanidine, with only one, oronate, being consistently elevated. In addition, several amino acids and their associated metabolites were significantly lower in the liver (Supplementary Figure S9A) and blood (Supplementary Figure S9B) of both INS1BP and DEL12B mice, consistent with Dexi-associated changes in protein metabolism. At the pathway level, several metabolites within the lysine metabolism pathway were affected in both INS1BP and DEL12BP mice (Figure 4C; Supplementary Figures S10A to S10C). One such compound, 5-amino-valerate, was reduced in liver, spleen and blood in both INSIBP and DEL12BP mice compared to wild-type NOD (Figure 4D). This branched chain fatty acid (BCFA) compound is a product of protein degradation by anaerobic bacteria, particularly Clostridial strains, and is known to be absent from the metabolome of germ-free mice $(52,53)$. We detected this compound at the highest concentration in the liver, which receives the 'first-pass' blood from the gastro-intestinal tract via the hepatic portal vein, providing further evidence for this metabolite being produced by bacteria in the gut.

BCFAs can influence immunity by modulating the host mucosal immune system and impacting on signaling pathways in epithelial cells $(54,55)$. BCFAs can also affect bacterial gene expression of enzymes associated with amino acid metabolism (56). Notably, further degradation of 5-amino valerate produces ammonia and the other volatile short chain fatty acids (SCFAs) acetate and proprionate (Figure 4E) (53). These SCFAs which can be derived from 5-aminovalerate protect against type 1 diabetes in NOD mice by decreasing the frequency of autoreactive $\mathrm{T}$ cells in lymphoid tissues, through effects on B cells and regulatory T cells (57). 
To determine whether depletion of SCFA precursors in the blood and liver is associated with depletion of acetate, butyrate, isobutryate or proprionate in the INSIBP and DEL12BP mice, we measured these four compounds in the serum and liver of a second cohort of 6-week old female mice $(n=10)$ (Figure 5). Consistent with our hypothesis that SCFA depletion would be associated with Dexi-disruption, butyrate was depleted in the liver of the Dexi-disrupted NOD mice compared to wild-type NOD mice $(\mathrm{p}=0.0016$ - Figure 5a). There was also a trend for acetate depletion in the Dexi-disrupted NOD mice but this was not significant after correction for multiple hypothesis testing. The relative depletion of butyrate in the liver was not evident in serum (Figure 5b), which provides further evidence for its production by the microbiota in the gut and subsequent transport via the hepatic portal vein.

We conclude that Dexi has a protective effect in type 1 diabetes. Based on our data, we propose a model whereby Dexi disruption alters the gut microbiome, which in turn influences both serum IgA production and diabetes risk via metabolites in pathways including lysine metabolism, BCFAs and SCFAs (Figure 6). Our data demonstrate that increased serum IgA (and $\operatorname{IgM}$ ) are associated with diabetes susceptibility and Dexi disruption. We propose that altered microbial metabolism in the gut results in a lack of substrate for synthesis of SCFAs in Dexi-disrupted female mice, leading to acceleration of spontaneous diabetes. We hypothesize that the importance of Dexi's effect on the microbiome is reduced in male NOD mice because they naturally harbor a more diabetesprotective microbiome than female NOD mice $(28,29)$. We confirm Dexi as a diabetes risk gene which impacts on the gut microbiome and measurable microbial metabolites. 
This study has several important implications. Firstly, it illustrates the importance of tissuespecific metabolic studies for identification of disease-associated metabolic phenotypes, rather than reliance on serum measurements. Secondly, it demonstrates an approach by which a candidate causal gene of unknown function, identified by a GWAS study, may be confirmed in the context of a specific complex disease. Thirdly, this study highlights the complex relationship between host genetic variations, serum immunoglobulins (particularly IgA) and microbial diversity in the gut. Finally, our results highlight $D E X I$ as a novel therapeutic target in the development of protective strategies in a wide variety of complex autoimmune diseases including T1D, multiple sclerosis and primary biliary sclerosis. 
bioRxiv preprint doi: https://doi.org/10.1101/393421; this version posted August 16,2018 . The copyright holder for this preprint (which was not certified by peer review) is the author/funder. All rights reserved. No reuse allowed without permission.

\section{Figure 4A}

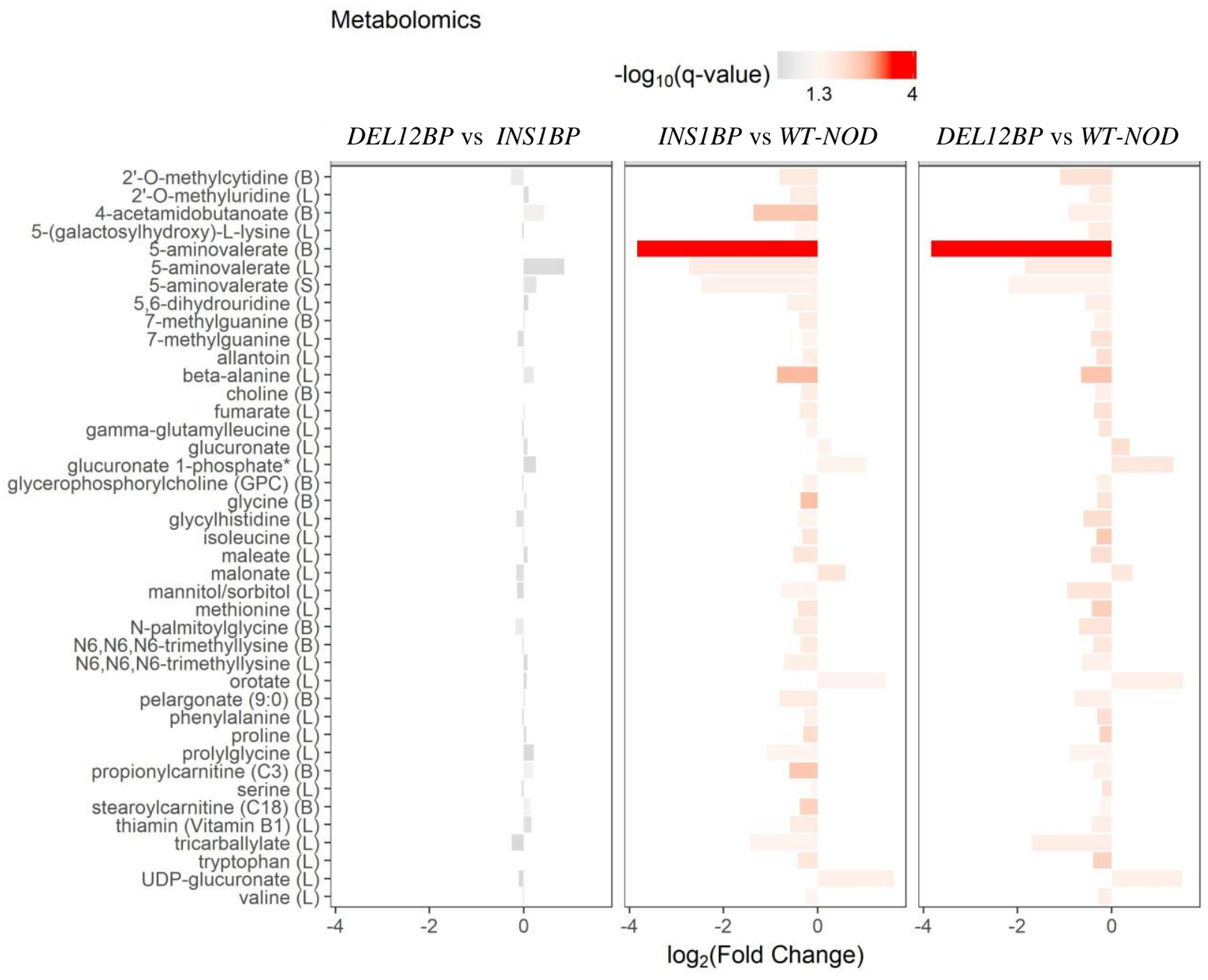

Figure 4B

Pathways of altered biochemical levels in All

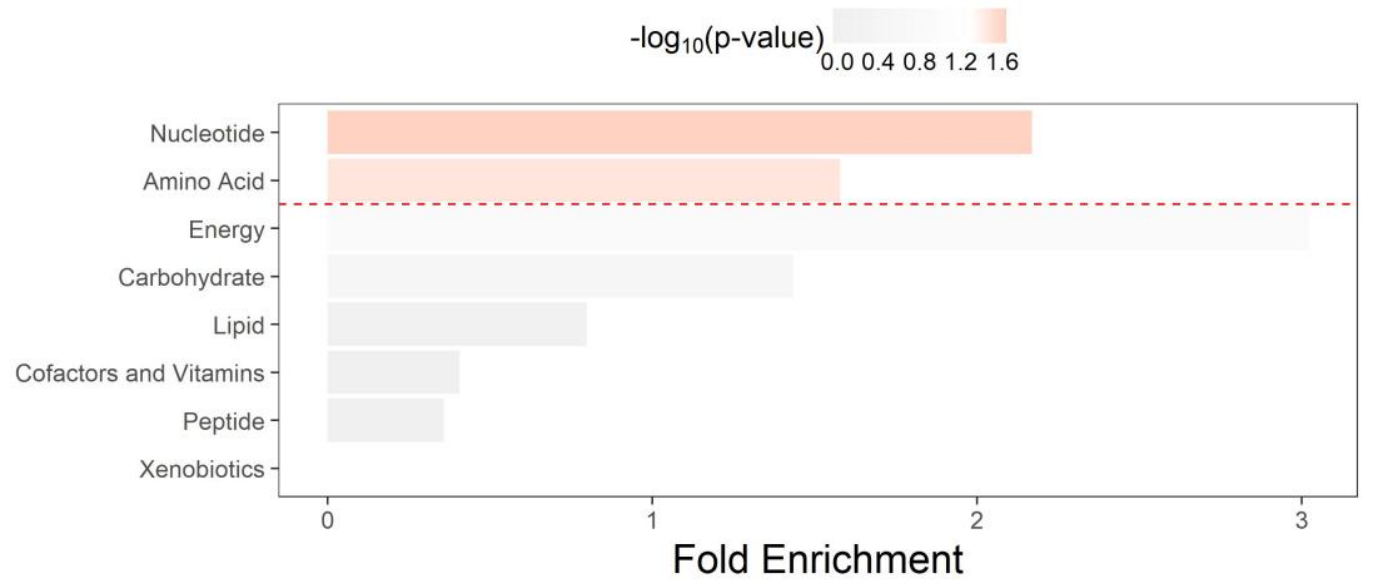


bioRxiv preprint doi: https://doi.org/10.1101/393421; this version posted August 16,2018 . The copyright holder for this preprint (which was not certified by peer review) is the author/funder. All rights reserved. No reuse allowed without permission.

\section{Figure 4C}

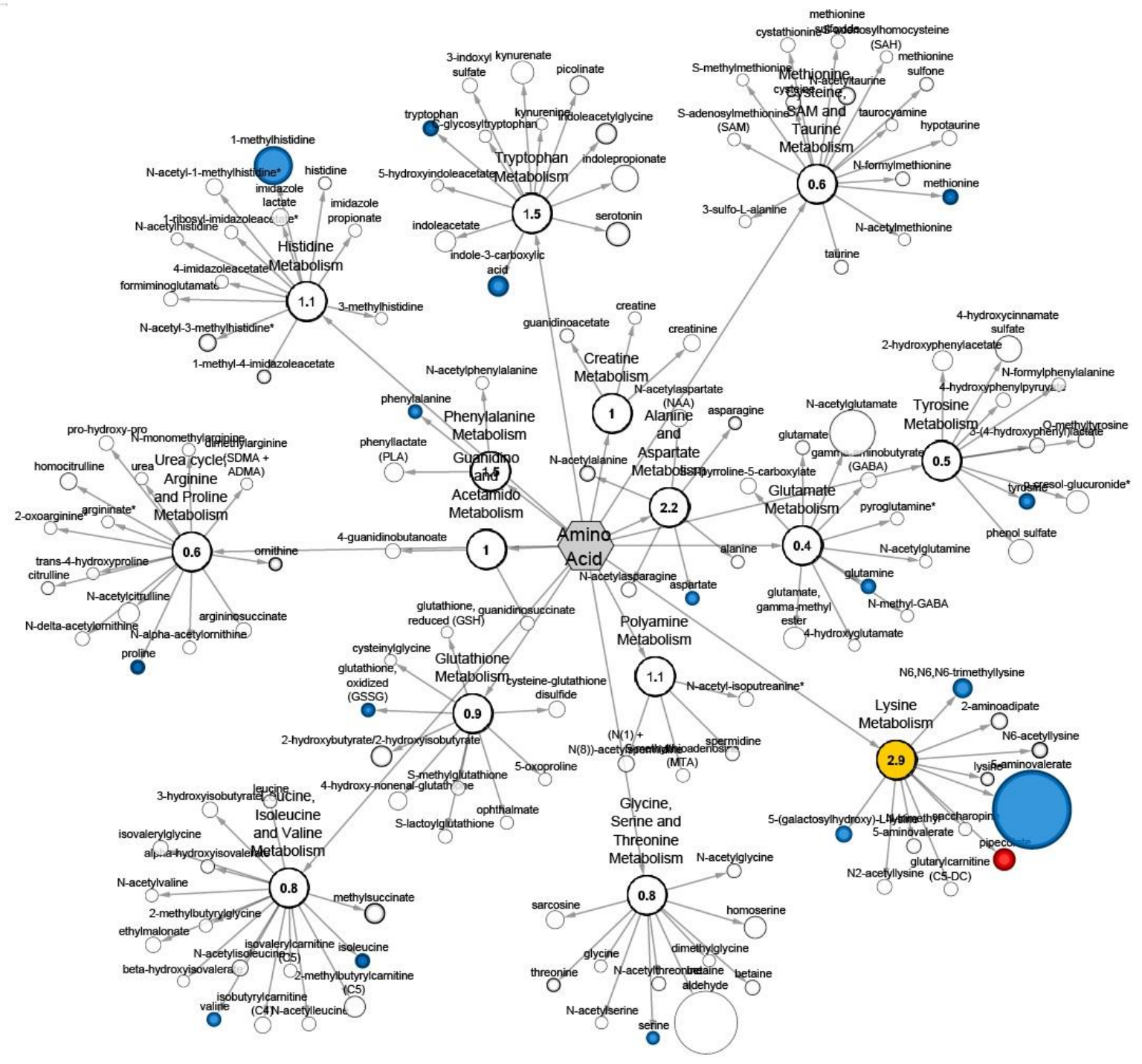




\section{Figure 4D}

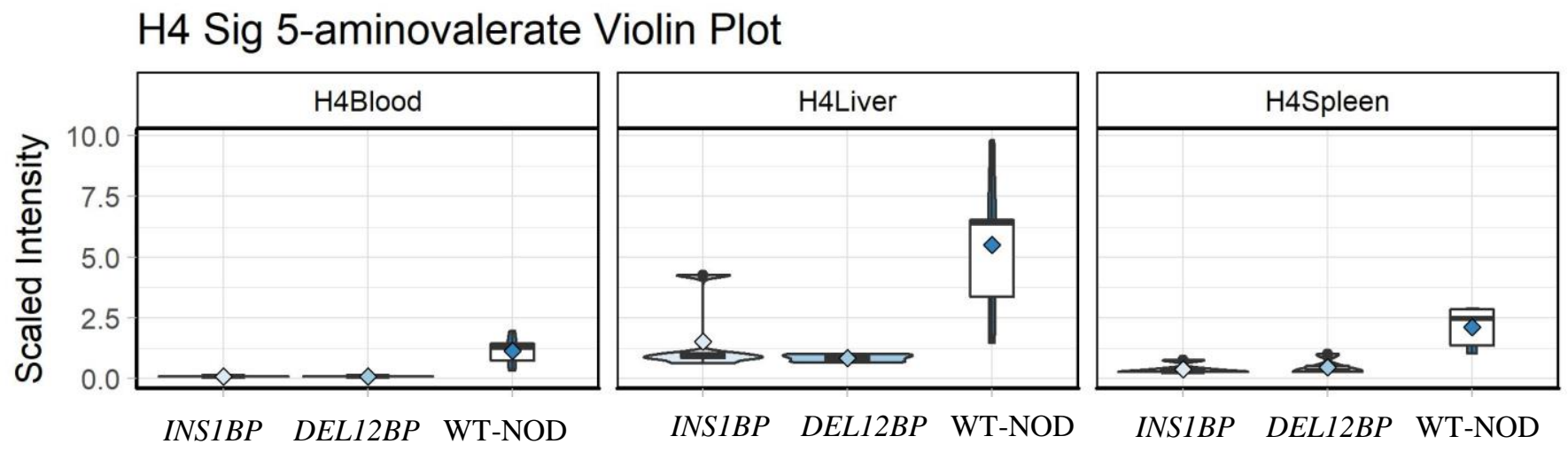

p values for data in Fig 4D:

\begin{tabular}{|l|c|c|c|}
\hline Tissue & INS1BP vs WT-NOD & DEL12BP vs WT-NOD & INS1BP vs DEXL12BP \\
\hline BLOOD & $<0.0001$ & $<0.0001$ & 1 \\
\hline LIVER & 0.001 & 0.0044 & 0.4158 \\
\hline SPLEEN & 0.0002 & 0.0003 & 0.6529 \\
\hline
\end{tabular}

Figure 4E

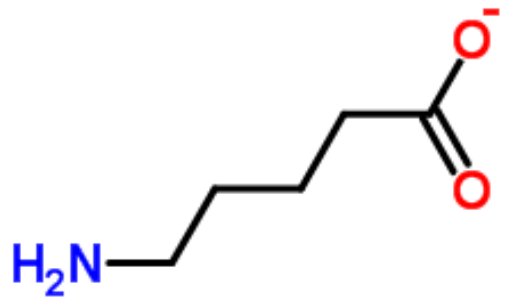

$\mathrm{O}_{3}$<smiles>CCCC(=O)[O-]</smiles>

\section{5-Amino-valerate}

Acetate

\section{Butyrate}


Figure 4: Metabolomic changes in Dexi-disrupted NOD mice compared to wild-type NOD mice

A. Bar plot of biochemical compounds demonstrating significant and consistent fold-change direction in 6-week old females from both INSIBP and DEL12BP Dexi-disrupted mouse lines (n=5 per line) compared to wild-type NOD (WT) $(\mathbf{n = 5})$. Bar color represents $-\log 10$ (q-value) scale, where red is significant and grey is not significant. The $\mathrm{x}$-axis is $\log 2$ (Fold Change) of the biochemical level in Dexi-disrupted compared to wild-type NOD mice. Parentheses beside the biochemical name on the $\mathrm{y}$-axis indicate sample tissue type: $(\mathrm{L})=$ Liver, $(\mathrm{B})=$ Blood and $(\mathrm{S})=$ spleen.

B. Pathway set enrichment analysis of compounds in A. The red horizontal dashed line separates non-significant pathways (grey) from significant pathways (red), where bar color is scaled by $-\log 10(\mathrm{p}$-value).

C. Amino acid pathway network (Cytoscape) for mouse liver comparing INS1BP to wildtype NOD mice. Shaded nodes correspond to significantly different metabolites (blue for reduced in Dexi-disrupted INSIBP mice; red for increased in Dexi-disrupted mice; yellow for a significant change in a pathway). Dark red or blue represent change at $\mathrm{p}<0.05$ and lighter colored nodes correspond to trending threshold $\mathrm{p}<0.1$. White nodes correspond to detected compounds with no significant change.

D. Biochemical scaled intensity violin plots of 5-aminovalerate in liver, blood, and spleen in Dexi-disrupted lines and WT-NOD mice shown in A.

E. Schematic structures of 5-aminovalerate and its breakdown products acetate and butyrate 


\section{Figure 5a}

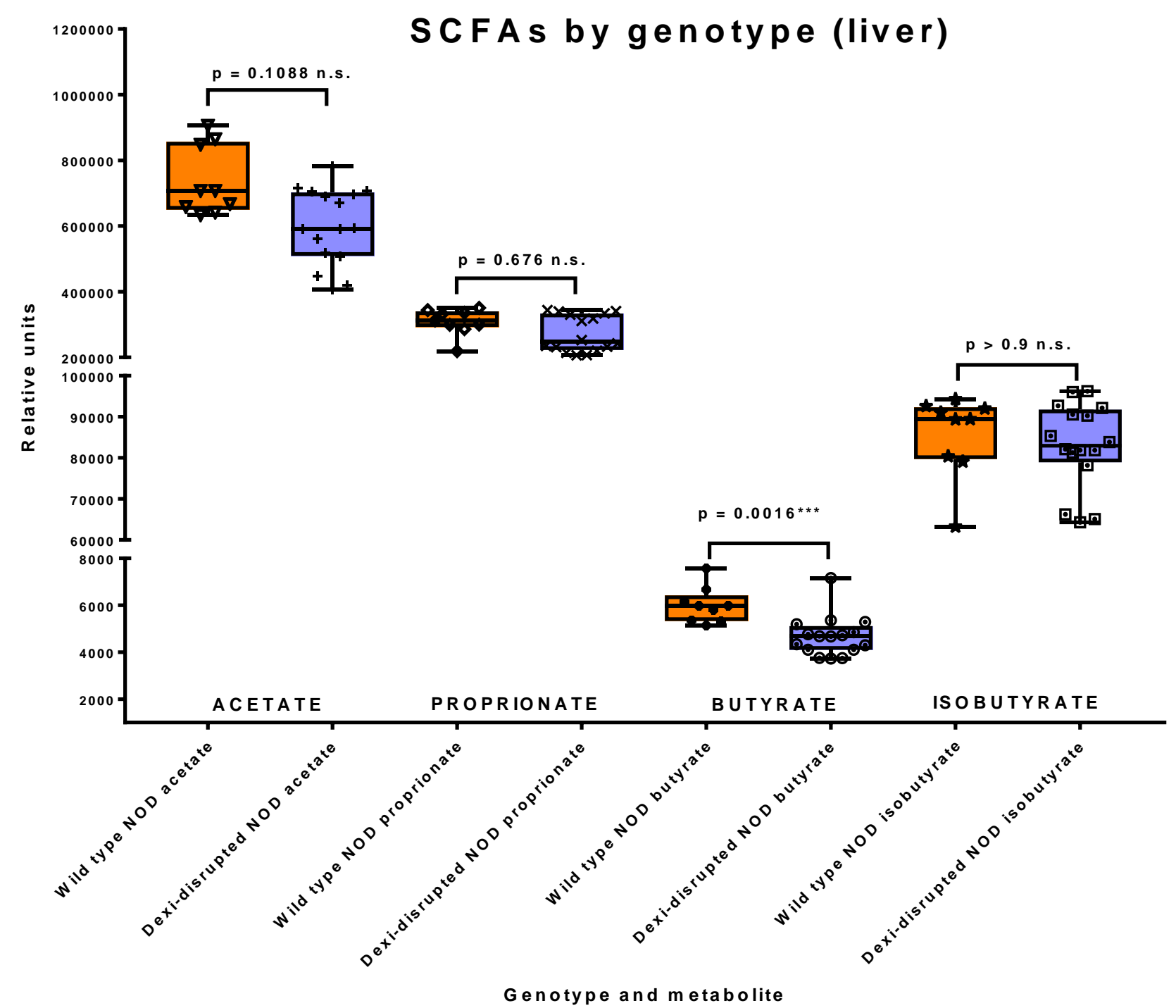

Figure 5b 


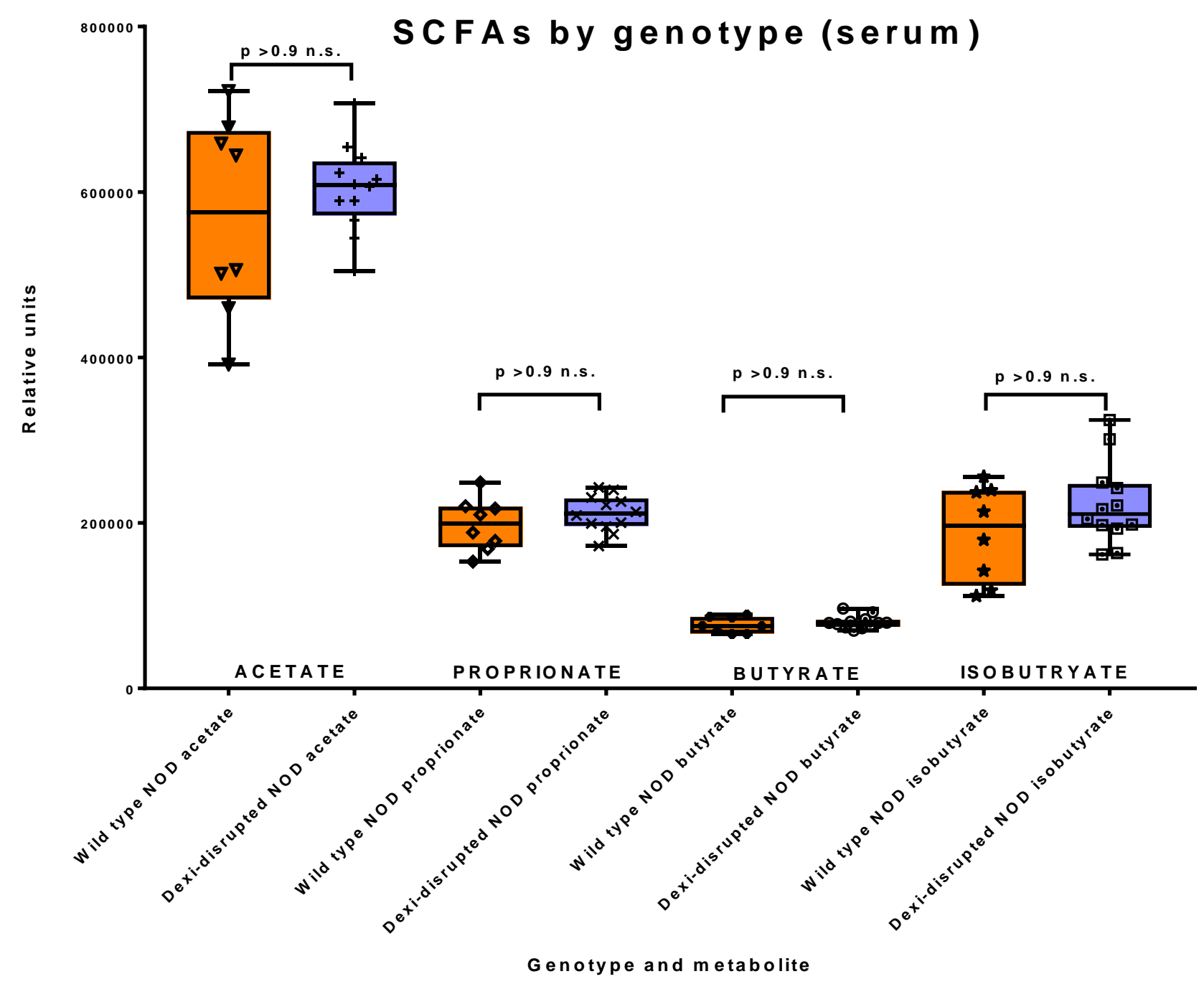

Figure 5: Box and whisker plots demonstrating metabolomic data (short chain fatty acid measurement) from wild-type NOD ( $\mathrm{n}=4$ ) and Dexi-disrupted NOD mice (n=6) in liver (a) and serum (b). Groups were compared using the Mann-Whitney test and $\mathrm{p}$ values are shown after Bonferroni correction for multiple testing. Technical replicates of each sample were run - (a) triplicate and (b) duplicate; individual data points are shown. 
Figure 6 - Summary and proposed model of Dexi impact on serum IgA, microbiome, metabolome and diabetes risk

\section{MOUSE MODEL:}

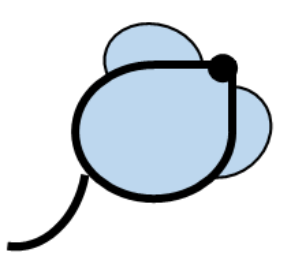

Dexi-disrupted NOD female mouse

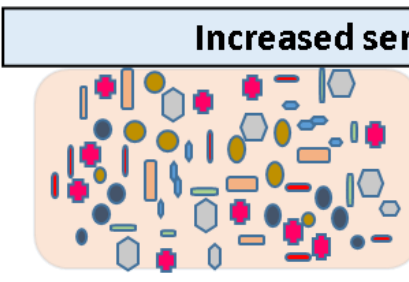

Dexi-disrupted Female NOD gut microbiome more 'pro-diabetic' than female wild type NOD microbiome

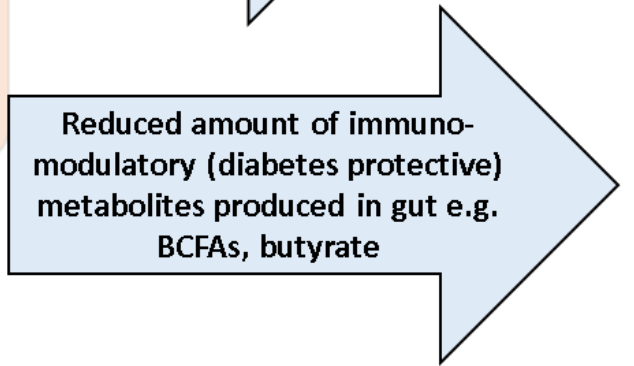

Reduced amount of immunomodulatory (diabetes protective) metabolites produced in gut e.g. BCFAs, butyrate

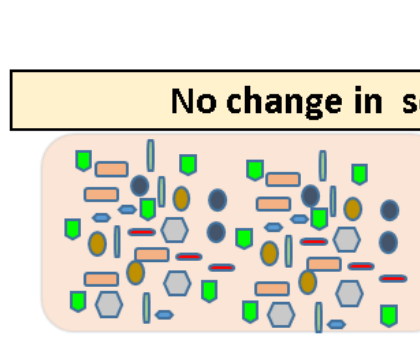

Female NOD gut

Wild type NOD female mouse microbiome - more 'prodiabetic' than male wild type NOD microbiome
Median

diabetes onset at 113 days i.e. 15 days earlier than wild type NOD

female

Median diabetes onset at 129 days; (26 days earlier than male wild

type NOD which has a

different microbiome)

\section{HUMAN HYPOTHESIS MODEL:}

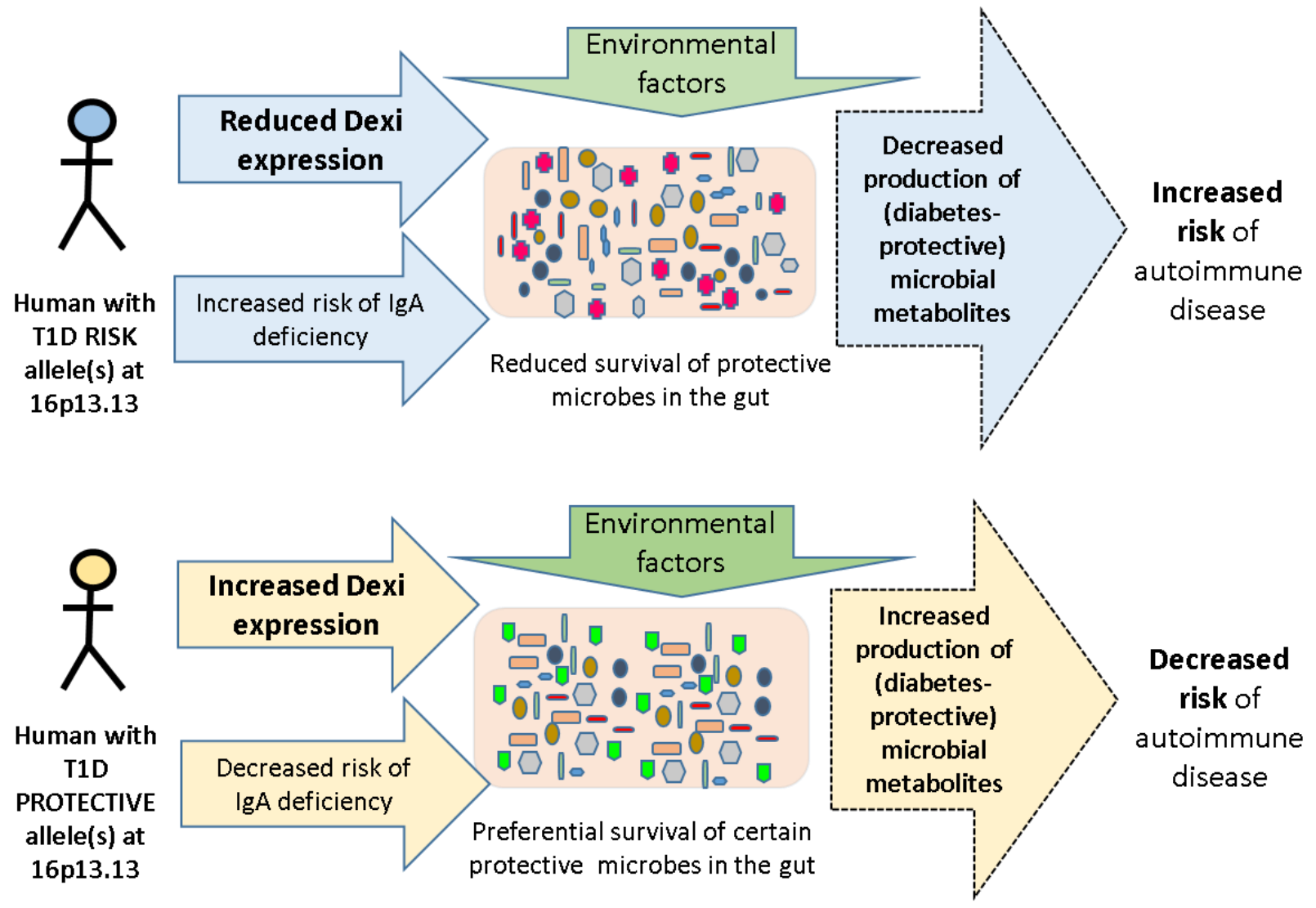




\section{Supplementary information:}

\section{Supplementary Figures S1 to S10}

2. Supplementary Tables S1 to S10 (Tables S8 to S19 are in Excel sheets)

3. Materials and Methods

4. References

5. Author contributions

6. Funding

7. Acknowledgments 


\section{Supplementary materials:}

\section{Supplementary Figure S1:}

\section{UCSC Genome Browser image of part of the 16p13.13 region}

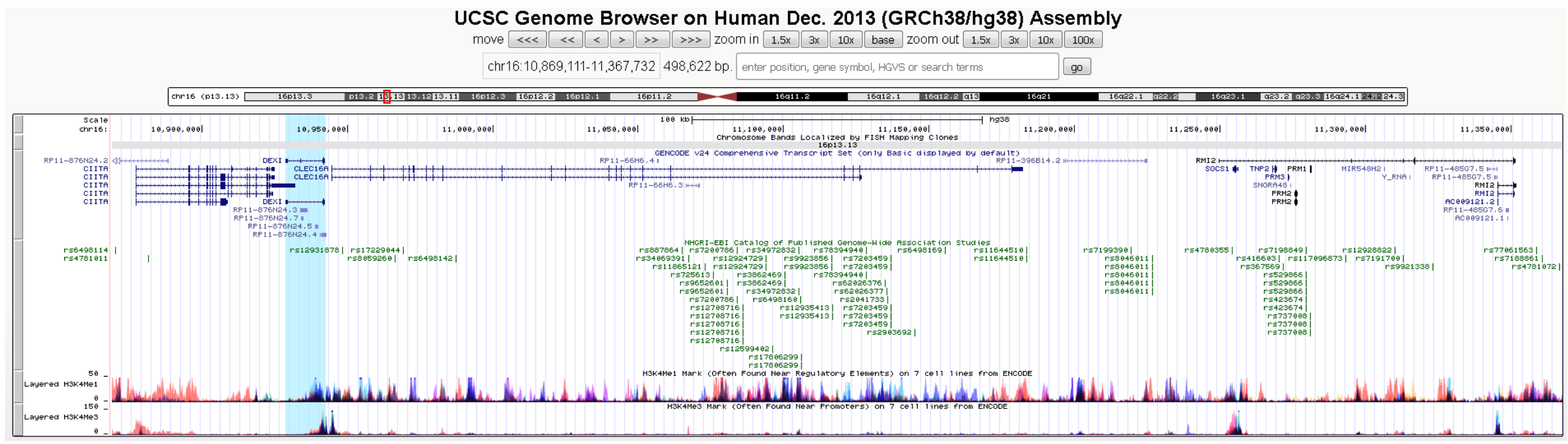

Supplementary Figure S1: A screenshot from the UCSC genome browser illustrating the relationship between DEXI and the autoimmune disease-associated SNPs clustered in and around intron 19 of CLEC16A. The DEXI gene is highlighted in blue and published (significant) GWAS SNPs are coloured in green 


\section{Supplementary Figure S2A: Genotyping of the $1 \mathrm{bp}$ insertion INS1BP mutation}

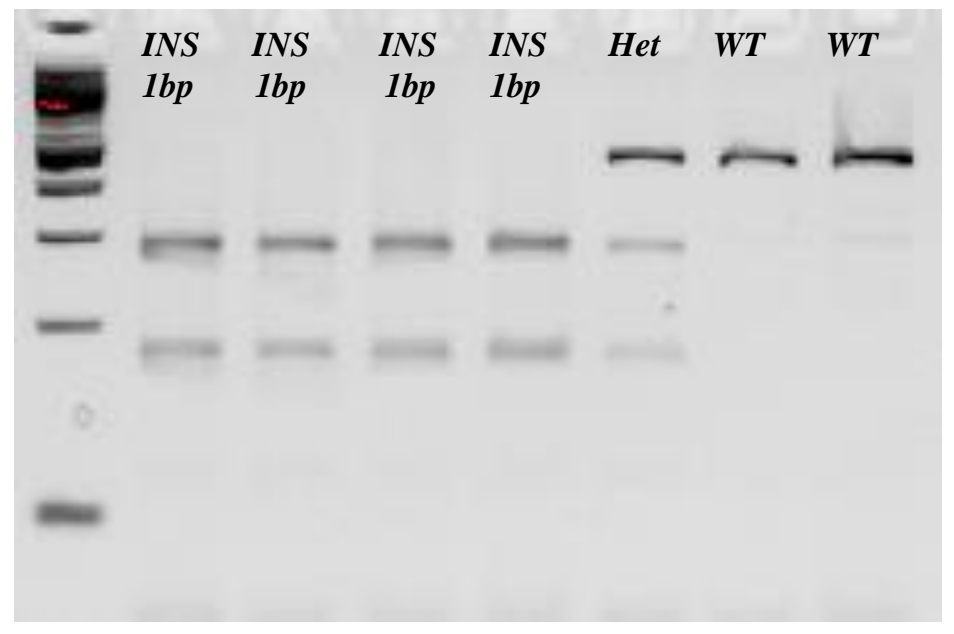

Supplementary Figure S2A: Genomic DNA was amplified using gene specific primers and Q5

Hi-fidelity DNA polymerase for 35 cycles. Samples were separated on a $2 \%$ agarose gel for 1 hour following a 6-hour digestion with AvaII enzyme. Wild-type NOD (WT) do not demonstrate any evidence of digestion, but INSIBP Dexi-disrupted mice display either partial digestion (Het heterozygotes) or full digestion (INSIBP Ho - homozygotes) due to the presence of a $1 \mathrm{bp}$ insertion which generates an AvalI digestion site. 


\section{Supplementary Figure S2B: Genotyping of the 12bp deletion $D E L 12 B P$ mutation}

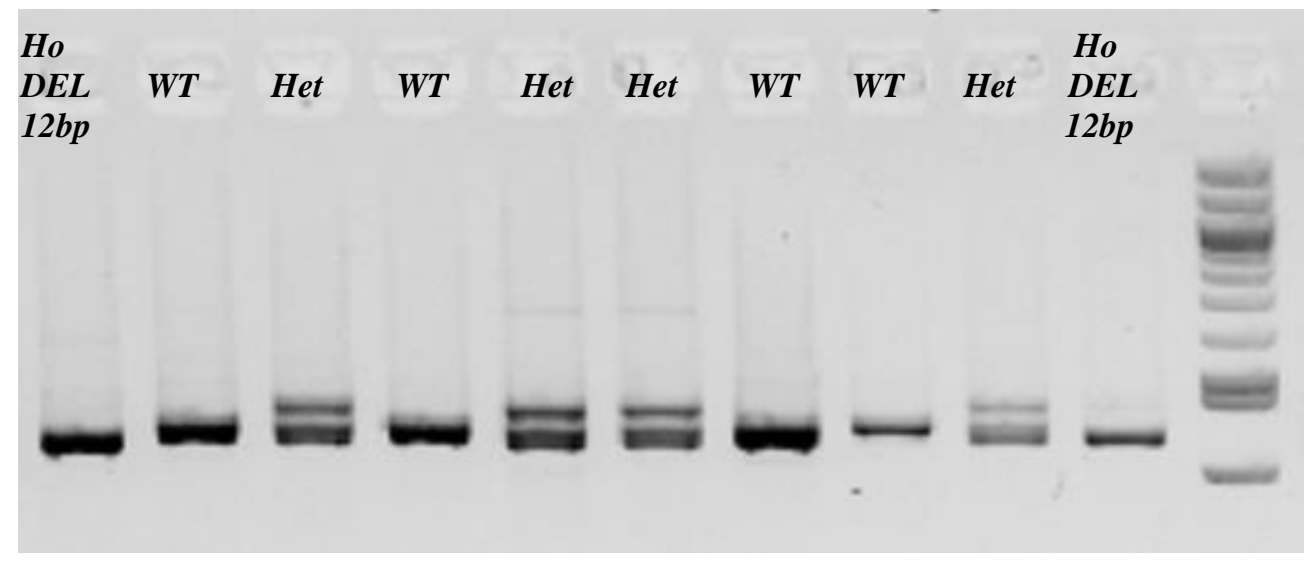

Supplementary Figure S2B: Genomic DNA was amplified using gene specific primers and Q5

Hi-fidelity DNA polymerase for 35 cycles. Samples were separated on a 5\% agarose gel for 2 hours at $100 \mathrm{~V}$. The amplicon from wild-type (WT) mice is $12 \mathrm{bp}$ larger than the amplicon from the Dexi-disrupted DEL12bp homozygous mice $(\mathrm{Ho})$. Heterozygous mice (Het) demonstrate three bands due to heteroduplex formation 
Experiments to investigate the Dexi protein focused on tissue where Dexi expression has been reported by transcriptomic studies e.g. liver. We identified two antibodies (Sigma Prestige and Proteintech) that were able to recognize recombinant DEXI, giving a single band of the correct size in an over-expression lysate sample. However neither antibody revealed a band corresponding to endogenous Dexi in any mouse tissues and nor were differences between wild-type NOD and Dexi-disrupted mice evident. (Representative western blots are shown in Supplementary Figures S2C and S2D). Several other commercial antibodies failed to recognize the recombinant protein and also resulted in multiple non-specific bands when tested against tissue lysate. 


\section{Supplementary Figure 2C}

HEK293 DEXI

overexpression lysate

$+$
WT NOD

12
INSIBP NOD DEL12BP NOD

$\begin{array}{llll}1 & 2 & 1 & 2\end{array}$

Supplementary Figure S2C: Western blot demonstrating reactivity of commercial polyclonal antibody with recombinant DEXI (+) but no evidence of a band of the correct size in mouse liver lysates (1 and 2) from wild-type NOD (WT NOD) or Dexi-disrupted NOD mice (INSIBP and DEL12BP). 50ul protein per well was loaded on a 4-20\% Tris-Glycine SDS-PAGE gel and blotted onto a PVDF membrane following electrophoresis. The primary antibody for western blotting was a rabbit anti-DEXI polyclonal antibody (Sigma Prestige) at 1:400 dilution, the secondary antibody was a goat anti-rabbit HRP conjugate (VectorLabs) at 1:50,000 dilution and the blot was developed with ECL Advance reagent. 


\section{Supplementary Figure 2D}

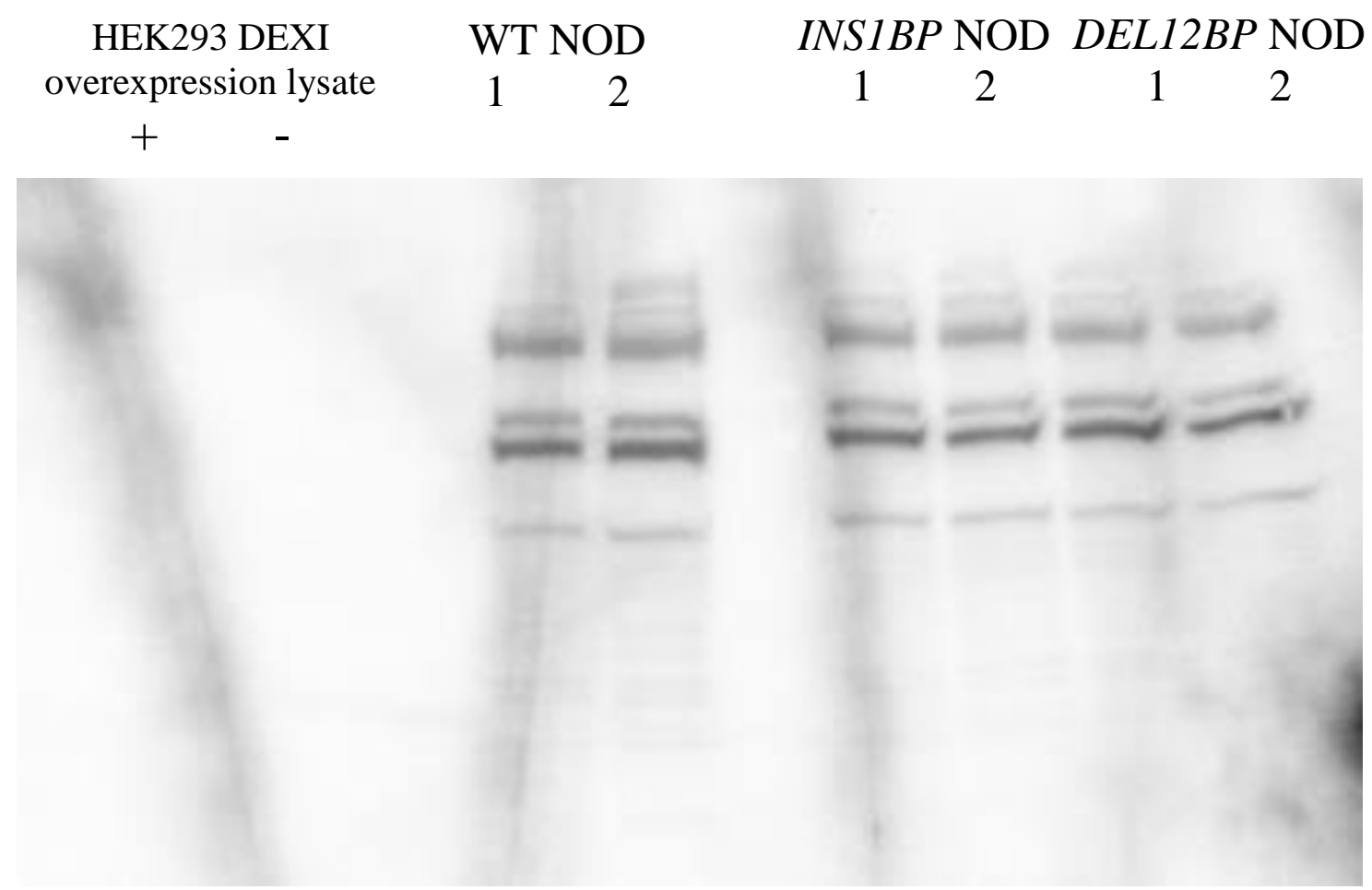

Supplementary Figure S2D: Western blot demonstrating lack of a Dexi band of the correct size using a commercial polyclonal antibody with recombinant DEXI (+) and with mouse liver lysates (1 and 2) from wild-type NOD (WT NOD) or Dexi-disrupted NOD mice (INSIBP and DEL12BP). 50ul protein per well was loaded on a 4-20\% Tris-Glycine SDS-PAGE gel and blotted onto a PVDF membrane following electrophoresis. The primary antibody for western blotting was a rabbit anti-DEXI polyclonal antibody (Abgent) at 1:400 dilution and the blot was developed with ECL Advance reagent. 
A further attempt to identify Dexi protein using the Sigma Prestige polyclonal antibody was made by immunohistochemistry on wild-type and Dexi-disrupted mouse tissues but a persistent high background staining was observed despite optimization (Supplementary Figure S2E).

\section{Supplementary Figure S2E}

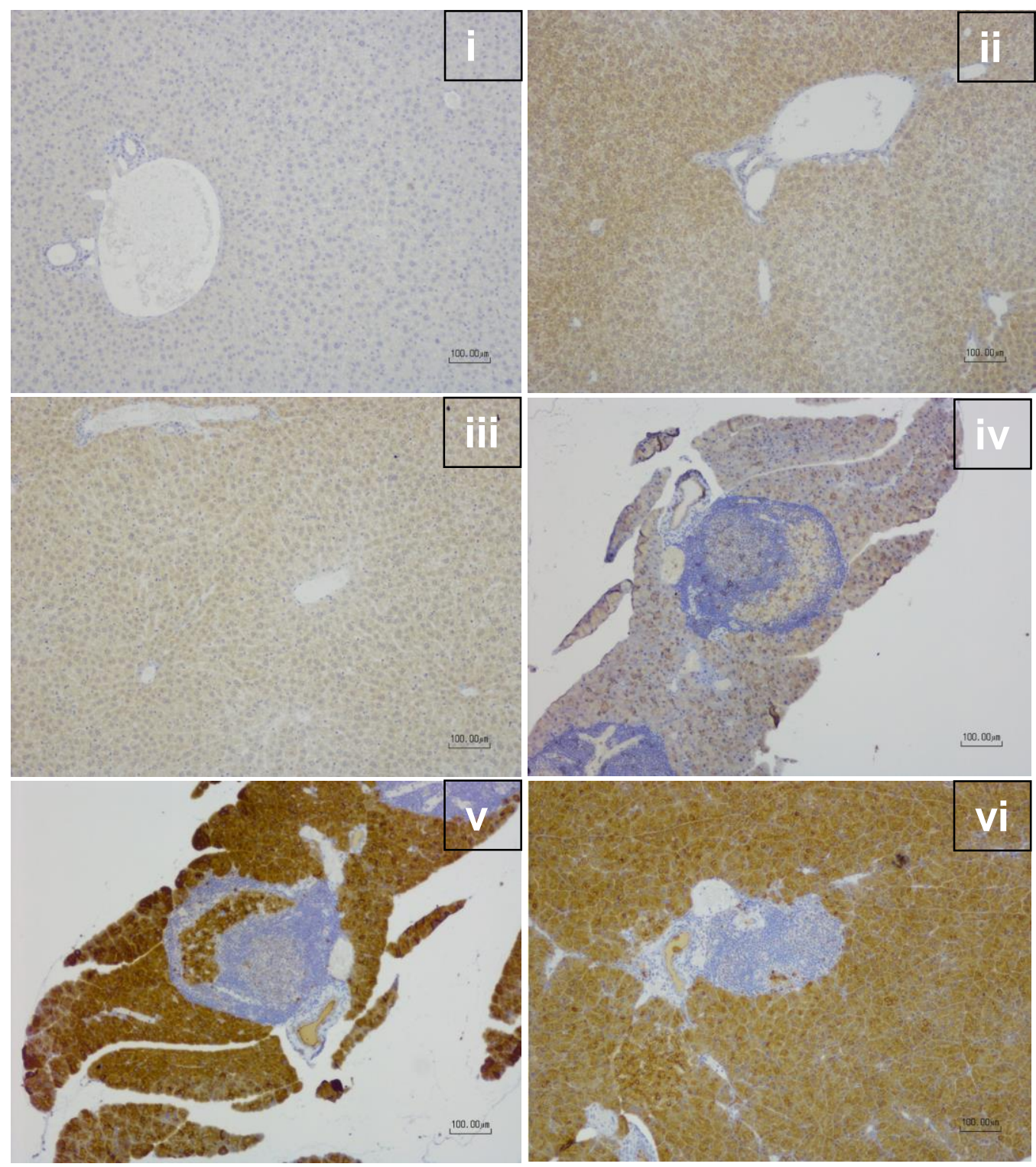

Supplementary Figure S2E. Immunohistochemical staining for DEXI using a commercial polyclonal antibody (Sigma Prestige) reveals non-specific background staining in wild -type NOD 
mice (ii,v) and Dexi-disrupted NOD mice (iii,vi). Representative sections of liver (i,ii,iii) and pancreas (iv,v,vi) are shown. Immunohistochemical staining (ii,iii,v,vi) and isotype-matched immunoglobulin control (i,iv) all with haematoxylin counterstain. Scale bar indicates 100 microns. 


\section{Supplementary Figure S2F}

Dexi transcripts are detectable in wild-type and Dexi-disrupted NOD mice using quantitative PCR to amplify the 3' and 5' ends of the transcript.

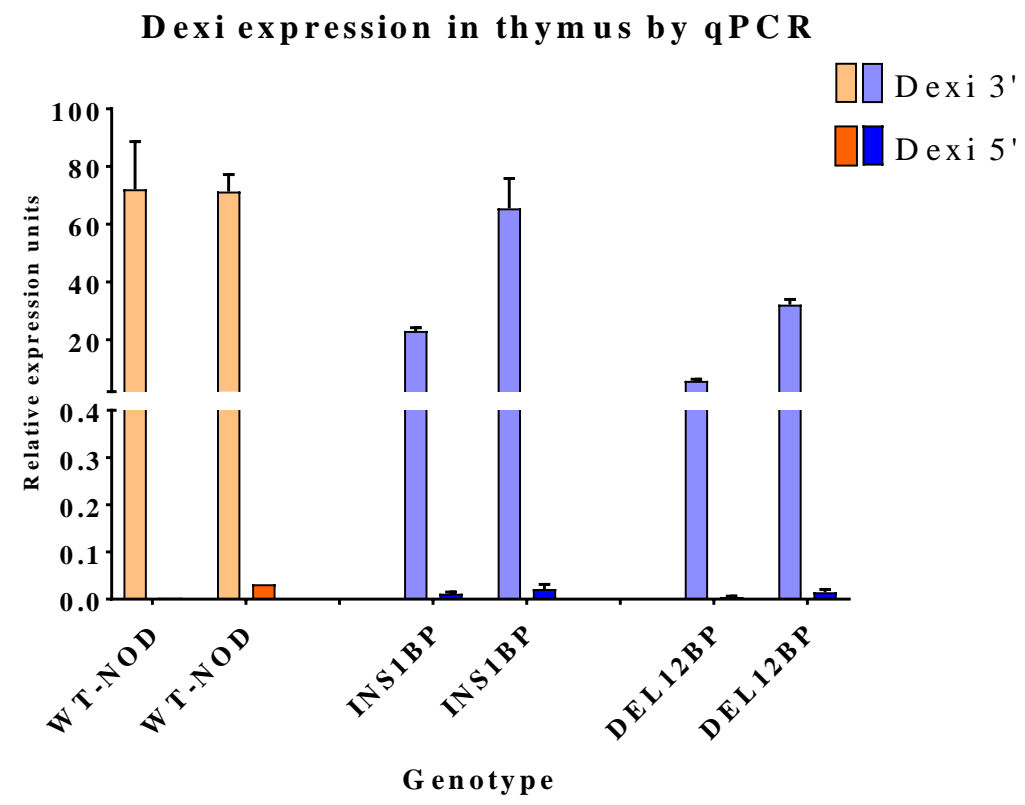

Dexi expression in spleen by qPCR

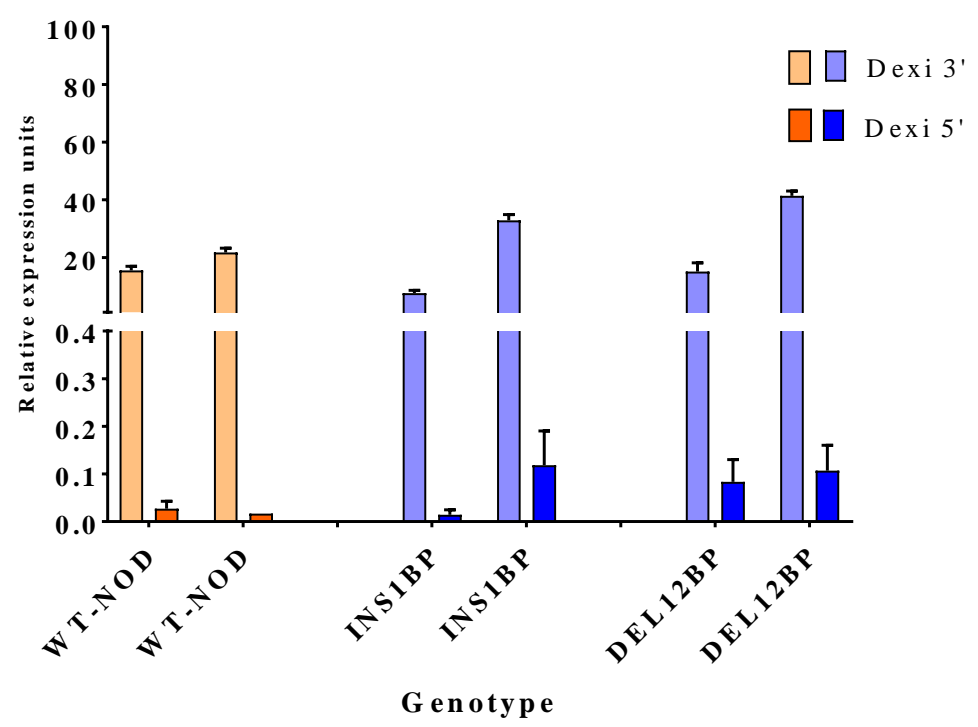

Supplementary Figure S2F Dexi transcripts were detected in cDNA prepared from thymus and spleen using qPCR directed towards the 3' and the 5' end of the Dexi transcript in age-matched 
female wild-type (orange) NOD (n=2), homozygous Dexi-disrupted (blue) NOD INSIBP (n=2) and homozygous Dexi-disrupted (blue) NOD DEL12BP $(\mathrm{n}=2)$ mice. Data are shown for individual mice as mean and SD of triplicate assays using beta actin as a housekeeping gene. 


\section{Supplementary Figure S3A: The INS1BP Dexi mutation does not impact on diabetes-free survival in male NOD mice}
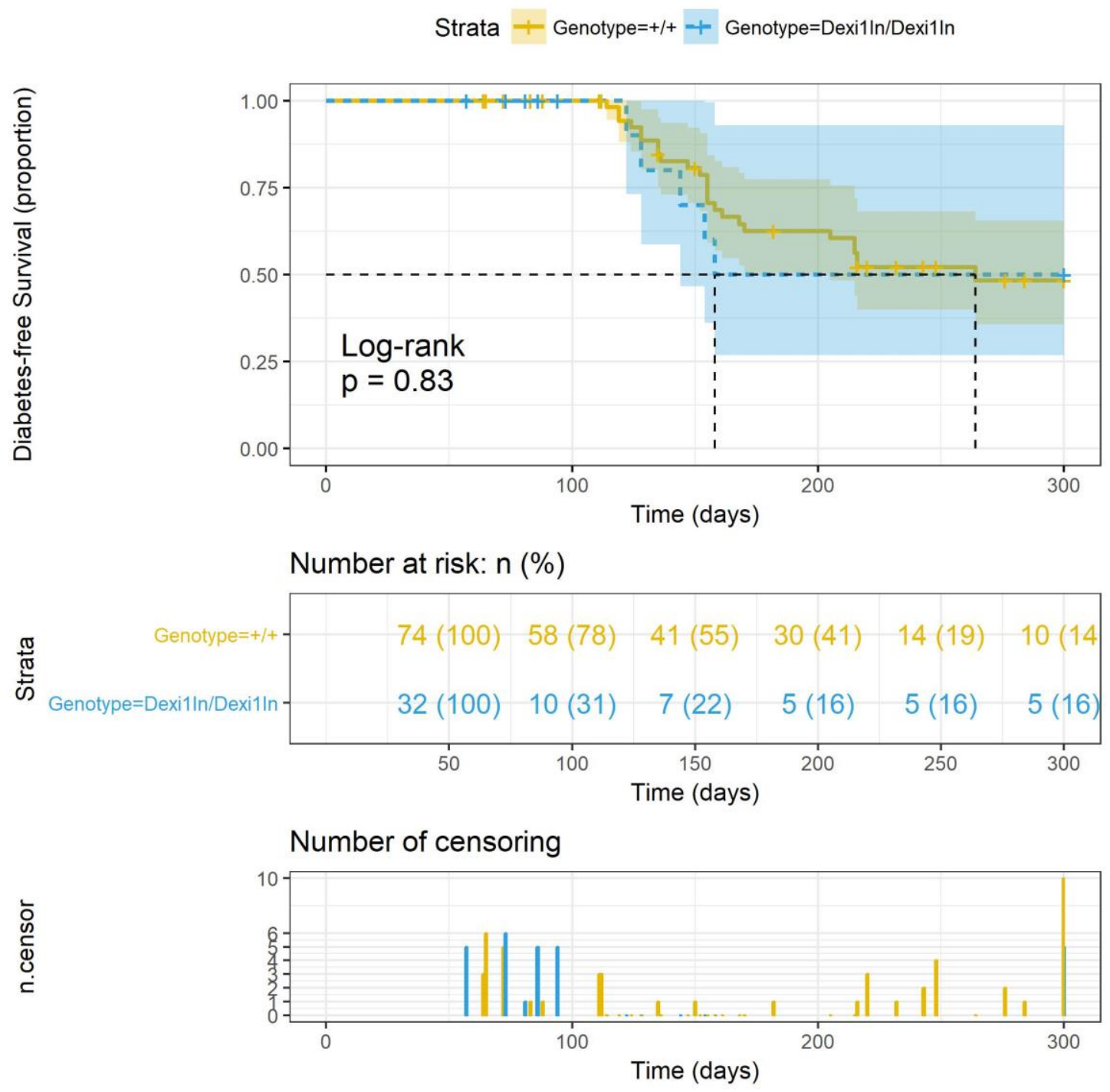
Supplementary Figure S3B: The DEL12BP Dexi mutation does not impact on diabetes-free survival in male NOD mice
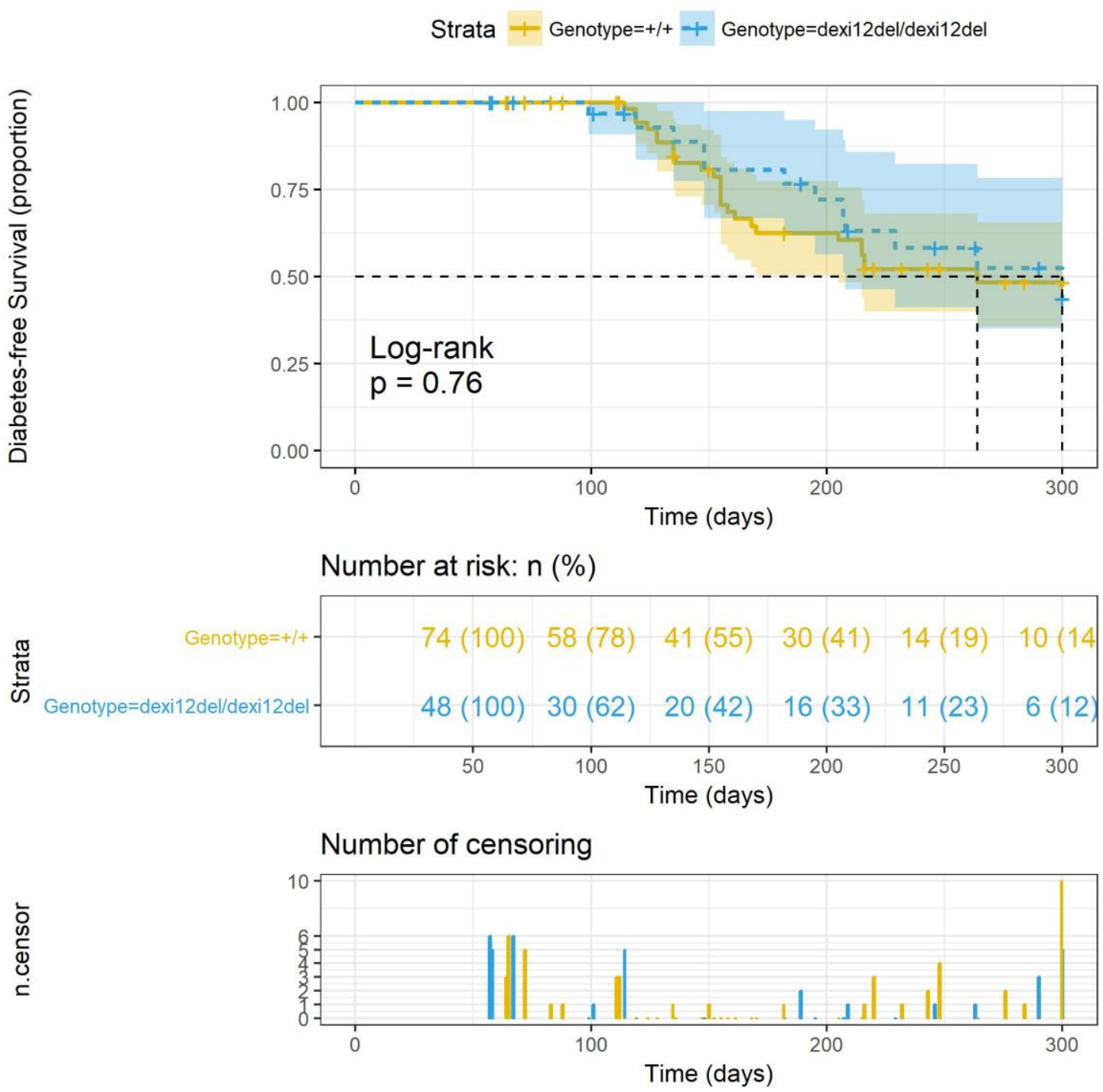

Supplementary Figure S3: The presence of a homozygous INS1BP (A) or DEL12BP (B) Dexi mutation does not affect diabetes-free survival in male NOD mice.

Top panel for each line: Kaplan-Meier diabetes-free survival curve with log-rank p-value for wild-type NOD mice $(n=74)$ represented as yellow-orange $(+/+)$. Dexi-disrupted mice survival curves are represented in blue, for homozygous INSIBP mice $(\mathrm{n}=32$; labelled as Dexilin/Dexilin) and DEL12BP mice ( $\mathrm{n}=48)$; labelled as dexi12del/dexi12del). 
bioRxiv preprint doi: https://doi.org/10.1101/393421; this version posted August 16,2018 . The copyright holder for this preprint (which was not certified by peer review) is the author/funder. All rights reserved. No reuse allowed without permission.

95\% Confidence Intervals are shown for each genotype as translucent shaded regions surrounding the genotype line.

Mid panel: Numbers of animals at risk over time.

Bottom panel: Bar plot of censorship data for each line. 


\section{Supplementary Figure S4}
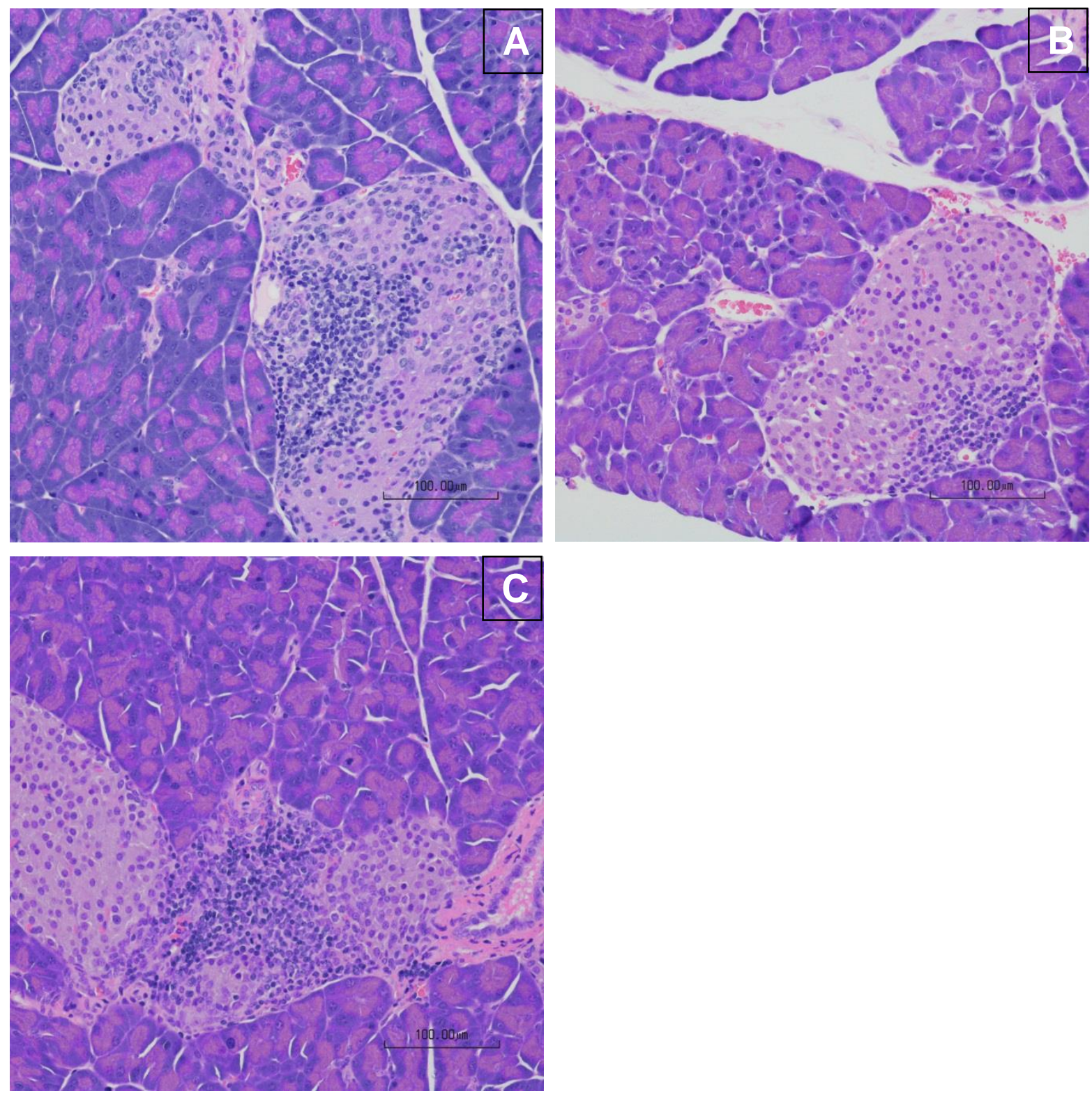

Supplementary Figure S4. Multifocal pancreatic islets exhibit infiltration of variable numbers of lymphocytes in both NOD-WT control mice (A) and Dexi-disrupted NOD mice (B - INS1BPNOD; C - DEL12BP-NOD). Haematoxylin and eosin stain. Scale bar indicates 100 microns. 


\section{Supplementary Figure S5A}

Absolute B cell numbers in the spleen in wild type and Dexi-deficient NOD mice

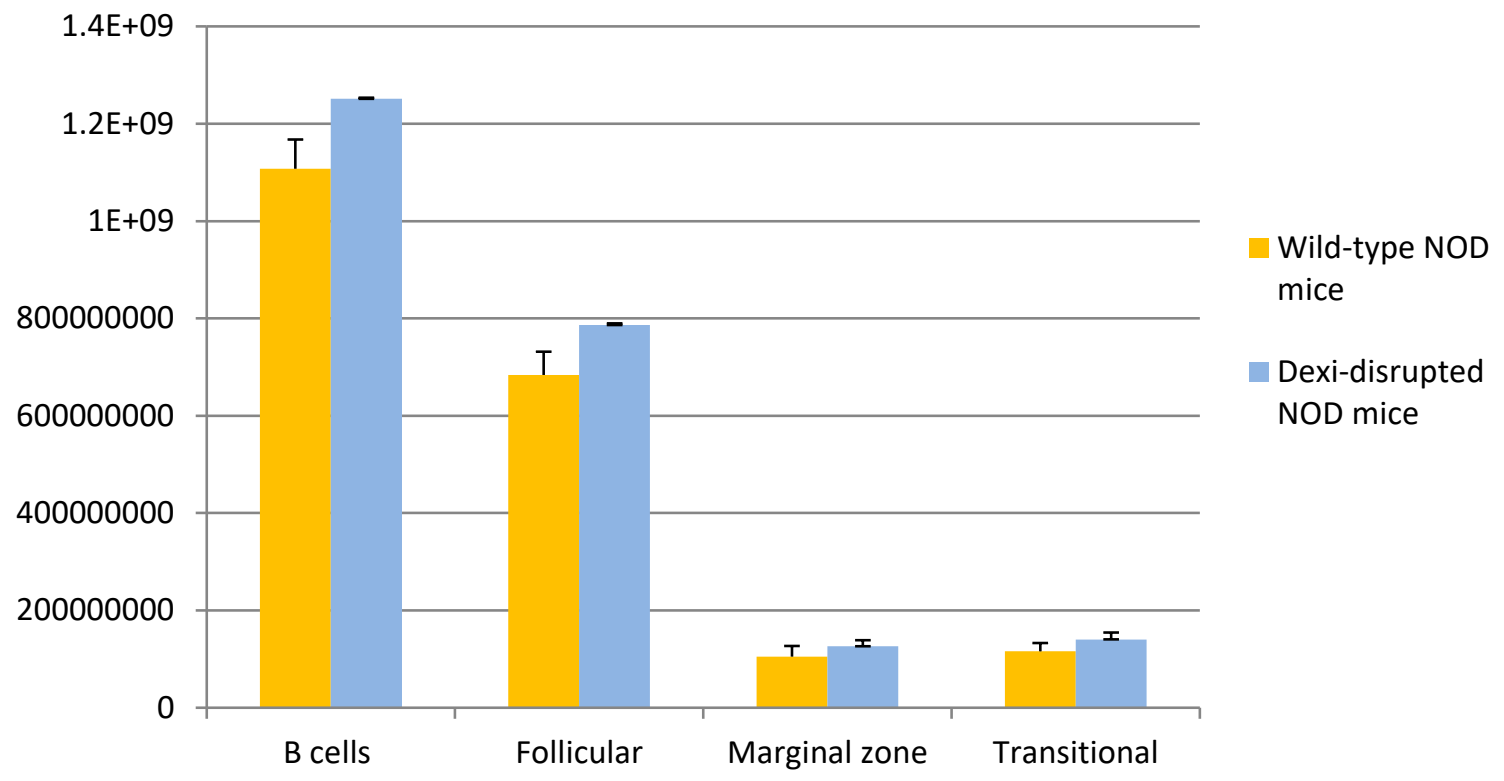

\section{Supplementary Figure S5B}

Absolute B cell numbers in the bone marrow in wild type and Dexidisrupted NOD mice (Hardy fractions)

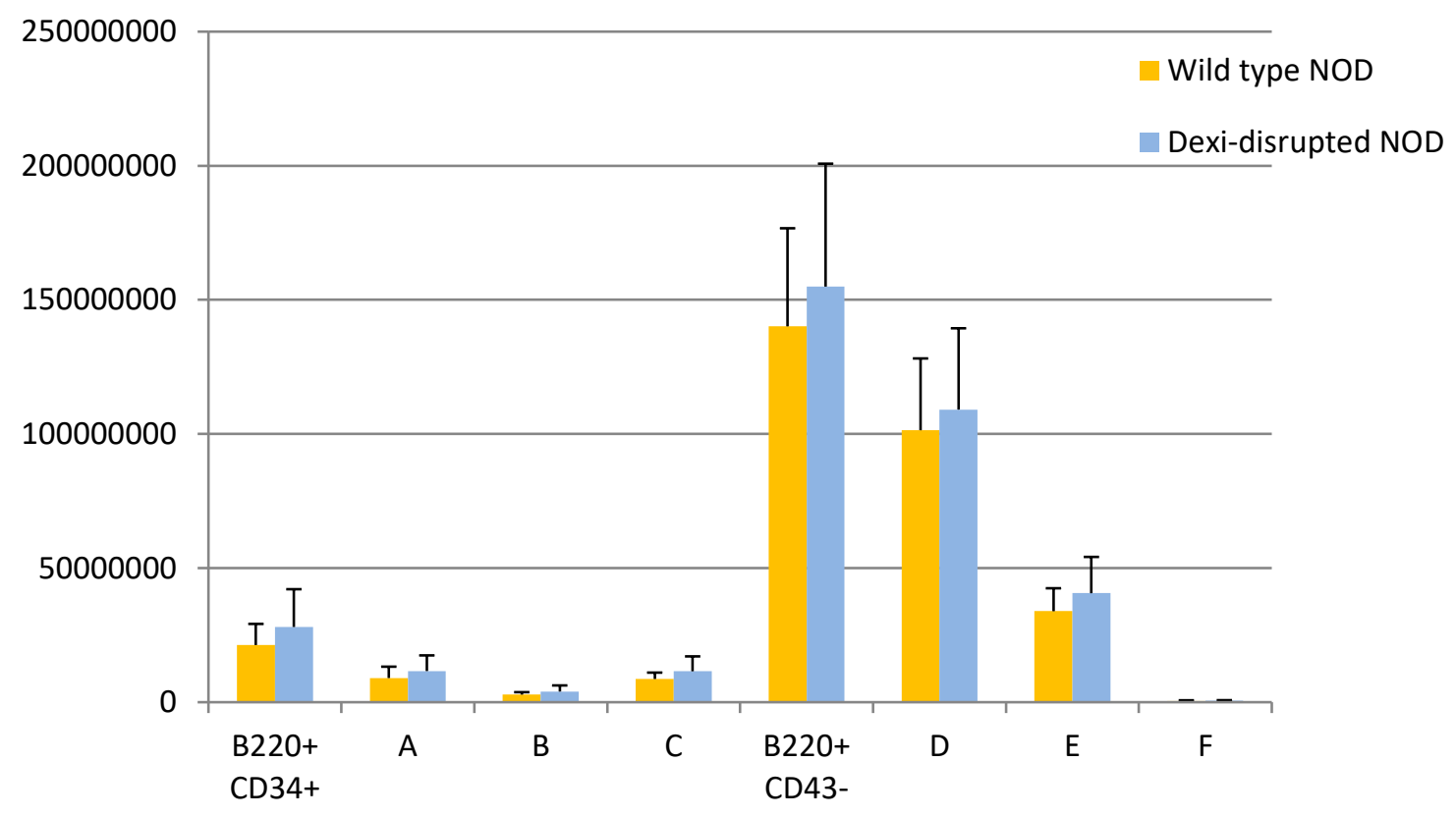




\section{Supplementary Figure S5C}

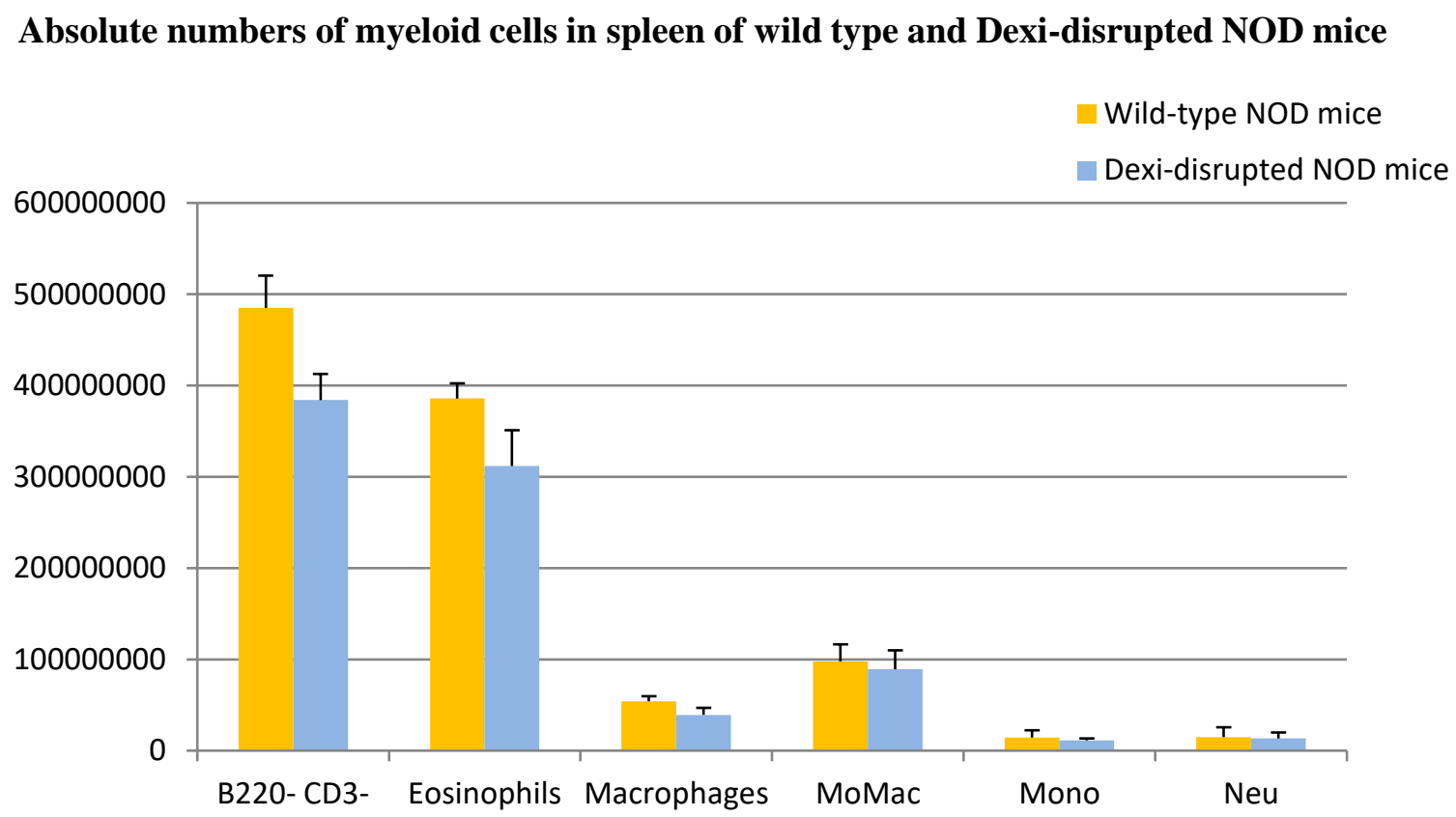

\section{Supplementary Figure S5D}

\section{Absolute numbers of myeloid cells in the bone marrow of wild type and}

\section{Dexi-disrupted NOD mice}

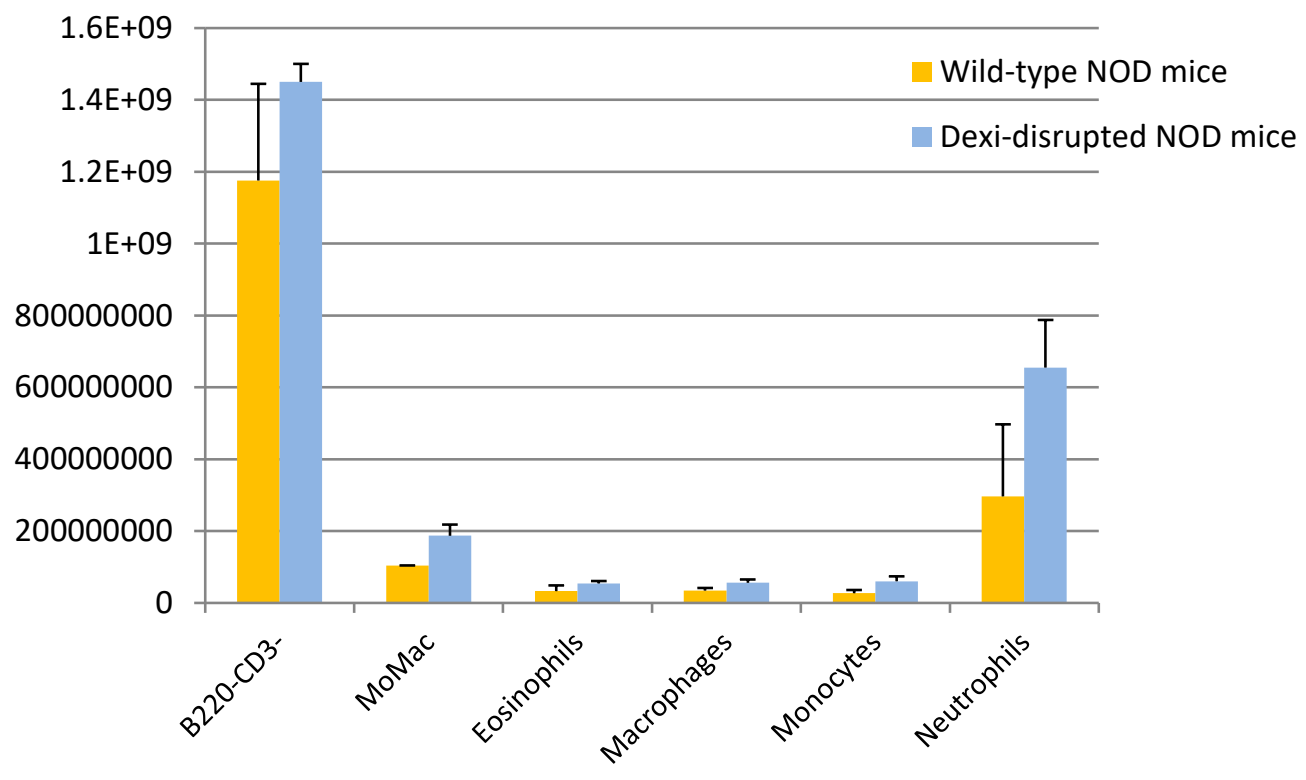




\section{Supplementary Figure S5E}

\section{Absolute numbers of $\mathbf{T}$ cell populations in the spleen of wild-type NOD and Dexi-disrupted mice}

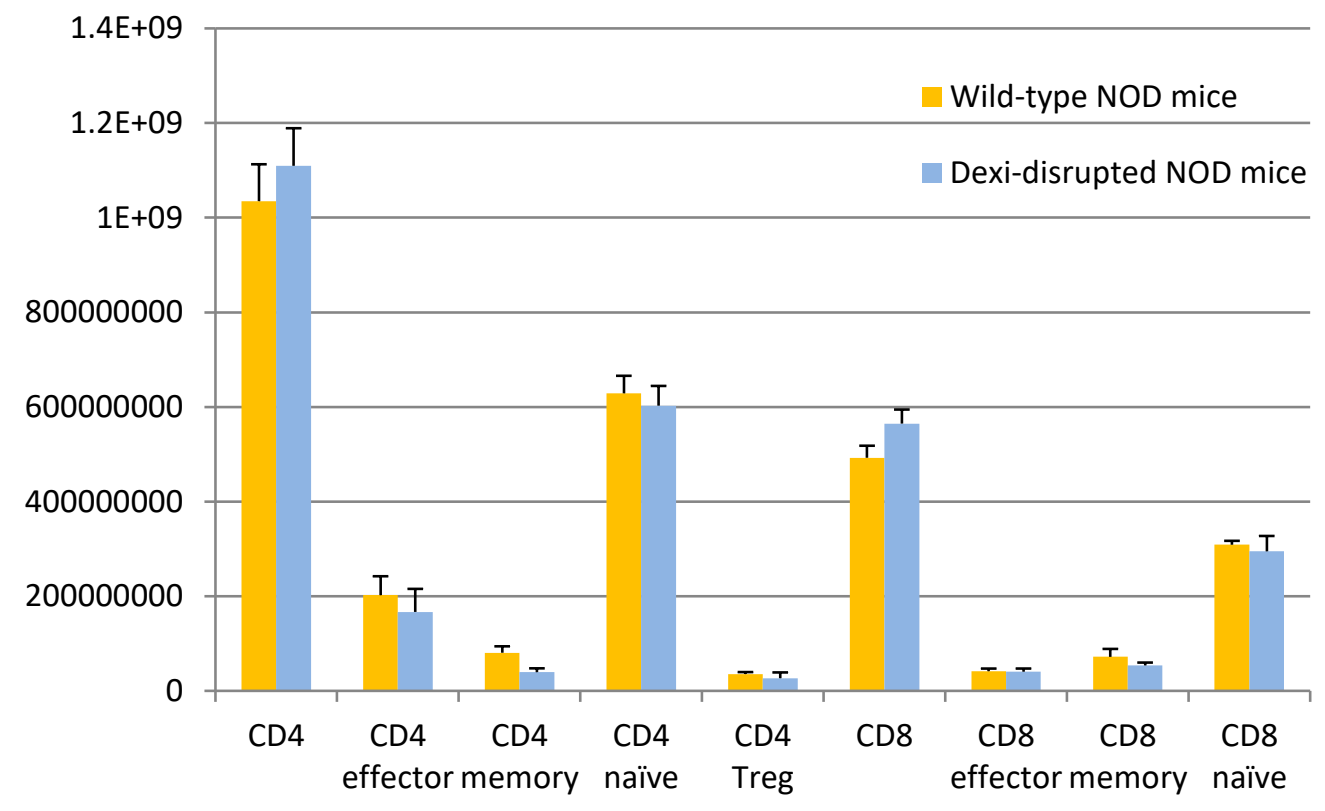

\section{Supplementary Figure 5SF}

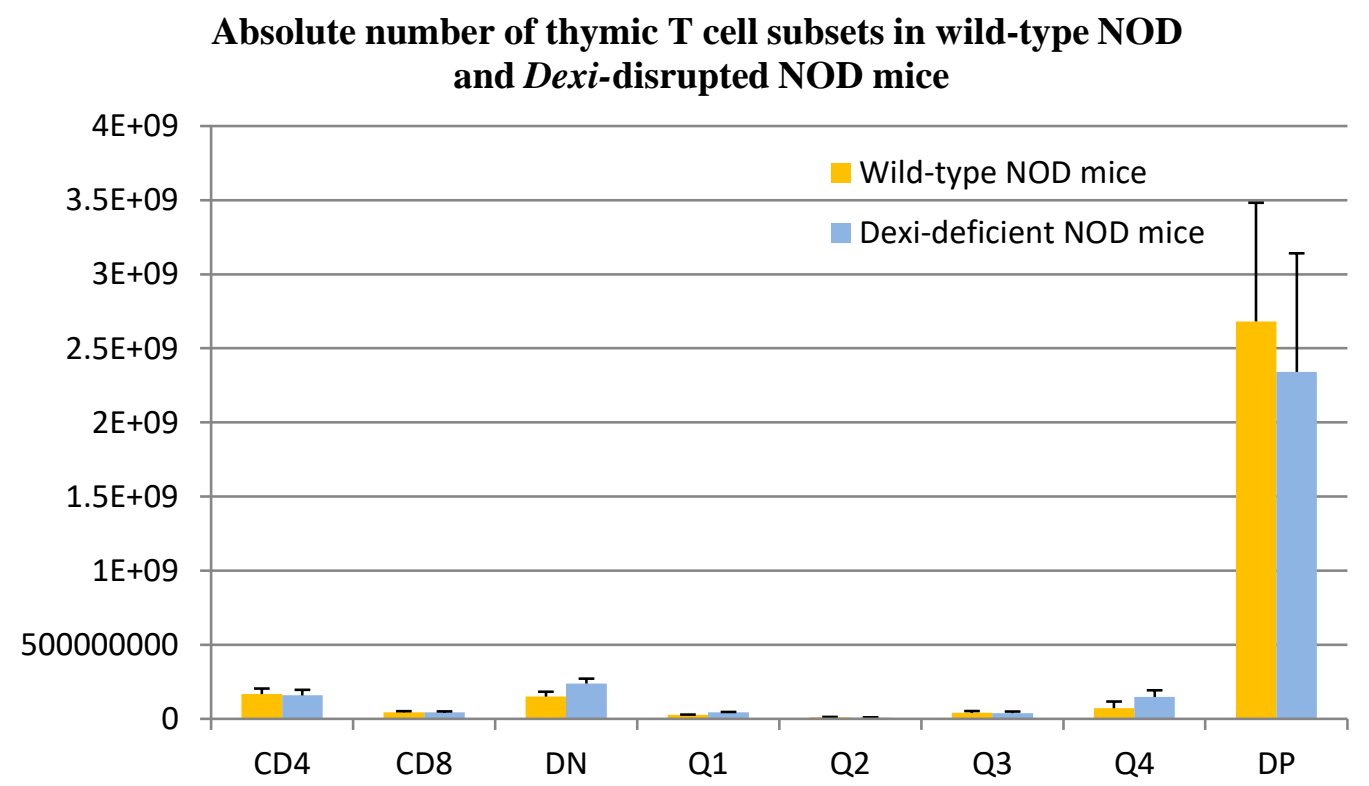




\section{Supplementary Figure S5:}

Dexi-disrupted mice $(\mathrm{n}=2)$ show no change in resting cellular immunophenotype compared to wild-type NOD mice $(n=2)$ using a panel of monoclonal antibodies and flow cytometry. Data shown are representative of more than one experiment. See Materials and methods for gating strategies. A. Splenic B cell subsets B. Bone marrow B cell subsets C. Splenic myeloid subsets D. Bone marrow myeloid subsets E. Splenic T cells F. Thymic T cells (DN - double negative; DP double positive). 


\section{Supplementary Figure S7}

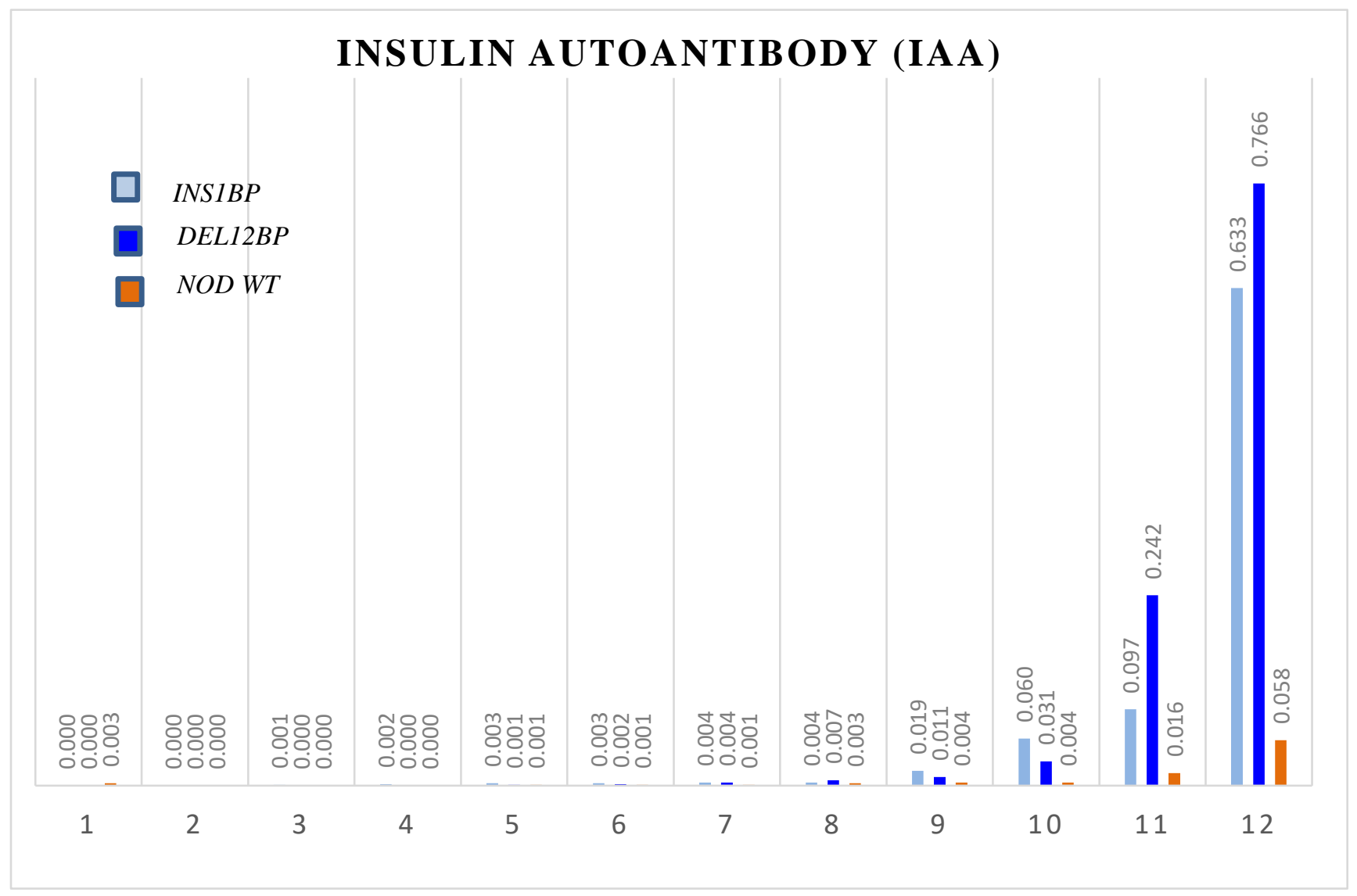

Supplementary Figure S7: Insulin autoantibodies (IAA) were measured in the serum of 12 agematched female mice of each genotype (NOD wild-type - NOD WT; Dexi-disrupted INS1BP; Dexi-disrupted $D E L 12 B P$ ) using a radioimmunoassay (at the Barbara Davis Center for Childhood Diabetes, USA). The result from each mouse (1-12) is shown individually, in ascending order of IAA. The cut-off for positivity was 0.01 . Two out of 12 WT-NOD showed positivity for IAA compared to 4 out of 12 INS1BP mice and 4 out of 12 DEL12BP Dexi-disrupted mice. 


\section{Supplementary Figure S7A}

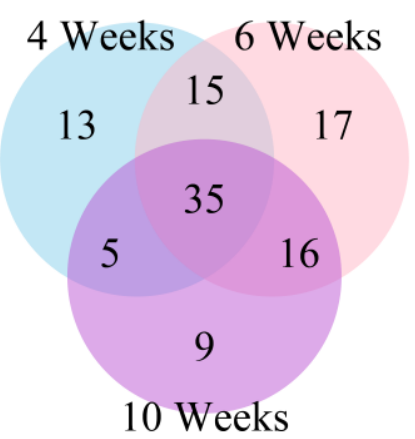

\section{Supplementary Figure S7B}

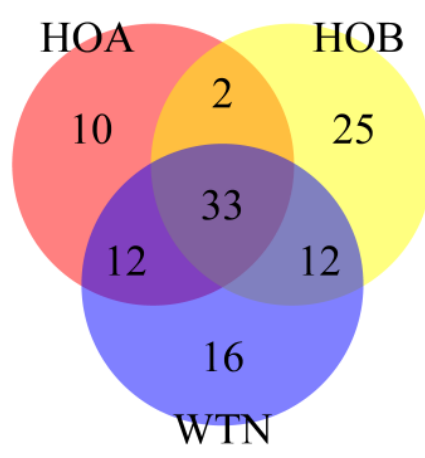

\section{Supplementary Figure 7}

A. Venn diagram of the number of microbial species robustly detected in the feces in a total of 44 Dexi-disrupted and WT mice at 4, 6, and 10 weeks of age using the Axiom Microbiome array (Thermo-Fisher Scientific).

B. Venn diagram of microbial species detected in the feces of Dexi-disrupted INS1BP (HOA), Dexi-disrupted DEL12BP (HOB), and wild-type NOD (WTN) mouse lines. 


\section{Supplementary Figure S8}
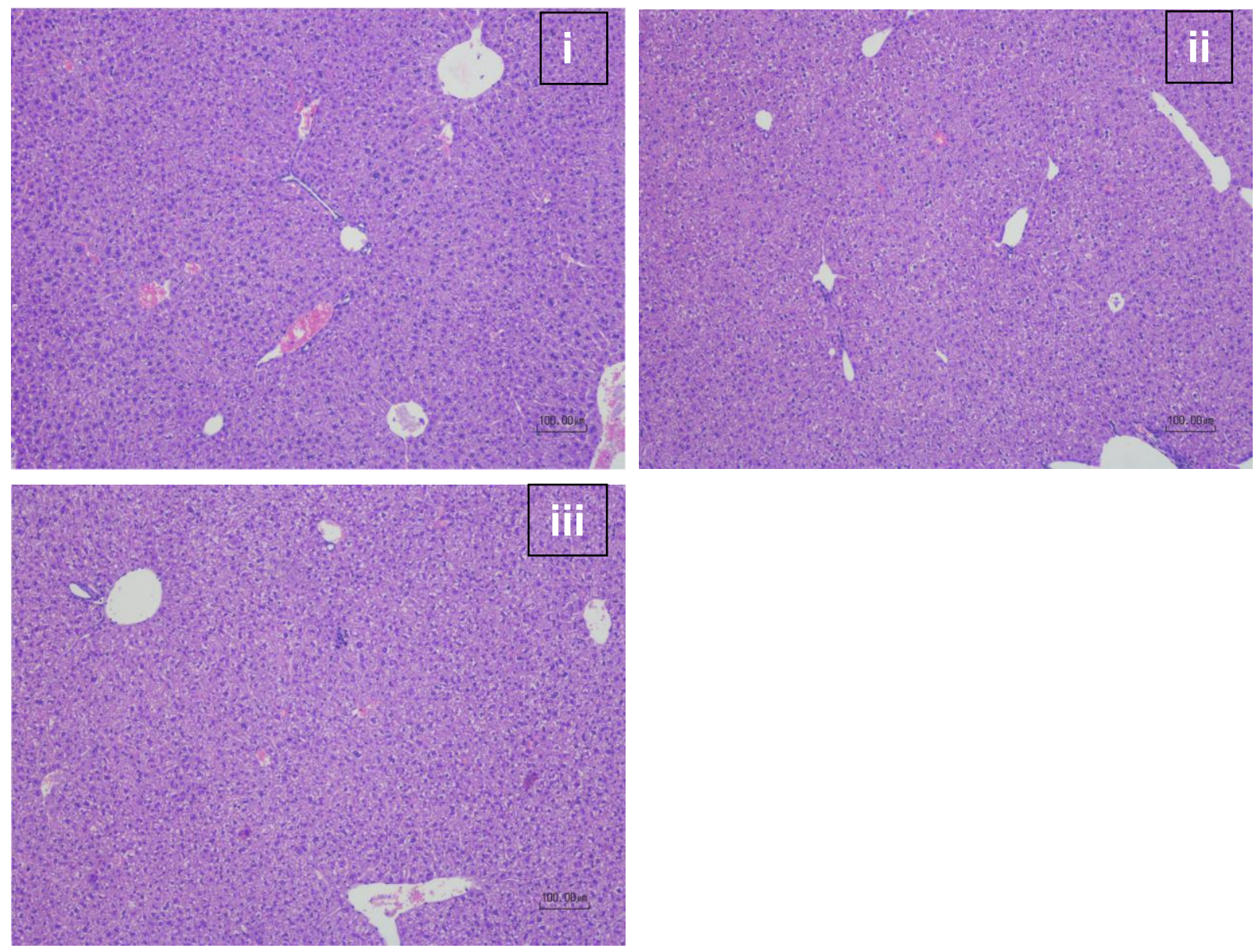

Supplementary Figure S8A. There is no histologically appreciable difference in the liver morphology of wild-type NOD mice (i) and Dexi-disrupted NOD mice (ii - INSIBP and iii DEL12BP). Haematoxylin and eosin stain. Scale bar indicates 100 microns. 


\section{Supplementary Figure S9A}

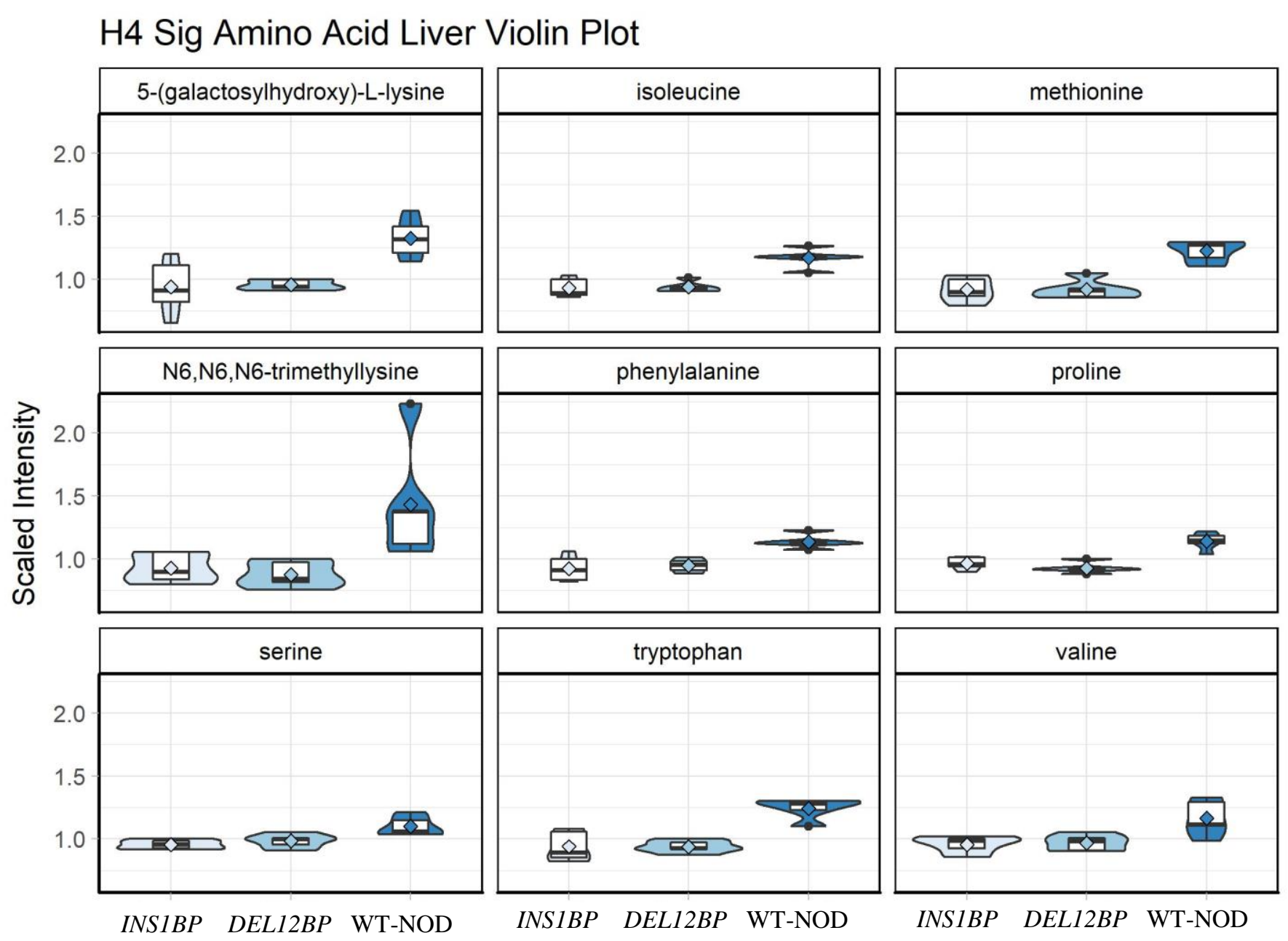

\section{Supplementary Figure S9B}

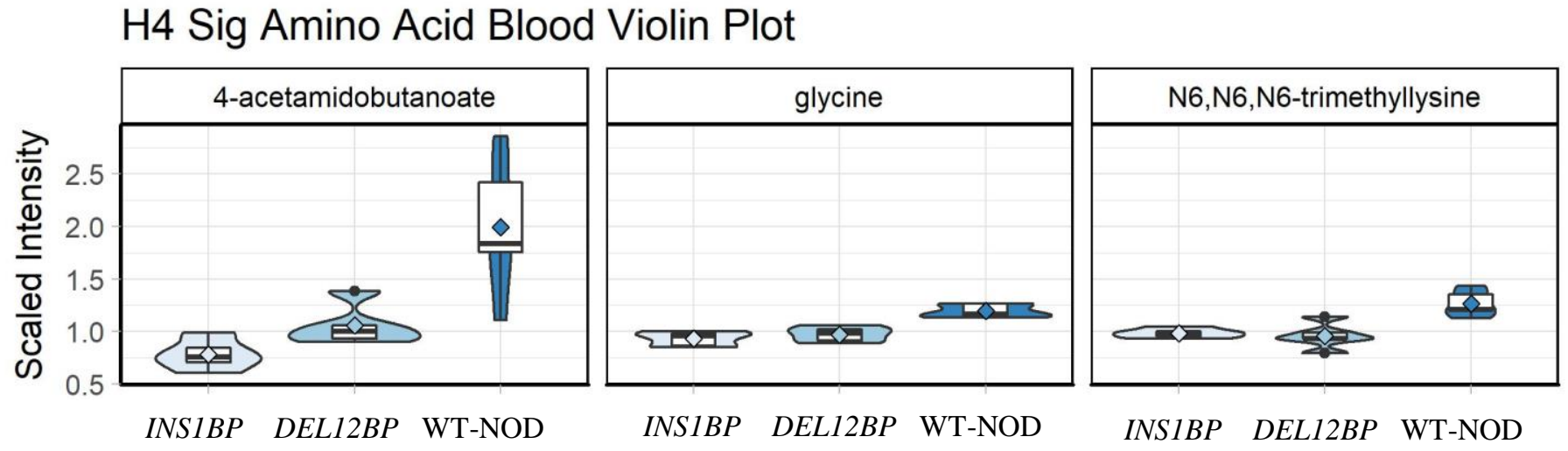


Supplementary Figure 9: Biochemical scaled intensity violin plots of significantly different amino acids in liver (A) and blood (B). Data are shown from INS1BP and DEL12BP homozygote mice compared to wild-type (WT) NOD mice at 6 weeks of age. 
bioRxiv preprint doi: https://doi.org/10.1101/393421; this version posted August 16,2018 . The copyright holder for this preprint (which was not certified by peer review) is the author/funder. All rights reserved. No reuse allowed without permission.

\section{Supplementary Figure S10A}

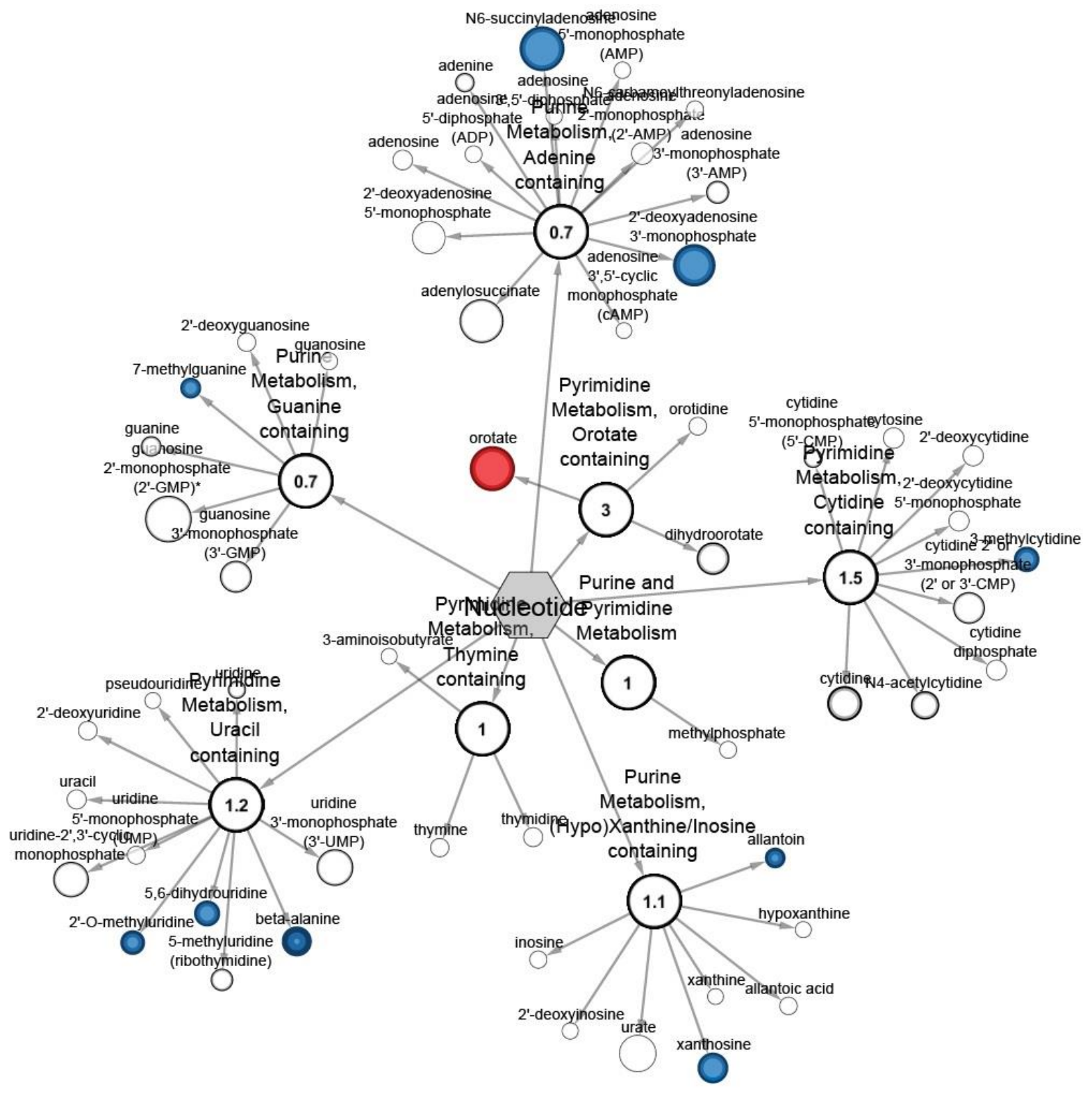


bioRxiv preprint doi: https://doi.org/10.1101/393421; this version posted August 16,2018 . The copyright holder for this preprint (which was not certified by peer review) is the author/funder. All rights reserved. No reuse allowed without permission.

\section{Supplementary Figure S10B}

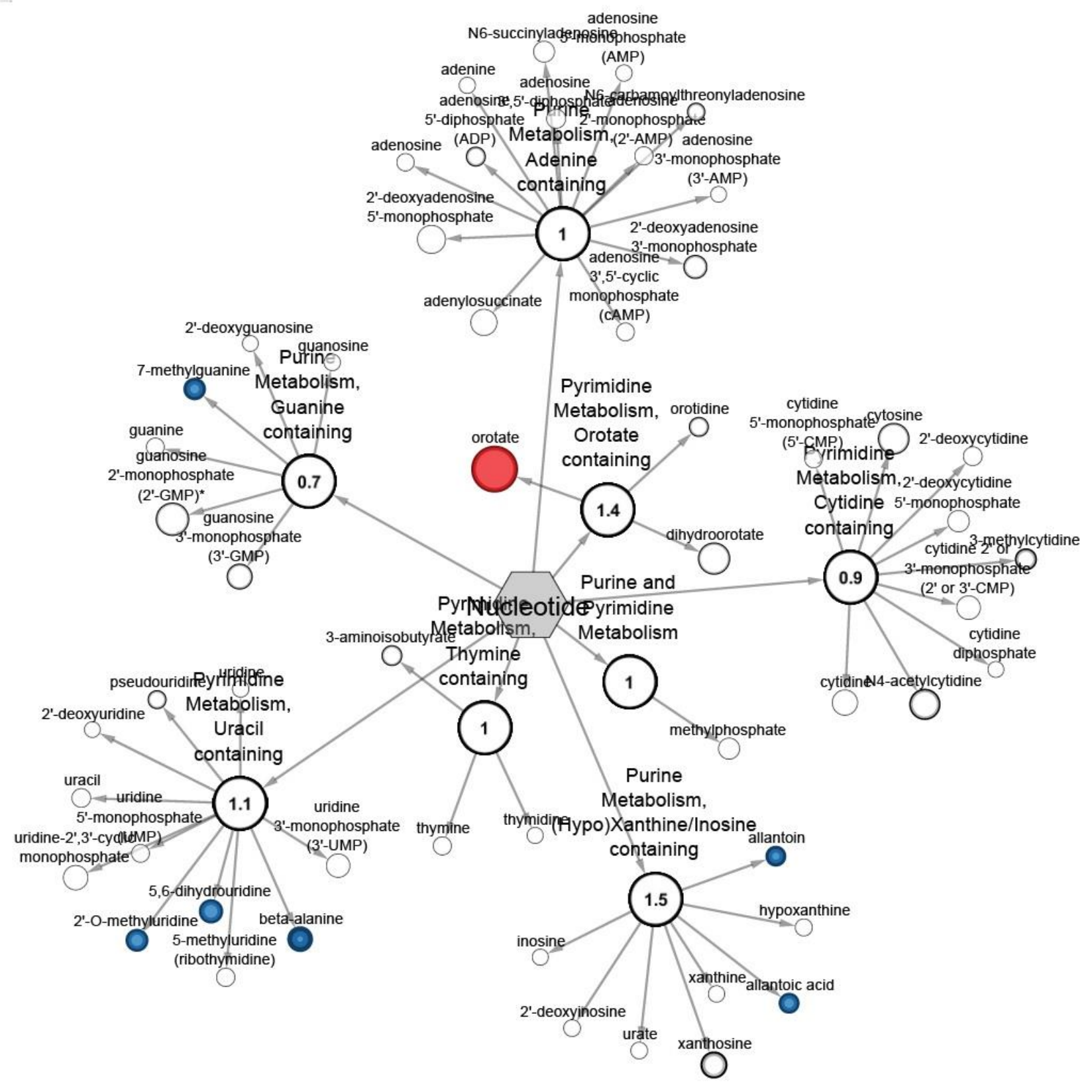




\section{Supplementary Figure S10C}

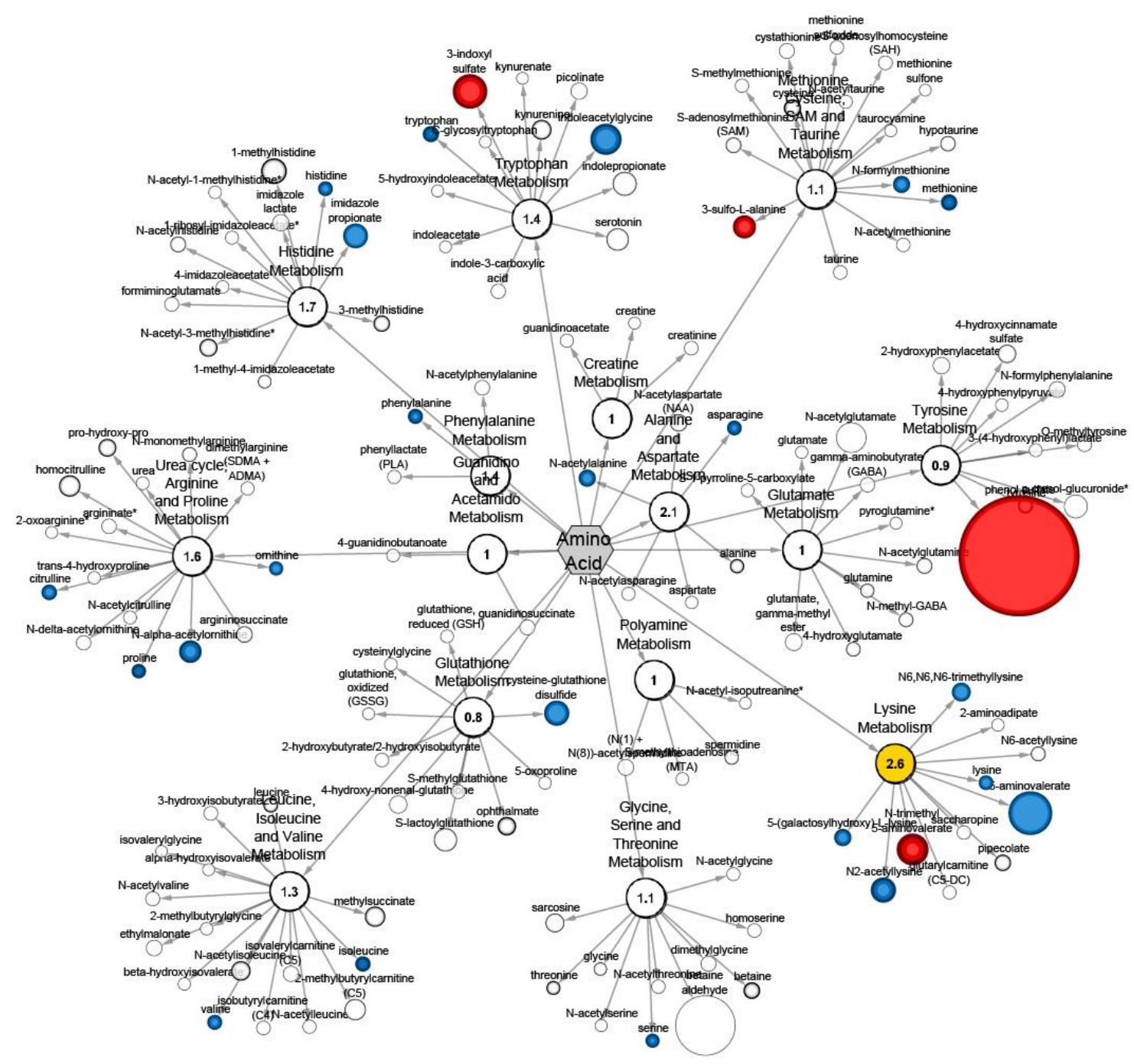

\section{Supplementary Figure 10}

A. Cytoscape network for mouse liver comparing INSIBP to wild-type NOD mice (Nucleotide pathway)

B. mouse liver comparing DEXL12BP to wild-type NOD mice (Nucleotide pathway)

C. mouse liver comparing DEXL12BP to wild-type NOD mice (Amino acid pathway)

Shaded nodes correspond to significantly different metabolites (blue for reduced in Dexi-disrupted mice; red for increased in Dexi-disrupted mice; yellow for a significant difference in the whole 
bioRxiv preprint doi: https://doi.org/10.1101/393421; this version posted August 16,2018 . The copyright holder for this preprint (which was not certified by peer review) is the author/funder. All rights reserved. No reuse allowed without permission.

pathway). Dark red or blue represent change at $\mathrm{p}<0.05$ and lighter colored nodes correspond to trending threshold $\mathrm{p}<0.1$. White nodes correspond to detected compounds with no significant change. 


\section{Supplementary Tables S1 to S10}

\section{Supplementary Table S1}

Examples of published SNPs in 16p13.13 region associated with immune-related conditions

\begin{tabular}{|c|c|c|c|c|}
\hline SNP & $\begin{array}{l}\text { Major }>\text { Minor } \\
\text { allele }\end{array}$ & Condition & Odds Ratio & p value \\
\hline rs12708716 & $\mathrm{G}>\mathrm{A}$ & Multiple sclerosis (58) & 0.9 & $1.08 \mathrm{e}-4$ \\
\hline rs12927355 & $\mathrm{T}>\mathrm{C}$ & Multiple sclerosis (59) & 0.87 & $7.4 \mathrm{e}-18$ \\
\hline rs6498184 & $\mathrm{C}>\mathrm{T}$ & Multiple sclerosis (59) & 0.83 & $6.4 e^{-46}$ \\
\hline rs7200786 & $\mathrm{G}>\mathrm{A}$ & Multiple sclerosis $(60)$ & 1.15 & $8.5 \mathrm{e}^{-17}$ \\
\hline rs1646019 & $\mathrm{T}>\mathrm{C}$ & $\begin{array}{l}\text { Primary biliary sclerosis } \\
(61)\end{array}$ & 0.71 & $6.72 \mathrm{e}-15$ \\
\hline rs12924729 & $\mathrm{A}>\mathrm{G}$ & $\begin{array}{l}\text { Primary biliary } \\
\text { sclerosis }(62)\end{array}$ & 0.76 & $2.39 \mathrm{e}-14$ \\
\hline rs12708716 & $\mathrm{G}>\mathrm{A}$ & Type 1 diabetes (64) & 0.81 & $7.43 e^{-14}$ \\
\hline rs12708716 & $\mathrm{G}>\mathrm{A}$ & Type 1 diabetes (4) & 0.84 & $4.92 \mathrm{e}-7$ \\
\hline rs12921922 & $\mathrm{C}>\mathrm{T}$ & Type1 diabetes(63) & 0.7 & $9.14 \mathrm{e}-07$ \\
\hline rs12927355 & $\mathrm{T}>\mathrm{C}$ & Type 1 diabetes $(65)$ & 0.82 & $3 e-22$ \\
\hline rs6498169 & $\mathrm{A}<\mathrm{G}$ & $\begin{array}{l}\text { Anti-CCP negative } \\
\text { juvenile idiopathic } \\
\text { arthritis }(11)\end{array}$ & 1.01 to 1.24 & 0.036 \\
\hline rs9652601 & $A>G$ & $\begin{array}{l}\text { Systemic Lupus } \\
\text { Erythematosus }(66)\end{array}$ & 0.83 & $7.42 \mathrm{e}-17$ \\
\hline rs12917716 & $\mathrm{G}>\mathrm{C}$ & $\begin{array}{l}\text { Primary adrenal } \\
\text { insufficiency }(8)\end{array}$ & 0.72 & 0.0004 \\
\hline rs12924112 & $\mathrm{T}>\mathrm{G}$ & $\begin{array}{l}\text { Eosinophilic } \\
\text { oesophagitis }(67)\end{array}$ & 0.763 & $1 \mathrm{e}-08$ \\
\hline rs17806056 & $\mathrm{T}>\mathrm{A}$ & $\begin{array}{l}\text { Combined variable } \\
\text { immunodeficiency }(16)\end{array}$ & 0.66 & $2.0 \mathrm{e}-9$ \\
\hline rs6498142 & $\mathrm{G}>\mathrm{C}$ & $\begin{array}{l}\text { Primary IgA deficiency } \\
(31)\end{array}$ & 0.64 & $2.7 \mathrm{e}^{-7}$ \\
\hline rs7201845 & $\mathrm{A}>\mathrm{G}$ & $\begin{array}{l}\text { Primary IgA deficiency } \\
(31)\end{array}$ & 0.66 & $2.7 e^{-7}$ \\
\hline rs34069391 & $\begin{array}{l}\text { null }>\mathrm{T}(1 \mathrm{bp} \\
\text { insertion) }\end{array}$ & $\begin{array}{l}\text { Primary IgA deficiency } \\
\text { (15) }\end{array}$ & 0.71 & $1.4 \mathrm{e}^{-9}$ \\
\hline
\end{tabular}




\begin{tabular}{|c|c|c|c|c|}
\hline rs62026376 & $\mathrm{T}>\mathrm{C}$ & $\begin{array}{l}\text { Asthma with } \\
\text { hayfever }(68)\end{array}$ & 1.17 & $1 \mathrm{e}-8$ \\
\hline rs2041733 & $\mathrm{C}>\mathrm{T}$ & Atopic dermatitis (69) & 1.26 & $1.00 \mathrm{e}-11$ \\
\hline rs998592 & $\mathrm{C}>\mathrm{T}$ & Alopecia areata $(10)$ & 1.32 & $2.45 \mathrm{e}-07$ \\
\hline rs12931878 & $A>G$ & $\begin{array}{l}\text { beta diversity gut } \\
\text { microbiome }(17)\end{array}$ & $\begin{array}{l}0.65 \% \text { effect } \\
\text { size }\end{array}$ & NA \\
\hline rs12928822 & $\mathrm{C}>\mathrm{T}$ & Celiac disease (70) & 0.86 & $3.12 \mathrm{e}-8$ \\
\hline
\end{tabular}

Supplementary Table S2 - Primers for genotyping

\begin{tabular}{|l|l|l|}
\hline Primer purpose & FORWARD & REVERSE \\
\hline $\begin{array}{l}\text { PCR for 12bp deletion and } \\
\text { Sanger sequencing of Dexi } \\
\text { mutations }\end{array}$ & CCCCTGGATGGCTGAGCTGC & TGGTCCAGGCCAAGAGTTGC \\
\hline $\begin{array}{l}\text { Generation of PCR product } \\
\text { for digestion with AvalI } \\
\text { enzyme and RFLP analysis }\end{array}$ & GAGTCGCTGGCCACTTCTAG & TCGAAGACGTCAAGCTCTGA \\
\hline
\end{tabular}

Supplementary Table S3: Mice included in the diabetes incidence study

\begin{tabular}{|c|c|c|c|c|c|c|c|c|}
\hline Cohort & Sex & $\begin{array}{l}\text { Mantel } \\
\text { Haenszel } \\
\text { p-value }\end{array}$ & $\begin{array}{l}\text { Dexi- } \\
\text { disrupted } \\
\text { mice \# }\end{array}$ & $\begin{array}{l}\text { Mean Dexi- } \\
\text { disrupted } \\
\text { diabetes } \\
\text { onset (days) }\end{array}$ & $\begin{array}{l}\text { Median } \\
\text { Dexi- } \\
\text { disrupted } \\
\text { diabetes } \\
\text { onset (days) }\end{array}$ & $\begin{array}{l}\text { WT } \\
\text { NOD } \\
\text { Sample } \\
\#\end{array}$ & $\begin{array}{l}\text { Mean WT } \\
\text { NOD } \\
\text { diabetes } \\
\text { onset } \\
\text { (days) }\end{array}$ & $\begin{array}{l}\text { Median } \\
\text { WT NOD } \\
\text { diabetes } \\
\text { onset } \\
\text { (days) }\end{array}$ \\
\hline INSIBP & Female & \begin{tabular}{|l|l|}
0.0254 \\
\end{tabular} & 37 & 110 & 113 & 79 & 153 & 129 \\
\hline$I N S 1 B P$ & Male & 0.8284 & 32 & 122 & 86 & 74 & 172 & 155 \\
\hline$D E L 12 B P$ & Female & 0.0307 & 77 & 122 & 114 & 79 & 153 & 129 \\
\hline$D E L 12 B P$ & Male & 0.7649 & 48 & 154 & 117 & 74 & 172 & 155 \\
\hline
\end{tabular}


Supplementary Table S4: Mice included in the histopathological islet study

\begin{tabular}{|c|c|c|}
\hline mutation & Litter & Age (days) \\
\hline$I N S 1 B P$ & 1 & 42 \\
\hline$I N S 1 B P$ & 1 & 42 \\
\hline$I N S 1 B P$ & 1 & 42 \\
\hline INS1BP & 1 & 42 \\
\hline$I N S 1 B P$ & 1 & 42 \\
\hline$I N S 1 B P$ & 1 & 42 \\
\hline INSIBP & 2 & 45 \\
\hline INS1BP & 2 & 45 \\
\hline$I N S 1 B P$ & 2 & 45 \\
\hline INS1BP & 2 & 45 \\
\hline INS1BP & 2 & 45 \\
\hline DEL12BP & 3 & 43 \\
\hline DEL12BP & 3 & 43 \\
\hline$D E L 12 B P$ & 3 & 43 \\
\hline DEL12BP & 3 & 43 \\
\hline DEL12BP & 3 & 43 \\
\hline DEL12BP & 4 & 45 \\
\hline DEL12BP & 4 & 45 \\
\hline DEL12BP & 4 & 45 \\
\hline DEL12BP & 4 & 45 \\
\hline DEL12BP & 4 & 45 \\
\hline DEL12BP & 4 & 45 \\
\hline wild-type NOD & 5 & 45 \\
\hline wild-type NOD & 5 & 45 \\
\hline wild-type NOD & 5 & 45 \\
\hline wild-type NOD & 5 & 45 \\
\hline wild-type NOD & 5 & 45 \\
\hline wild-type NOD & 6 & 45 \\
\hline wild-type NOD & 6 & 45 \\
\hline wild-type NOD & 6 & 45 \\
\hline wild-type NOD & 6 & 45 \\
\hline wild-type NOD & 6 & 45 \\
\hline wild-type NOD & 6 & 45 \\
\hline
\end{tabular}




\section{Supplementary Table S5 Antibodies for flow cytometry}

\begin{tabular}{|l|l|l|l|}
\hline $\begin{array}{l}\text { B cell panel } \\
\text { (BM) }\end{array}$ & $\begin{array}{l}\text { B cell panel } \\
\text { (Spleen) }\end{array}$ & Myeloid panel & T cell panel \\
\hline CD24-FITC & IgD-FITC & CD11c-FITC & CD44-FITC \\
\hline BPI-PE & IgM-PE & CD8a-PE & CD25-PE \\
\hline CD19-PerCP & CD19-PerCP & Ly6c-PerCP & CD8a-PerCP \\
\hline IgM-PECy7 & CD23-PECy7 & F4/80-PECy7 & \\
\hline CD43-APC & $\begin{array}{l}\text { MHCII-APC (I- } \\
\text { Ad) }\end{array}$ & CD11b-APC & CD62-APC \\
\hline B220 -AF700 & B220-AF700 & Ly6g Gr1-AF700 & CD4-AF700 \\
\hline IgD-APC-Cy7 & & CD3e-PB & $\begin{array}{l}\text { TCR } \alpha \beta \\
\text { Cy7 APC- }\end{array}$ \\
\hline & CD21-B605 & B220-BV605 & CD69-BV605 \\
\hline
\end{tabular}

Antibodies were purchased from Biolegend (Waltham, USA) and eBioscience (Thermo-Fisher Scientific, USA). 


\section{Supplementary Table S6 - Descriptive statistics of mice included in ELISA experiments}

All mice were normoglycemic and were aged between 9 and 15 weeks. Dexi-disrupted mice were homozygous for either the DEL12BP mutation or the INS1BP mutation on the NOD genetic background.

\begin{tabular}{|c|c|c|c|}
\hline $\begin{array}{l}\text { Sample } \\
\text { number }\end{array}$ & Genotype & $\begin{array}{c}\text { Age } \\
\text { (weeks) }\end{array}$ & Sex \\
\hline 1 & INS1BP & 11.9 & Female \\
\hline 2 & $I N S 1 B P$ & 11.9 & Female \\
\hline 3 & INS1BP & 12.3 & Female \\
\hline 4 & INS1BP & 12.7 & Female \\
\hline 5 & $I N S 1 B P$ & 12.7 & Female \\
\hline 6 & INS1BP & 12.7 & Female \\
\hline 7 & INS1BP & 12.7 & Female \\
\hline 8 & INSIBP & 9 & Female \\
\hline 9 & $I N S 1 B P$ & 9 & Female \\
\hline 10 & INS1BP & 9 & Female \\
\hline 11 & $I N S 1 B P$ & 12.7 & Female \\
\hline 12 & $I N S 1 B P$ & 12.7 & Female \\
\hline 13 & DEL12BP & 11.7 & Female \\
\hline 14 & DEL12BP & 11.7 & Female \\
\hline 15 & DEL12BP & 10.3 & Female \\
\hline 16 & DEL12BP & 10.3 & Female \\
\hline 17 & DEL12BP & 14.7 & Female \\
\hline 18 & DEL12BP & 14.6 & Female \\
\hline 19 & DEL12BP & 13 & Female \\
\hline 20 & DEL12BP & 13 & Female \\
\hline 21 & DEL12BP & 13 & Female \\
\hline 22 & DEL12BP & 13 & Female \\
\hline 23 & DEL12BP & 13 & Female \\
\hline 24 & DEL12BP & 12.7 & Female \\
\hline 25 & Wild-type NOD & 12.9 & Female \\
\hline 26 & Wild-type NOD & 9.3 & Female \\
\hline 27 & Wild-type NOD & 13.7 & Female \\
\hline 28 & Wild-type NOD & 12.3 & Female \\
\hline 29 & Wild-type NOD & 12.3 & Female \\
\hline 30 & Wild-type NOD & 12.3 & Female \\
\hline 31 & Wild-type NOD & 12.3 & Female \\
\hline 32 & Wild-type NOD & 12.3 & Female \\
\hline 33 & Wild-type NOD & 12.3 & Female \\
\hline 34 & Wild-type NOD & 13.4 & Female \\
\hline
\end{tabular}


bioRxiv preprint doi: https://doi.org/10.1101/393421; this version posted August 16,2018 . The copyright holder for this preprint (which was not certified by peer review) is the author/funder. All rights reserved. No reuse allowed without permission.

\begin{tabular}{|l|l|l|l|}
35 & Wild-type NOD & 14.7 & Female \\
\hline 36 & Wild-type NOD & 14.7 & Female \\
\hline
\end{tabular}




\section{Supplementary Table S7 - Mice included in the microbiome study}

\begin{tabular}{|c|c|c|c|c|}
\hline $\begin{array}{l}\text { Sample } \\
\text { number }\end{array}$ & Genotype & \begin{tabular}{|l|} 
age \\
(weeks)
\end{tabular} & sex & litter \\
\hline 1 & $I N S 1 B P$ & 4 & $\mathrm{~F}$ & $\mathrm{a}$ \\
\hline 2 & INS1BP & 4 & $\mathrm{~F}$ & $\mathrm{a}$ \\
\hline 3 & INSIBP & 4 & $\mathrm{~F}$ & $\mathrm{a}$ \\
\hline 4 & INSIBP & 4 & $\mathrm{~F}$ & $\mathrm{a}$ \\
\hline 5 & $I N S I B P$ & 6 & $\mathrm{~F}$ & $\mathrm{~b}$ \\
\hline 6 & INS1BP & 6 & $\mathrm{~F}$ & $\mathrm{~b}$ \\
\hline 7 & $I N S I B P$ & 6 & $\mathrm{~F}$ & $\mathrm{~b}$ \\
\hline 8 & $I N S 1 B P$ & 10 & $\mathrm{~F}$ & $\mathrm{c}$ \\
\hline 9 & $I N S 1 B P$ & 10 & $\mathrm{~F}$ & $\mathrm{c}$ \\
\hline 10 & $I N S 1 B P$ & 10 & $\mathrm{~F}$ & $\mathrm{~d}$ \\
\hline 11 & $D E L 12 B P$ & 4 & $\mathrm{~F}$ & e \\
\hline 12 & $D E L 12 B P$ & 4 & $\mathrm{~F}$ & $\mathrm{e}$ \\
\hline 13 & DEL12BP & 4 & $\mathrm{~F}$ & $\mathrm{e}$ \\
\hline 14 & $D E L 12 B P$ & 4 & $\mathrm{~F}$ & $\mathrm{e}$ \\
\hline 15 & $D E L 12 B P$ & 6 & $\mathrm{~F}$ & $\mathrm{f}$ \\
\hline 16 & $D E L 12 B P$ & 6 & $\mathrm{~F}$ & $\mathrm{f}$ \\
\hline 17 & $D E L 12 B P$ & 6 & $\mathrm{~F}$ & $\mathrm{f}$ \\
\hline 18 & DEL12BP & 6 & $\mathrm{~F}$ & $\mathrm{f}$ \\
\hline 19 & $D E L 12 B P$ & 6 & $\mathrm{~F}$ & $\mathrm{f}$ \\
\hline 20 & DEL12BP & 6 & $\mathrm{~F}$ & $\mathrm{~g}$ \\
\hline 21 & $D E L 12 B P$ & 6 & $\mathrm{~F}$ & $\mathrm{~g}$ \\
\hline 22 & DEL12BP & 6 & $\mathrm{~F}$ & $\mathrm{~h}$ \\
\hline 23 & $D E L 12 B P$ & 6 & $\mathrm{~F}$ & $\mathrm{~h}$ \\
\hline 24 & $D E L 12 B P$ & 10 & $\mathrm{~F}$ & $\mathrm{i}$ \\
\hline 25 & $D E L 12 B P$ & 10 & $\mathrm{~F}$ & $\mathrm{i}$ \\
\hline 26 & DEL12BP & 10 & $\mathrm{~F}$ & $\mathrm{i}$ \\
\hline 27 & Wild-type NOD & 4 & $\mathrm{~F}$ & $\mathrm{j}$ \\
\hline 28 & Wild-type NOD & 4 & $\mathrm{~F}$ & $\mathrm{j}$ \\
\hline 29 & Wild-type NOD & 4 & $\mathrm{~F}$ & $\mathrm{j}$ \\
\hline 30 & Wild-type NOD & 4 & $\mathrm{~F}$ & $\mathrm{j}$ \\
\hline 31 & Wild-type NOD & 4 & $\mathrm{~F}$ & $\mathrm{j}$ \\
\hline 32 & Wild-type NOD & 6 & $\mathrm{~F}$ & $\mathrm{k}$ \\
\hline 33 & Wild-type NOD & 6 & $\mathrm{~F}$ & $\mathrm{k}$ \\
\hline 34 & Wild-type NOD & 6 & $\mathrm{~F}$ & $\mathrm{k}$ \\
\hline 35 & Wild-type NOD & 6 & $\mathrm{~F}$ & $\mathrm{k}$ \\
\hline 36 & Wild-type NOD & 6 & $\mathrm{~F}$ & 1 \\
\hline 37 & Wild-type NOD & 6 & $\mathrm{~F}$ & $\mathrm{~m}$ \\
\hline
\end{tabular}




\begin{tabular}{|l|l|l|l|l|}
38 & Wild-type NOD & 6 & F & 1 \\
\hline 39 & Wild-type NOD & 6 & F & $\mathrm{n}$ \\
\hline 40 & Wild-type NOD & 6 & F & $\mathrm{n}$ \\
\hline 41 & Wild-type NOD & 6 & $\mathrm{~F}$ & $\mathrm{~m}$ \\
\hline 42 & Wild-type NOD & 10 & $\mathrm{~F}$ & $\mathrm{j}$ \\
\hline 43 & Wild-type NOD & 10 & $\mathrm{~F}$ & $\mathrm{j}$ \\
\hline 44 & Wild-type NOD & 10 & $\mathrm{~F}$ & $\mathrm{j}$ \\
\hline
\end{tabular}

Supplementary Table S8 (Excel document Tab1) - Detected microbial species

Supplementary Table S9 (Excel document Tab2) - Robustly detected species

Supplementary Table S10 (Excel document Tab3) - Pathway set enrichment (microbiome) 


\section{Materials and Methods:}

\section{Mice}

NOD/ShiLtJ mice were purchased from Charles River (Italy) for the purpose of generating the Dexi-disrupted mice used for this project. They were bred and maintained under a Home Office License and with the approval of the Local Animal Welfare Ethics Review Board (Clinical Medicine, University of Oxford). Mice were housed in same sex littermate groups of up to 6 mice in individually ventilated cages and were fed a standardized autoclaved commercial diet ad libitum. Standard conditions in the facility include shredded paper bedding and a 12 hour lightdark cycle. All animals were inspected daily and weekly urine testing for diabetes was undertaken from the age of 9-10 weeks. Mice were sacrificed as soon as glycosuria was detected, which was the endpoint of the cumulative diabetes incidence study.

\section{Generation and breeding of Dexi-disrupted NOD mice by CRISPR genome editing in NOD} oocytes

A target site for CRISPR/Cas9 mutagenesis directed against the first exon of Dexi, [5'CGTCCAGGTGGGCTGCGACC-3'] which contains the entire coding sequence of the protein, was designed using the CRISPOR algorithm (71). This target site was predicted by the algorithm to be genome-unique and in fact, a match to only a single putative off-target site (an intergenic region on a different chromosome) was only theoretically achievable with hybridization mismatches at 3 nucleotide positions within the target site, with also no predicted off-target sites predicted when 4 nucleotides were mismatched. As such, the target site for CRISPR/Cas9 mutagenesis selected for the Dexi loss-of-function has a high specificity score of 90 (72). The 
sgRNA was synthesized by in vitro transcription of a synthetic DNA template by T7 polymerase using the MEGAshortscript ${ }^{\mathrm{TM}}$ T7 Transcription Kit (ThermoFisher Scientific), purified using the MEGAclear Kit (ThermoFisher Scientific) and diluted prior to microinjection in $10 \mathrm{mM}$ Tris.HCl pH7.5, 0.1 mM EDTA pH8.0. Female NOD mice at 6 weeks of age were superovulated and mated with male NOD mice. Fertilized zygotes were harvested from plugged females and microinjected with ribonucleoprotein preparation of sgRNA (at $20 \mathrm{ng} / \mu \mathrm{l}$ ) complexed with $100 \mathrm{ng} / \mathrm{ul}$ Cas 9 protein (Caribou Biosciences, Inc). Zygotes were cultured overnight and 47 of the resulting 2-cell embryos were implanted into 3 pseudopregnant foster CD1 females and carried to term. 19 live pups were obtained and genotyped for the presence of disruptive mutations at the CRISPR/Cas9 target site by PCR followed by Sanger sequencing.

Genotyping of pups was performed following PCR with Q5 HotStart Hi-fidelity DNA polymerase enzyme (New England Biolabs, Ipswich, MA, USA) using Sanger sequencing with primers directed at the first exon of Dexi (Supplementary Table S2). Mice with Dexi mutations were back-crossed onto the NOD background and resulting pups genotyped by Sanger sequencing to confirm the nature of the individual mutations. From this point forwards genotyping was undertaken by PCR and restriction fragment length polymorphism analysis after 6 hour digestion with AvaII (New England Biolabs, USA) for the INSIBP 1bp insertion mutation (Supplementary Figure 2A) or by PCR alone followed by $4 \%$ agarose gel electrophoresis for the DEL12BP $12 \mathrm{bp}$ deletion mutation (Supplementary Figure 2B).

Once it had been established that homozygous Dexi disruption was not lethal by evaluating offspring of heterozygous intercrosses, INS1BP and DEL12BP homozygous Dexi-disrupted mice were bred using homozygote intercrosses for the remainder of the project. Control NOD mice were generated by intercrossing wild-type NOD mice resulting from the original heterozygous 
intercrosses and these mice were used to breed control mice for subsequent experiments. Pups were weaned into same-sex littermate cages at 3 weeks of age. Mice were allocated to experimental groups according to genotype, age and sex. Randomization was not required since no additional interventions were undertaken. Wherever possible, data were collected and analyzed in a blinded fashion, as indicated in methods for individual experiments.

\section{Western blotting}

SDS-PAGE gel electrophoresis was undertaken using 4-20\% pre-cast Tris-Glycine gels (NuSep, Homebush, Australia) and PVDF blotting membrane. Tissue lysates from age matched nondiabetic female mice were prepared in RIPA buffer (with c0mplete Protease Inhibitor Cocktail Sigma Aldrich, Gillingham UK) and 50ug total protein per well was loaded. Positive control Dexi protein lysate was obtained from Novus Biologicals (NBL1-09841, Abingdon, UK). Skimmed milk (5\%) was used as a blocking agent in $0.5 \%$ Tween Phosphate Buffered Saline. Anti-DEXI antibodies were obtained from Proteintech (14811-1-AP, Rosemont, IL, USA), Sigma Aldrich (HPA041511, Gillingham UK) and Abgent (WA-AP 16938b, Hamburg, Germany). The secondary antibody was obtained from VectorLabs (Peterborough, UK - Goat anti-rabbit HRP conjugate, PI-1000) and the blots were developed with ECL Advance chemiluminescent reagent (Amersham, UK).

\section{Quantitative PCR}

Tissues from 10-week old non-diabetic female mice were harvested immediately after sacrifice by cervical dislocation, and placed into Trizol for storage at -80 degrees. RNA was extracted using phenol-chloroform extraction and purified using Qiagen RNeasy columns, with an on-column 
DNAse digestion step. One microgram of RNA from each sample was used for cDNA synthesis with Bio Script enzyme and cDNA was diluted to 1:10 with purified water prior to use in qPCR reactions. Standard Master Mix (Primer Design, Southampton) was used for all reactions, which were undertaken using a Bio-Rad thermal cycler. Double-dye hydrolysis qPCR was used (TaqMan style) in duplex assays with beta actin (VIC-labelled probe) as the housekeeping gene. 5' and 3' Dexi assays (shown below) were designed and manufactured by PrimerDesign (FAM labelled probe), with the amplicons detected outlined on the image below. All samples were tested in triplicate and data shown for each mouse show mean + SD. Results are representative of multiple experiments.

\section{Mouse DEXI sequence showing mapping sites of qPCR assays onto cDNA sequence: Transcript: Dexi-001 ENSMUST00000038281}

5' Assay primers and sequence amplified 3' Assay primers and sequence amplified

\section{1bp insertion site INS1BP (an extra C inserted)}

\section{2bp deletion site $D E L 12 B P$}

1 GAGCCTGCGGGGGCGCCGAAGGTGCCTGAGGAACGCCTCGGGGAGACAGCAGCGGCCTCA

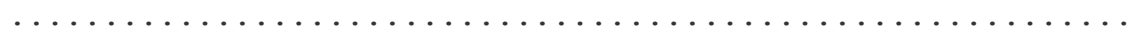

61 ACTCTGAGCTGCGGCGGGGGCGCGCGAGCGCAGCGTACAAAGCGAGTCGCTGGCCACTTC

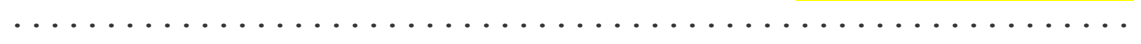

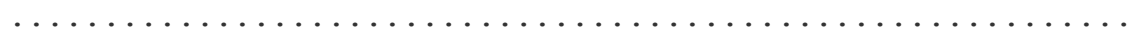

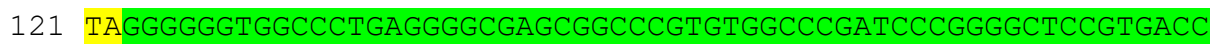

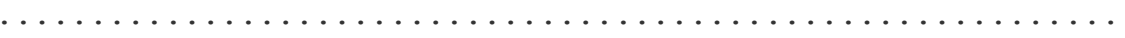

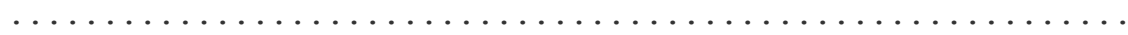

181 CGGCCCTGAGCATCTCGGGGTGTCAAGGAGCGTCTTCGGAGGCCGCCCGGGGCCCAGCGC

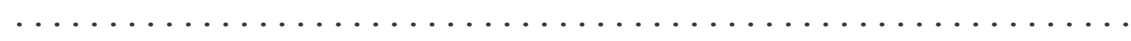

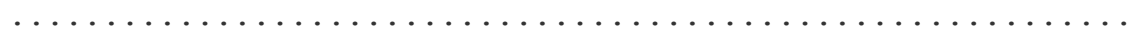


bioRxiv preprint doi: https://doi.org/10.1101/393421; this version posted August 16,2018 . The copyright holder for this preprint (which was not certified by peer review) is the author/funder. All rights reserved. No reuse allowed without permission.

241 TGCCGCCACCGAGCCCCGGGGCGCCCCCTGGATGGCTGAGCTGCCCCCTCGCCGGCCGCC

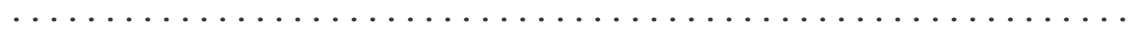

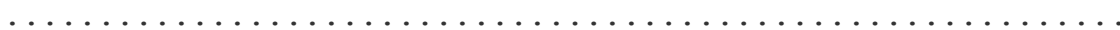

301 CGGGCGCCGCAGCGGCTGAGGTCGCTGGGATCGCCCGGCCGCCGCCCCCATCGCCGGCCC

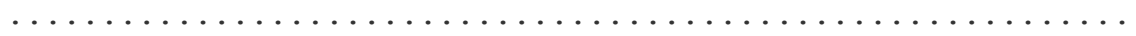

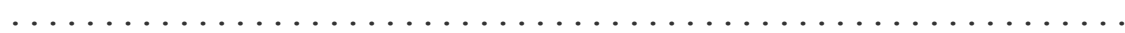

361 CTGCATGCCCGGCGCCCGGGTCGCAGCCCACCTGGACGCTCTGGGCCCCCTGGTCTCCTA .....ATGCCCGGCGCCCGGGTCGCAGCCCACC TGGACGCTCTGGGCCCCCTGGTCTCCTA ....-M--P--G--A--R--V--A--A--H-- $-\mathrm{A}--\mathrm{D}--\mathrm{A}--\mathrm{L}--\mathrm{G}--\mathrm{P}--\mathrm{L}--\mathrm{V}--\mathrm{S}--\mathrm{Y}$

421 CGTGCAGCCACCGCTGCTGCCCTCTATGTTCTACGTGGGCCTGTTCTTCGTCAATGTGCT

57 CGTGCAGCCACCGCTGCTGCCCTCTATGTTCTACGTGGGCCTGTTCTTCGTCAATGTGCT

$19--\mathrm{V}--\mathrm{Q}--\mathrm{P}--\mathrm{P}--\mathrm{L}--\mathrm{L}--\mathrm{P}--\mathrm{S}--\mathrm{M}--\mathrm{F}--\mathrm{Y}--\mathrm{V}--\mathrm{G}--\mathrm{L}--\mathrm{F}--\mathrm{F}--\mathrm{V}--\mathrm{N}--\mathrm{V}--\mathrm{L}$

481 GATCCTTTACTACGCCTTCCTTATGGAATACATCGTTCTCAATGTGGGCCTCGTCTTCCT

117 GATCCTTTACTACGCCTTCCTTATGGAATACATCGTTCTCAATGTGGGCCTCGTCTTCCT

$39--\mathrm{I}--\mathrm{L}--\mathrm{Y}--\mathrm{Y}--\mathrm{A}--\mathrm{F}--\mathrm{L}--\mathrm{M}--\mathrm{E}--\mathrm{Y}--\mathrm{I}--\mathrm{V}--\mathrm{L}--\mathrm{N}--\mathrm{V}--\mathrm{G}--\mathrm{L}--\mathrm{V}--\mathrm{F}--\mathrm{L}$

541 GCCCGAGGACTTGGACCAGGCGCTGGTGGACCTCGGCGTACTTTCAGACCCTGGCTCTGG

177 GCCCGAGGACTTGGACCAGGCGCTGGTGGACCTCGGCGTACTTTCAGACCCTGGCTCTGG

$59--\mathrm{P}--\mathrm{E}--\mathrm{D}--\mathrm{L}--\mathrm{D}--\mathrm{Q}--\mathrm{A}--\mathrm{L}--\mathrm{V}--\mathrm{D}--\mathrm{L}--\mathrm{G}--\mathrm{V}--\mathrm{L}--\mathrm{S}--\mathrm{D}--\mathrm{P}--\mathrm{G}--\mathrm{S}--\mathrm{G}$

601 CCTTTACGATGCCGACTCAGAGCTTGACGTCTTCGATGGATATTTGGAATAATGTCGTGA

237 CCTTTACGATGCCGACTCAGAGCTTGACGTCTTCGATGGATATTTGGAATAA........

$79--\mathrm{L}--\mathrm{Y}--\mathrm{D}--\mathrm{A}--\mathrm{D}--\mathrm{S}--\mathrm{E}--\mathrm{L}--\mathrm{D}--\mathrm{V}--\mathrm{F}--\mathrm{D}--\mathrm{G}--\mathrm{Y}--\mathrm{L}--\mathrm{E}--\star-\ldots . .$.

661 TTACTGTTCCCCACTTGCCTTCCACCATCCGCAACTCTTGGCCTGGACCAGCCGCCCGTA

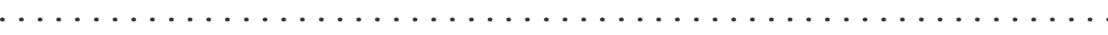

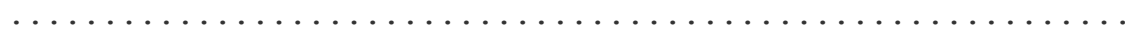

721 CCATGCCGCTGCCACTGGTTGGGGGCACCATCTGGACAGGGATGGGACCCCAGGAAGAGG

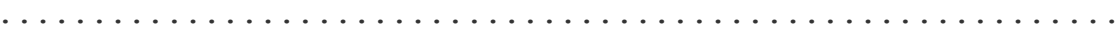

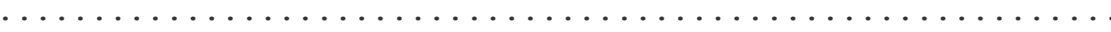

781 CCCGCCTGCTCATGCCAACAACAGGGTTCCTGCCCCAACCCAGGTGTCTGCCAGGAGAAA

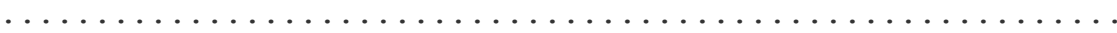

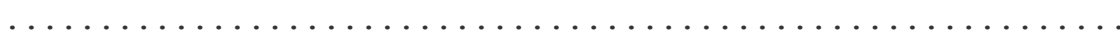

841 TGAGGACTCGGCGCAGGGACAGGGAGTGTCCAGGCCCTCCGAAGGCCCCGCTCGCCTGCC

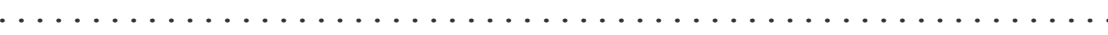

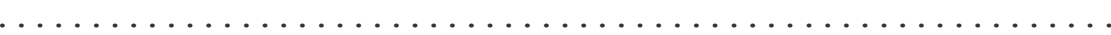

901 ACCCGGCTCTCCACTGTCCTGGGTCTGGTTGTGACTCGCCACCTTTGTGATGGATGTTTA

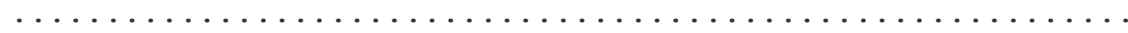

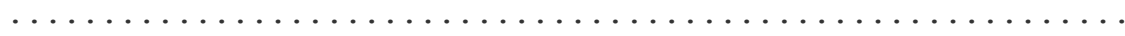




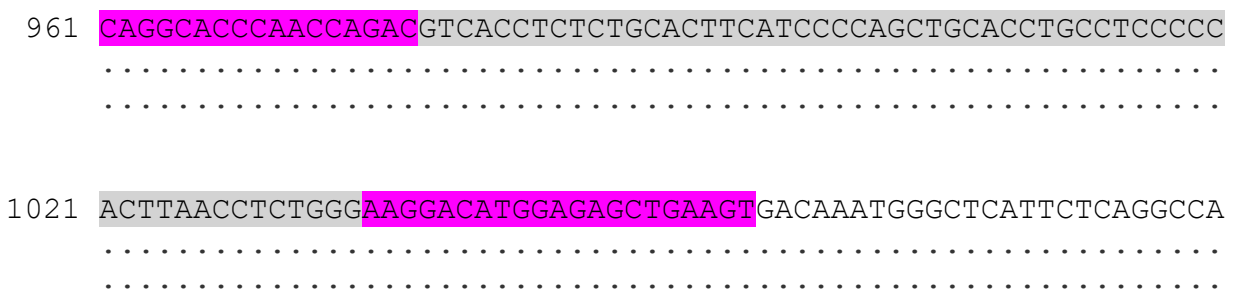

Cumulative diabetes incidence study: From the age of 9-10 weeks, all mice in the colony underwent regular urine testing (weekly) for diabetes and were sacrificed as soon as glycosuria was detected. Since mice were kept in groups and cages labelled by genotype it was not possible for blinding to be undertaken with respect to genotype whilst urine testing was being undertaken. To avoid confounding hormonal effects, mice in breeding pairs and trios were not included in phenotyping studies or evaluation of diabetes incidence, although they received the same monitoring as non-breeding mice and were sacrificed as soon as glycosuria was detected. The Study endpoint for diabetes incidence was set at 300 days. The 'survival' R package (version 2.413) was used to calculate diabetes-free survival, and the 'survminer' R package (version 0.4.0) was used to generate Kaplan-Meier plots.

Histopathology (Insulitis study): Pancreas tissue from thirty three 6-week old female mice (Supplementary Table S3), was fixed for 24 hours in formalin before being transferred to $70 \%$ ethanol and stored at $4{ }^{\circ} \mathrm{C}$. Samples tissues were then embedded in paraffin and tissue sections cut in two planes. Following hematoxylin and eosin staining, an insulitis score (0 to 5) was evaluated by a board-certified veterinary pathologist in a blinded manner staining by evaluation of multiple islets in both planes for each mouse. 
Histopathology (Early phenotyping of first generations of Dexi-disrupted mice) : Six littermate wild-type NOD and homozygous Dexi-disrupted NOD mice were sacrificed at 4-6 weeks of age and multiple tissues including pancreas, salivary gland, liver, spleen, kidney, bone marrow, thymus, lung, heart, gastro-intestinal tract and brain fixed in formalin for a minimum of 24 hours before embedding in paraffin. Sections were stained with hematoxylin and eosin before histopathological examination.

\section{Flow cytometry}

After culling by cervical dislocation, spleen, thymus and femoral bone marrow (BM) from agematched wild-type and Dexi-disrupted NOD mice were harvested into iced RPMI buffer with 10\% fetal calf serum. A single cell suspension was made for each tissue and cells passed through a cell strainer before washing twice with ice-cold phosphate buffered saline/ 1\% bovine serum albumin. After a red blood cell lysis step, cells were washed and re-suspended at 10 million cells / ml. One million cells per well were used for flow cytometry staining, which was performed on ice. Cells were stained with lineage-specific panels (Supplementary Table S4), with dead cells being excluded by Zombie Aqua staining (Biolegend, SanDiego, CA, USA). A mouse FC blocker (TruStain fcX $\mathrm{X}^{\mathrm{TM}}$ (anti-mouse CD16/32) Biolegend) was included in the blocking step. For thymus, only the T cell panel was used. Data were acquired on a FACSCANTO machine and analyzed using FlowJo software. Fluorescence minus one controls and single-stained compensation controls were used to ensure that gates were set correctly and that fluorescently labelled antibodies in panels were compatible. For each subset identified, percentage of each subset within the population was calculated and this was converted to absolute number by multiplication by the total cell count from that tissue. Representative data from 4 mice (2 wild-type NOD and 2 Dexi-disrupted mice) are shown, and the experiment was repeated several times with similar results. 
Flow cytometry gating strategies were as follows:

Live B cells in the bone marrow were classified by Hardy fraction. B220+CD43+ cells were classified into Fraction A : early uncommitted cells BPI-CD24lo; Fraction B : rearranged H chain cells BPI-CD24hi; Fraction C : B cells post-H chain rearrangement BPI+CD24hi. B220+CD43cells were classified into Fraction D : B cells rearranging L chain: IgM-IgD-; Fraction E: immature B cells with rearrangements finished IgM+IgD-; Fraction F: mature B cells IgM+IgD+.

Live peripheral B cells in the spleen were classified as B cells according to B220+CD19+ status and then sub-classified as follicular (CD21+CD23+), marginal zone (CD21+CD23-) and transitional B cells (CD21-CD23-).

Live myeloid cells in the bone marrow and spleen were identified by their CD3-B220- status initially and subclassified into neutrophils (Gr-1+CD11b+) and MonoMac cells (Gr-1-CD11b+). MonoMac cells were subsequently further subclassified into monocytes (Ly6c+F4/80+); macrophages (Ly6c-F4/80+) and eosinophils (Ly6c-F4/80-).

Live $\mathrm{T}$ cells in the spleen were identified by their CD4+ and CD8+ status initially. CD4+ cells were subclassified into Tregs (CD62+CD25+); CD4+ and CD8+ T lymphocytes were also subclassified into effector cells (CD62-CD44+), memory cells (CD62+CD44+) and naïve cells (CD62+CD44-).

Live T cells in the thymus were sub-classified by CD4 and CD8 status as double negative (DN), double positive (DP), CD4+CD8- or CD4-CD8+. Double negative cells were further sub-classified by developmental stage into Q1 (CD44+CD25-), Q2 (CD44+CD25+), Q3 (CD44-CD25+) and Q4 (CD44-CD25-). 
Mice for IgA, IgM and IgG ELISA: The descriptive data for mice included in ELISA experiments are shown in Supplementary Table S5. Quantification of serum $\operatorname{IgA}$, IgM and $\operatorname{IgG}$ was undertaken in age-matched young non-diabetic female mice using commercially available mouse ELISA kits, each containing a standard curve (ThermoFisher Scientific). Samples were tested in duplicate at a range of dilutions. Data were analyzed and displayed using GraphPad Prism. Since data were not normally distributed, wild-type NOD and Dexi-disrupted mice were compared (by group) using non-parametric testing (Mann-Whitney test), with significance set at $\mathrm{p}<0.05$ and a Bonferroni correction for multiple testing. Results are shown from a single experiment but are representative of multiple experiments and figures were prepared using GraphPad Prism 7.

Mice for IAA measurement: Aliquots of the same 36 mouse serum samples used for ELISA were shipped to the Barbara Davis Center for Childhood Diabetes, USA for measurement of IAA by radio-immunoassay. Investigators at this laboratory were blinded as to the genotype of each mouse.

Metabolomics / lipidomics study mice: Five littermate female mice from two separate litters of each genotype (wild-type NOD, INS1BP and DEL12BP) were sacrificed by cervical dislocation at 6 weeks of age. Blood was immediately harvested into an EDTA tube by cardiac puncture and snap-frozen in a dry ice / isopropanol bath. Liver and spleen tissue were similarly snap-frozen immediately in separate tubes and all frozen samples stored at -80 degrees until shipping to the service provider (Metabolon, USA) on dry ice. One litter of each genotype was used for metabolomics studies (Metabolon HD4 platform) and one litter for lipidomics (Metabolon Complex lipids platform) studies. For the Short Chain Fatty Acid measurement experiment, 6week old wild-type NOD (n=4), INSP1BP $(n=3)$ and DEL12BP $(n=3)$ mice from at least 2 litters 
per genotype were sacrificed by cervical dislocation at 6 weeks of age. Liver was immediately snap frozen as previously described. Blood was immediately harvested into a plain tube by cardiac puncture and after being allowed to clot for 10 minutes, was centrifuged and serum snap-frozen in a dry ice / isopropanol bath.

\section{Metabolomics sample processing for Ultra-high Performance Liquid Chromatography-Tandem}

Mass Spectroscopy (UPLC-MS/MS): Samples were processed according to Metabolon standard procedures and handled using the automated MicroLab STAR® system from Hamilton Company. Several recovery standards were added prior to the first step in the extraction process for Quality Control purposes. To remove protein, dissociate small molecules bound to protein or trapped in the precipitated protein matrix, and to recover chemically diverse metabolites, proteins were precipitated with methanol under vigorous shaking for 2 min followed by centrifugation. The resulting extract was divided into five fractions: two for analysis by two separate reverse phase (RP)/UPLC-MS/MS methods with positive ion mode electrospray ionization (ESI), one for analysis by RP/UPLC-MS/MS with negative ion mode ESI, one for analysis by HILIC/UPLCMS/MS with negative ion mode ESI, and one sample was reserved for backup. Samples were placed briefly on a TurboVap® (Zymark) to remove the organic solvent. The sample extracts were stored overnight under nitrogen before preparation for analysis.

A pooled matrix sample, generated by taking a small volume of each experimental sample, served as a technical replicate. Extracted water samples served as process blanks. Metabolon QC standards were spiked into every analyzed sample. These steps allowed instrument performance monitoring and aided chromatographic alignment. Instrument variability was determined by calculating the median relative standard deviation (RSD) for the internal standards that were added 
to each sample prior to injection into the mass spectrometers. Overall process variability was determined by calculating the median RSD for all endogenous metabolites (i.e., non-instrument standards) present in $100 \%$ of the matrix samples, which are technical replicates of pooled samples.

All methods utilized a Waters ACQUITY ultra-performance liquid chromatography (UPLC) and a Thermo Scientific Q-Exactive high resolution/accurate mass spectrometer interfaced with a heated electrospray ionization (HESI-II) source and Orbitrap mass analyzer operated at 35,000 mass resolution. The sample extract was dried then reconstituted in solvents compatible to each of the four methods. Each reconstitution solvent contained a series of standards at fixed concentrations to ensure injection and chromatographic consistency. One aliquot was analyzed using acidic positive ion conditions, chromatographically optimized for more hydrophilic compounds. In this method, the extract was gradient eluted from a C18 column (Waters UPLC BEH C18-2.1x100 mm, $1.7 \mu \mathrm{m})$ using water and methanol, containing $0.05 \%$ perfluoropentanoic acid (PFPA) and $0.1 \%$ formic acid (FA). Another aliquot was also analyzed using acidic positive ion conditions; however it was chromatographically optimized for more hydrophobic compounds. In this method, the extract was gradient eluted from the same afore mentioned C18 column using methanol, acetonitrile, water, $0.05 \%$ PFPA and $0.01 \%$ FA and was operated at an overall higher organic content. Another aliquot was analyzed using basic negative ion optimized conditions using a separate dedicated C18 column. The basic extracts were gradient eluted from the column using methanol and water, however with $6.5 \mathrm{mM}$ Ammonium Bicarbonate at $\mathrm{pH}$. The fourth aliquot was analyzed via negative ionization following elution from a HILIC column (Waters UPLC BEH Amide 2.1x150 mm, $1.7 \mu \mathrm{m}$ ) using a gradient consisting of water and acetonitrile with $10 \mathrm{mM}$ Ammonium Formate, $\mathrm{pH}$ 10.8. The MS analysis alternated between MS and data- 
dependent $\mathrm{MS}^{\mathrm{n}}$ scans using dynamic exclusion. The scan range varied slighted between methods but covered 70-1000 m/z. Raw data files are archived and extracted as described below.

Data Extraction and Compound Identification : Raw data was extracted, peak-identified and QC processed using Metabolon's hardware and software. Compounds were identified by comparison to library entries of purified standards or recurrent unknown entities. Biochemical identifications were based on three criteria: retention index within a narrow RI window of the proposed identification, accurate mass match to the library $+/-10 \mathrm{ppm}$, and the MS/MS forward and reverse scores between the experimental data and authentic standards. The MS/MS scores were based on a comparison of the ions present in the experimental spectrum to the ions present in the library spectrum.

Metabolomics sample processing and data acquisition for the Complex Lipids Platform For the EDTA blood samples, lipids were extracted from the blood in the presence of deuterated internal standards using an automated BUME extraction according to the method of Lofgren et al. (J Lipid Res 2012;53(8):1690-700). For tissue samples, lipids were extracted from samples via a modified Bligh-Dyer extraction using methanol/water/dichloromethane in the presence of deuterated internal standards. The extracts were dried under nitrogen and reconstituted in ammonium acetate dichloromethane : methanol. The extracts were transferred to vials for infusion-MS analysis, performed on a Shimadzu LC with nano PEEK tubing and the Sciex SelexIon-5500 QTRAP. The samples were analyzed via both positive and negative mode electrospray. The 5500 QTRAP was operated in MRM mode with a total of more than 1,100 MRMs. Individual lipid species were quantified by taking the ratio of the signal intensity of each target compound to that of its assigned internal standard, then multiplying by the concentration of internal standard added to the 
sample. Lipid class concentrations were calculated from the sum of all molecular species within a class, and fatty acid compositions were determined by calculating the proportion of each class comprised by individual fatty acids.

Short Chain Fatty Acids were measured by Mass Spectrometry (73) by Dr Zhanru Yu at the Target Development Institute, University of Oxford. Figures were prepared using GraphPad Prism 7.

\section{Bioinformatics and statistical analysis}

Metabolon analysis: Raw counts were rescaled for each biochemical to set the median equal to 1. Missing values were imputed with the minimum observed value for each compound. ANOVA contrasts were used to identify biochemicals that differed significantly between experimental groups. An estimate of the false discovery rate ( $q$-value) was calculated to correct for multiple testing. The intersection of biochemical compounds with $q<0.05$ and consistent fold change direction in both Dexi-disrupted lines versus wild-type NOD mice was taken to pinpoint biochemical compounds for further investigation. Metabolon pathway annotation for chemical compounds was used to identify pathways of interest. Bar and violin plots were generated in $\mathrm{R}$ (version 3.4.1). Pathway graphics were generated in Cytoscape using the Metabolync plugin.

For the SCFA measurement experiment, values were compared between groups using the MannWhitney test and a Bonferroni correction made for multiple testing.

Fecal microbiome study: Fecal samples were collected non-invasively routinely from non-diabetic mice (either voided on handling or immediately after culling by cervical dislocation) and stored at 
-80 degrees for a maximum of 6 months until processed. Female mice were selected for this part of the study since the diabetes-acceleration phenotype had been detected in females. In addition, microbiome-dependent diabetes phenotypes in NOD mice are more apparent in females than males $(28,29,46,74)$. Samples were selected from the frozen archive based on age, sex and genotype, to ensure a wide variety of litters was represented. They comprised females of 4 weeks of age $(n=13), 6$ weeks of age $(n=22)$ and 10 weeks of age $(n=9)$. All three genotypes of interest were represented at all timepoints: total wild-type $\operatorname{NOD}(\mathrm{n}=18)$, total $\operatorname{INS1BP}(\mathrm{n}=10)$ and total $\operatorname{DEL12BP}(\mathrm{n}=16)$, across a total of 12 different litters housed in single-sex separate cages of the same genotype (Supplementary Table S7). DNA was extracted from one fecal pellet per mouse with a combination of heat, chemical and bead dissociation using the Pure-Link Microbiome DNA purification kit (Thermo-Fisher, Waltham, US). DNA quality and purity was assessed by Nanodrop, to confirm a 260/280 ratio between $1.8-2.0$ and 260/230 ratio of greater than 1.5 . Fifty nanograms of fecally-derived DNA from each mouse was submitted to the High Throughput Genomics Service at the Oxford Genomics Centre, Wellcome Centre for Human Genetics. Forty four samples were tested in a blinded fashion across two Axiom Microbiome arrays (ThermoFisher, Waltham, US), with the remaining two spaces on each 24-sample array taken up with positive and negative controls.

Raw .CEL output files were analyzed using Axiom Microbial Detection Analysis Software (MiDAS), which makes species 'Detected Target' calls based on the Composite Likelihood Maximization (CLiMax) algorithm. The 'pheatmap' R package (version 1.0.8) was used to cluster mouse samples by euclidean distance and generate a heatmap of Detected Target microbial species. The 'VennDiagram' R package (version 1.6.17) was used to generate Venn diagrams of 
Detected Targets. To minimize the risk of batch artifacts, analyses were restricted to only Detected

Target species found in both array runs and detected at each time point (4, 6, \& 10 weeks of age), which also corresponded to species detected in more than one mouse line. Fisher's Exact was used to test differences in the representation of these robustly detected microbial species in Dexidisrupted versus wild-type NOD mice.

\section{References and Notes:}

1. L. Nistico et al., Emerging effects of early environmental factors over genetic background for type 1 diabetes susceptibility: evidence from a Nationwide Italian Twin Study. J Clin Endocrinol Metab 97, E1483 (Aug, 2012).

2. I. Spagnuolo, A. Patti, G. Sebastiani, L. Nigi, F. Dotta, The case for virus-induced type 1 diabetes. Curr Opin Endocrinol Diabetes Obes 20, 292 (Aug, 2013).

3. A. Paun, C. Yau, J. S. Danska, The Influence of the Microbiome on Type 1 Diabetes. J Immunol 198, 590 (Jan 15, 2017).

4. H. Hakonarson et al., A genome-wide association study identifies KIAA0350 as a type 1 diabetes gene. Nature 448, 591 (Aug 2, 2007).

5. C. Wellcome Trust Case Control, Genome-wide association study of 14,000 cases of seven common diseases and 3,000 shared controls. Nature 447, 661 (Jun 7, 2007).

6. G. F. Mells et al., Genome-wide association study identifies 12 new susceptibility loci for primary biliary cirrhosis. Nat Genet 43, 329 (Mar 13, 2011).

7. C. International Multiple Sclerosis Genetics, The expanding genetic overlap between multiple sclerosis and type I diabetes. Genes Immun 10, 11 (Jan, 2009).

8. B. Skinningsrud et al., Polymorphisms in CLEC16A and CIITA at 16p13 are associated with primary adrenal insufficiency. The Journal of clinical endocrinology and metabolism 93, 3310 (Sep, 2008).

9. V. Gateva et al., A large-scale replication study identifies TNIP1, PRDM1, JAZF1, UHRF1BP1 and IL10 as risk loci for systemic lupus erythematosus. Nature genetics 41, 1228 (Nov, 2009).

10. D. Jagielska et al., Follow-up study of the first genome-wide association scan in alopecia areata: IL13 and KIAA0350 as susceptibility loci supported with genome-wide significance. The Journal of investigative dermatology 132, 2192 (Sep, 2012).

11. B. Skinningsrud et al., A CLEC16A variant confers risk for juvenile idiopathic arthritis and anti-cyclic citrullinated peptide antibody negative rheumatoid arthritis. Annals of the rheumatic diseases 69, 1471 (Aug, 2010).

12. M. Swanberg, F. E. McGuigan, K. K. Ivaska, P. Gerdhem, K. Akesson, Polymorphisms in the inflammatory genes CIITA, CLEC16A and IFNG influence BMD, bone loss and fracture in elderly women. PloS one 7, e47964 (2012).

13. T. Fujimaki et al., Association of genetic variants in SEMA3F, CLEC16A, LAMA3, and PCSK2 with myocardial infarction in Japanese individuals. Atherosclerosis 210, 468 (Jun, 2010).

14. T. Yoshida et al., Association of genetic variants with ischemic stroke in Japanese individuals with or without metabolic syndrome. International journal of molecular medicine 25, 281 (Feb, 2010).

15. P. G. Bronson et al., Common variants at PVT1, ATG13-AMBRA1, AHI1 and CLEC16A are associated with selective IgA deficiency. Nature genetics 48, 1425 (Nov, 2016).

16. J. Li et al., Association of CLEC16A with human common variable immunodeficiency disorder and role in murine B cells. Nature communications 6, 6804 (Apr 20, 2015).

17. J. Wang et al., Genome-wide association analysis identifies variation in vitamin D receptor and other host factors influencing the gut microbiota. Nature genetics 48, 1396 (Nov, 2016). 
18. T. Berge, I. S. Leikfoss, H. F. Harbo, From Identification to Characterization of the Multiple Sclerosis Susceptibility Gene CLEC16A. International journal of molecular sciences 14, 4476 (Feb 25, 2013).

19. I. L. Mero et al., Exploring the CLEC16A gene reveals a MS-associated variant with correlation to the relative expression of CLEC16A isoforms in thymus. Genes and immunity 12, 191 (Apr, 2011).

20. S. A. Soleimanpour et al., The diabetes susceptibility gene Clec16a regulates mitophagy. Cell 157, 1577 (Jun 19, 2014).

21. R. L. Zuvich et al., Interrogating the complex role of chromosome 16p13.13 in multiple sclerosis susceptibility: independent genetic signals in the CIITA-CLEC16A-SOCS1 gene complex. Hum Mol Genet 20, 3517 (Sep 1, 2011).

22. C. Schuster et al., The Autoimmunity-Associated Gene CLEC16A Modulates Thymic Epithelial Cell Autophagy and Alters T Cell Selection. Immunity 42, 942 (May 19, 2015).

23. I. S. Leikfoss et al., Multiple sclerosis-associated single-nucleotide polymorphisms in CLEC16A correlate with reduced SOCS1 and DEXI expression in the thymus. Genes and immunity 14, 62 (Jan, 2013).

24. M. J. t. Tomlinson et al., Fine mapping and functional studies of risk variants for type 1 diabetes at chromosome 16p13.13. Diabetes 63, 4360 (Dec, 2014).

25. L. J. Davison et al., Long-range DNA looping and gene expression analyses identify DEXI as an autoimmune disease candidate gene. Human molecular genetics 21, 322 (Jan 15, 2012).

26. X. Li et al., eQTL of bronchial epithelial cells and bronchial alveolar lavage deciphers GWAS-identified asthma genes. Allergy 70, 1309 (Oct, 2015).

27. J. A. Pearson, F. S. Wong, L. Wen, The importance of the Non Obese Diabetic (NOD) mouse model in autoimmune diabetes. J Autoimmun 66, 76 (Jan, 2016).

28. J. G. Markle, D. N. Frank, K. Adeli, M. von Bergen, J. S. Danska, Microbiome manipulation modifies sexspecific risk for autoimmunity. Gut Microbes 5, 485 (Jul 1, 2014).

29. J. G. Markle et al., Sex differences in the gut microbiome drive hormone-dependent regulation of autoimmunity. Science 339, 1084 (Mar 1, 2013).

30. M. H. Heineke, M. van Egmond, Immunoglobulin A: magic bullet or Trojan horse? Eur J Clin Invest 47, 184 (Feb, 2017).

31. R. C. Ferreira et al., Association of IFIH1 and other autoimmunity risk alleles with selective IgA deficiency. Nature genetics 42, 777 (Sep, 2010).

32. J. J. Bunker et al., Natural polyreactive IgA antibodies coat the intestinal microbiota. Science 358, (Oct 20, 2017).

33. J. D. Planer et al., Development of the gut microbiota and mucosal IgA responses in twins and gnotobiotic mice. Nature 534, 263 (Jun 9, 2016).

34. K. Singh, C. Chang, M. E. Gershwin, IgA deficiency and autoimmunity. Autoimmunity reviews 13, 163 (Feb, 2014).

35. F. L. Jahnsen, E. S. Baekkevold, J. R. Hov, O. J. Landsverk, Do Long-Lived Plasma Cells Maintain a Healthy Microbiota in the Gut? Trends Immunol 39, 196 (Mar, 2018).

36. J. G. Daft, R. G. Lorenz, Role of the gastrointestinal ecosystem in the development of type 1 diabetes. Pediatr Diabetes 16, 407 (Sep, 2015).

37. L. Krych, D. S. Nielsen, A. K. Hansen, C. H. Hansen, Gut microbial markers are associated with diabetes onset, regulatory imbalance, and IFN-gamma level in NOD mice. Gut Microbes 6, 101 (2015).

38. E. V. Marietta et al., Low incidence of spontaneous type 1 diabetes in non-obese diabetic mice raised on gluten-free diets is associated with changes in the intestinal microbiome. PLoS One 8, e78687 (2013).

39. J. Peng et al., Long term effect of gut microbiota transfer on diabetes development. J Autoimmun 53, 85 (Sep, 2014).

40. T. Vatanen et al., Variation in Microbiome LPS Immunogenicity Contributes to Autoimmunity in Humans. Cell 165, 842 (May 5, 2016).

41. A. D. Kostic et al., The dynamics of the human infant gut microbiome in development and in progression toward type 1 diabetes. Cell Host Microbe 17, 260 (Feb 11, 2015).

42. M. Knip, H. Siljander, The role of the intestinal microbiota in type 1 diabetes mellitus. Nat Rev Endocrinol 12, 154 (Mar, 2016).

43. M. Yassour et al., Natural history of the infant gut microbiome and impact of antibiotic treatment on bacterial strain diversity and stability. Sci Transl Med 8, 343ra81 (Jun 15, 2016).

44. L. Wen et al., Innate immunity and intestinal microbiota in the development of Type 1 diabetes. Nature 455, 1109 (Oct 23, 2008). 
45. M. P. Burrows, P. Volchkov, K. S. Kobayashi, A. V. Chervonsky, Microbiota regulates type 1 diabetes through Toll-like receptors. Proc Natl Acad Sci U S A 112, 9973 (Aug 11, 2015).

46. L. Yurkovetskiy et al., Gender bias in autoimmunity is influenced by microbiota. Immunity 39, 400 (Aug 22, 2013).

47. J. A. Mullaney et al., Type 1 diabetes susceptibility alleles are associated with distinct alterations in the gut microbiota. Microbiome 6, 35 (Feb 17, 2018).

48. D. Rothschild et al., Environment dominates over host genetics in shaping human gut microbiota. Nature 555, 210 (Mar 8, 2018).

49. M. Murri et al., Gut microbiota in children with type 1 diabetes differs from that in healthy children: a case-control study. BMC Med 11, 46 (Feb 21, 2013).

50. J. Zhang et al., Loss of Bone and Wnt10b Expression in Male Type 1 Diabetic Mice Is Blocked by the Probiotic Lactobacillus reuteri. Endocrinology 156, 3169 (Sep, 2015).

51. N. Hara et al., The role of the intestinal microbiota in type 1 diabetes. Clin Immunol 146, 112 (Feb, 2013 ).

52. H. A. Barker, L. D'Ari, J. Kahn, Enzymatic reactions in the degradation of 5-aminovalerate by Clostridium aminovalericum. J Biol Chem 262, 8994 (Jul 5, 1987).

53. E. P. Neis, C. H. Dejong, S. S. Rensen, The role of microbial amino acid metabolism in host metabolism. Nutrients 7, 2930 (Apr 16, 2015).

54. U. E. Schaible, S. H. Kaufmann, A nutritive view on the host-pathogen interplay. Trends Microbiol 13, 373 (Aug, 2005).

55. F. Blachier, F. Mariotti, J. F. Huneau, D. Tome, Effects of amino acid-derived luminal metabolites on the colonic epithelium and physiopathological consequences. Amino Acids 33, 547 (Nov, 2007).

56. P. A. Bron, C. Grangette, A. Mercenier, W. M. de Vos, M. Kleerebezem, Identification of Lactobacillus plantarum genes that are induced in the gastrointestinal tract of mice. J Bacteriol 186, 5721 (Sep, 2004).

57. E. Marino et al., Gut microbial metabolites limit the frequency of autoimmune T cells and protect against type 1 diabetes. Nat Immunol 18, 552 (May, 2017).

58. N. A. Patsopoulos et al., Genome-wide meta-analysis identifies novel multiple sclerosis susceptibility loci. Annals of neurology 70, 897 (Dec, 2011).

59. A. H. Beecham et al., Analysis of immune-related loci identifies 48 new susceptibility variants for multiple sclerosis. Nature genetics 45, 1353 (Nov, 2013).

60. S. Sawcer et al., Genetic risk and a primary role for cell-mediated immune mechanisms in multiple sclerosis. Nature 476, 214 (Aug 10, 2011).

61. J. Z. Liu et al., Dense fine-mapping study identifies new susceptibility loci for primary biliary cirrhosis. Nature genetics 44, 1137 (Oct, 2012).

62. H. J. Cordell et al., International genome-wide meta-analysis identifies new primary biliary cirrhosis risk loci and targetable pathogenic pathways. Nature communications 6, 8019 (Sep 22, 2015).

63. Y. Sang, W. Zong, J. Yan, M. Liu, The Correlation between the CLEC16A Gene and Genetic Susceptibility to Type 1 Diabetes in Chinese Children. International journal of endocrinology 2012, 245384 (2012).

64. Genome-wide association study of 14,000 cases of seven common diseases and 3,000 shared controls. Nature 447, 661 (Jun 7, 2007).

65. S. Onengut-Gumuscu et al., Fine mapping of type 1 diabetes susceptibility loci and evidence for colocalization of causal variants with lymphoid gene enhancers. Nature genetics 47, 381 (Apr, 2015).

66. J. Bentham et al., Genetic association analyses implicate aberrant regulation of innate and adaptive immunity genes in the pathogenesis of systemic lupus erythematosus. Nature genetics 47, 1457 (Dec, 2015).

67. L. C. Kottyan et al., Genetic variants at the $16 \mathrm{p} 13$ locus confer risk for eosinophilic esophagitis. Genes and immunity, (Jun 8, 2018).

68. M. A. Ferreira et al., Genome-wide association analysis identifies 11 risk variants associated with the asthma with hay fever phenotype. The Journal of allergy and clinical immunology 133, 1564 (Jun, 2014).

69. D. Ellinghaus et al., High-density genotyping study identifies four new susceptibility loci for atopic dermatitis. Nature genetics 45, 808 (Jul, 2013).

70. P. C. Dubois et al., Multiple common variants for celiac disease influencing immune gene expression. Nature genetics 42, 295 (Apr, 2010).

71. M. Haeussler et al., Evaluation of off-target and on-target scoring algorithms and integration into the guide RNA selection tool CRISPOR. Genome biology 17, 148 (Jul 5, 2016). 
72. P. D. Hsu et al., DNA targeting specificity of RNA-guided Cas9 nucleases. Nature biotechnology 31,827 (Sep, 2013).

73. Z. Yu et al., Optimizing 2D gas chromatography mass spectrometry for robust tissue, serum and urine metabolite profiling. Talanta 165, 685 (Apr 1, 2017).

74. M. A. Kriegel et al., Naturally transmitted segmented filamentous bacteria segregate with diabetes protection in nonobese diabetic mice. Proc Natl Acad Sci U S A 108, 11548 (Jul 12, 2011).

\section{Author contributions:}

Conceived and designed the study: LJD, CAO'C, JAT

Designed and generated the Dexi-disrupted mice: CP, BD

Undertook experiments: LJD

Undertook blinded histopathological analysis of tissues and immunohistochemistry: $\mathrm{KH}$

Analyzed data: LJD, MDW, CO’C

Wrote the manuscript: LJD, CAO'C

Prepared figures: LJD, MDW, KH

Reviewed data, reviewed and edited the manuscript: JAT, CP, BD

\section{Ethics:}

All animal studies were conducted with ethical approval from the John Radcliffe Hospital Clinical Medicine Animal Welfare and Ethical Review Board and in accordance with the UK Home Office regulations (Guidance on the Operation of Animals, Scientific Procedures Act, 1986), under Project License PPL 30/3029.

\section{Funding:}

This work was supported by a Wellcome Trust Veterinary Postdoctoral Fellowship to LJD (WT096398MA) and by a pilot study grant from Diabetes UK to LJD and CO'C (15/0005171). MDW's salary is supported by an EFSD/JDRF Lilly pilot grant (EFSD/JDRF/Lilly Programme 
2016) to LJD and CO'C. LJD is currently supported by an MRC Clinician Scientist Fellowship (MR/R007977/1).

The work was supported by the Juvenile Diabetes Research Fund [5-SRA-2015-130-A-N], [4SRA-2017-473-A-N]; the Wellcome Trust [107212/Z/15/Z]; National Institute of Health Research Oxford Biomedical Research Centre. JAT was in receipt of a National Institute of Health Research Senior Investigator Award.

No funding bodies had any role in study design, data collection and analysis, decision to publish, or preparation of the manuscript.

\section{Acknowledgments}

We thank the High-Throughput Genomics Group and the transgenic core at the Wellcome Centre for Human Genetics (funded by Wellcome Trust grant reference 203141/Z/16/Z) for the production of the Dexi mutant mice and the generation of the microbiome array data. We thank Dr. Joy Archer FRCPath at the University of Cambridge for undertaking the initial histopathology work on the mouse tissues. We thank the staff of the Functional Genomics Facility, University of Oxford for their technical expertise in caring for the mice. We are grateful to Dr. Consuelo Anzilloti and Dr. Mukta Deobagkar for help and guidance with immunophenotyping the mice by flow cytometry. We thank Prof. Linda Wicker for valuable discussions and Dr Zhanru Yu for undertaking SCFA measurements. 